This project has received funding from the ECSEL Joint Undertaking under grant agreement No. 737469. This Joint Undertaking receives support from the European Union's Horizon 2020 research and innovation programme and the ECSEL member states.
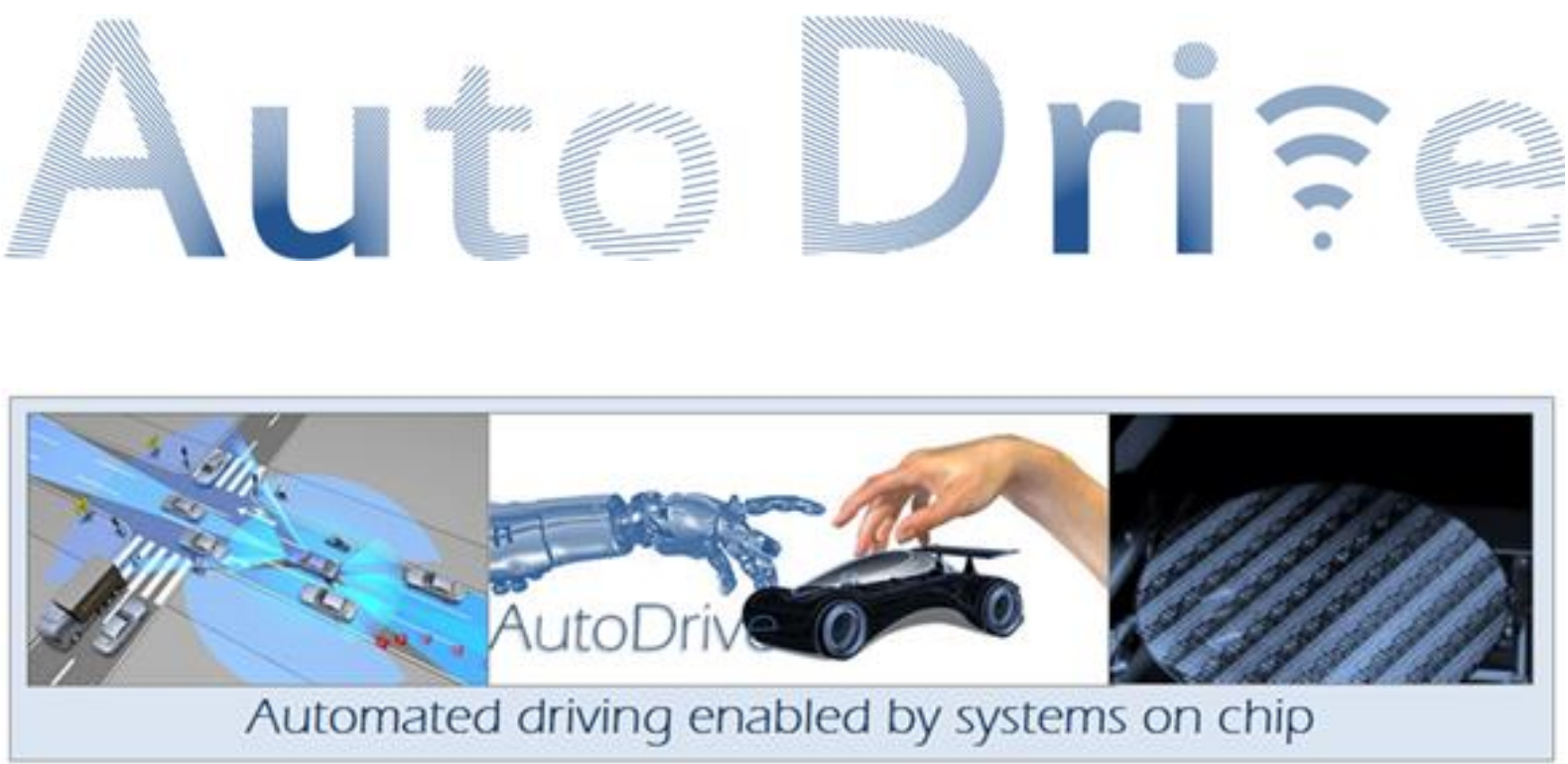

\begin{tabular}{|r|l|r|l|}
\hline Deliverable & Report on validation of the stochastic traffic simulation (Part A) \\
\hline Involved SCs & SC 10 & Deliverable type & Public \\
\hline Project & AutoDrive & $\begin{array}{r}\text { Grant Agreement } \\
\text { Number }\end{array}$ & 737469 \\
\hline Deliverable File & D6.23a & Last Modified & $29.06 .202009: 56$ \\
\hline Due Date & 30.06 .2020 & Actual Submission & \\
\hline Status & Final & Version & 1.0 \\
\hline Contact Person & Madlen Ringhand & Organisation & TUD \\
\hline Phone & +49351 463-36517 & E-Mail & $\begin{array}{l}\text { madlen.ringhand@tu- } \\
\text { dresden.de }\end{array}$ \\
\hline
\end{tabular}




\begin{tabular}{|l|l|l|l|}
\hline \multicolumn{2}{|l|}{ Document history } & Author & Description \\
\hline V & Date & Madlen Ringhand (TUD) & Initial Version \\
\hline 0.2 & 28.05 .2020 & Marcus Mai (TUD) & Review 1 \\
\hline 0.4 & 10.06 .2020 & Marcus Mai (TUD) & Rework \\
\hline 0.6 & 11.06 .2020 & Felix Elrod (AVLS) & Review 2 \\
\hline 0.8 & 22.06 .2020 & Marcus Mai (TUD) & Final Version \\
\hline 1.0 & 29.06 .2020 & & \\
\hline & & & \\
\hline
\end{tabular}




\section{Table of contents}

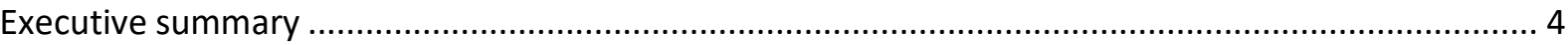

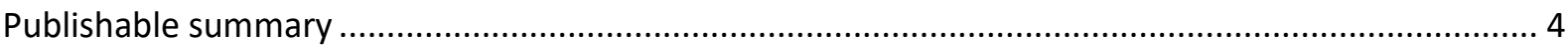

Non publishable information

Fehler! Textmarke nicht definiert.

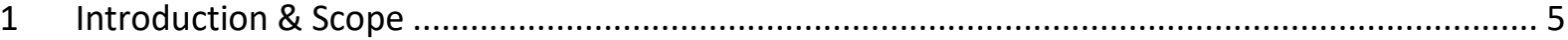

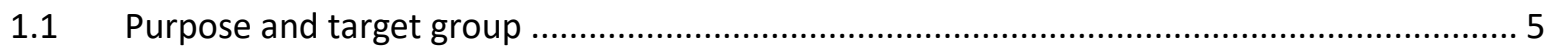

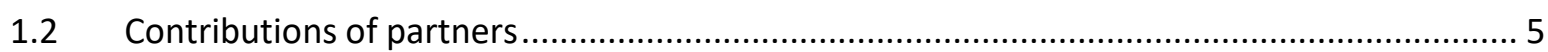

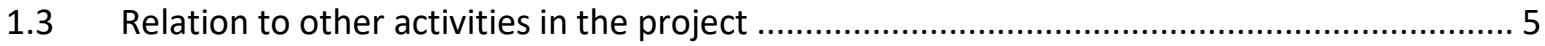

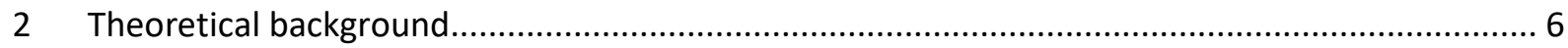

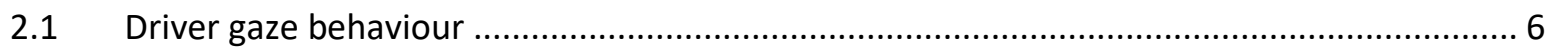

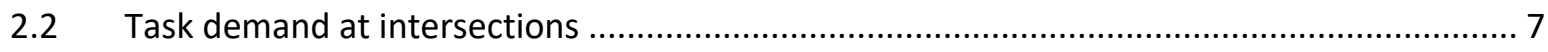

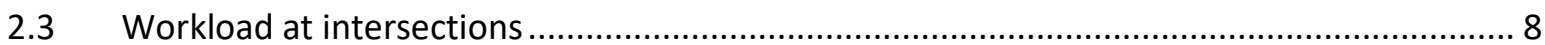

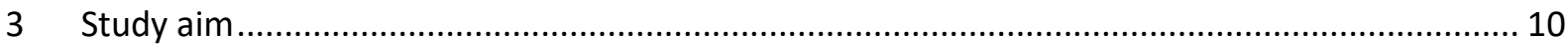

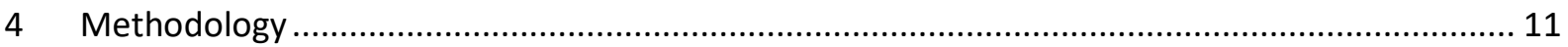

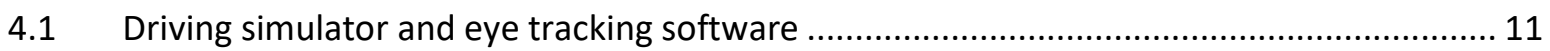

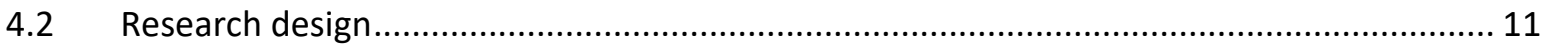

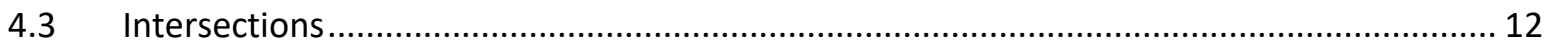

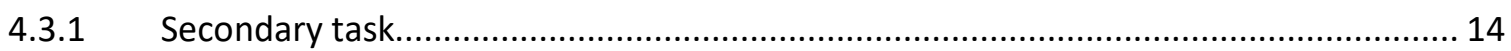

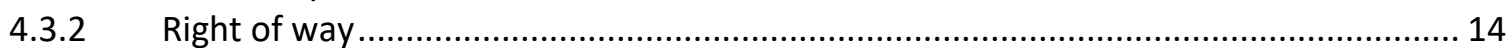

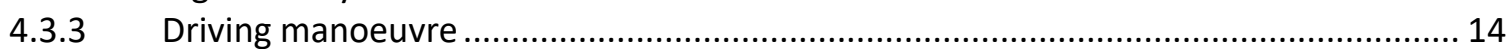

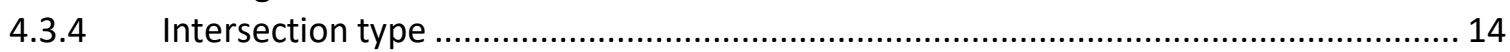

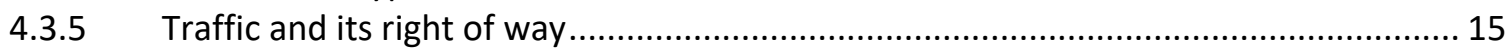

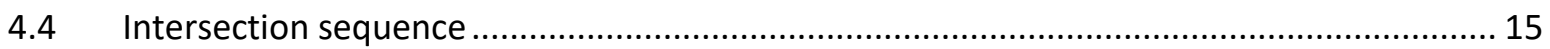

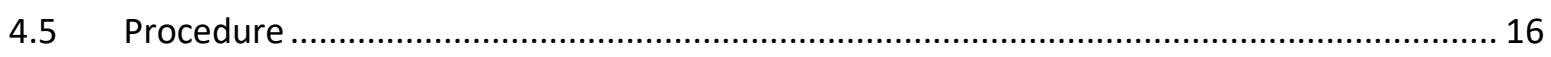

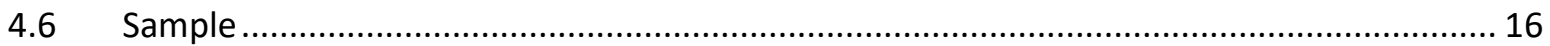

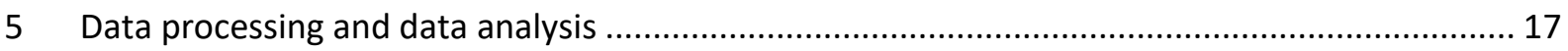

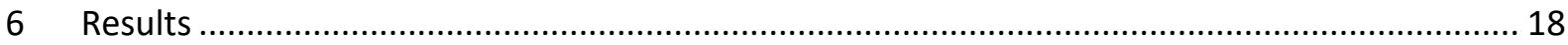

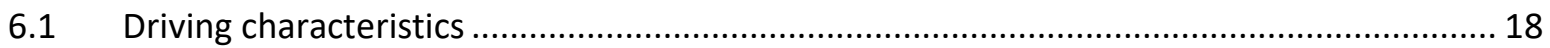

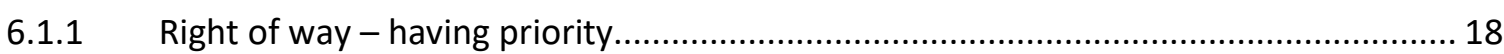

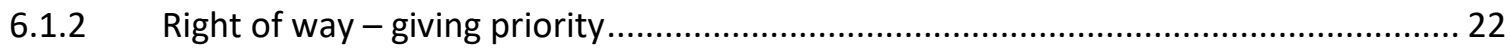

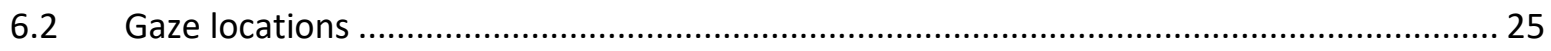

6.2.1 Right of way - having priority

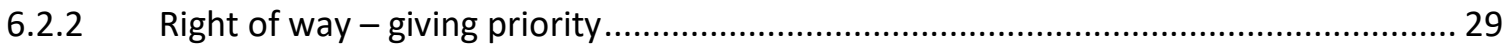

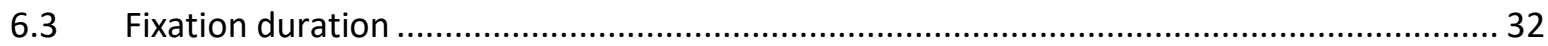

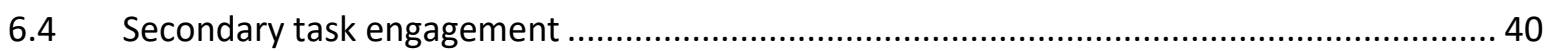

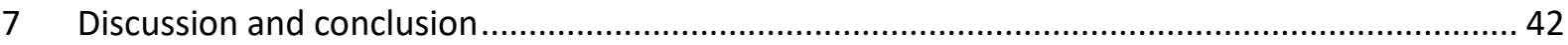

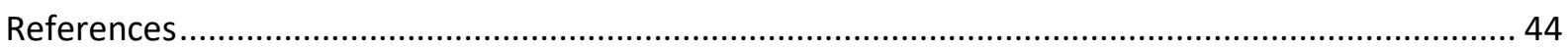

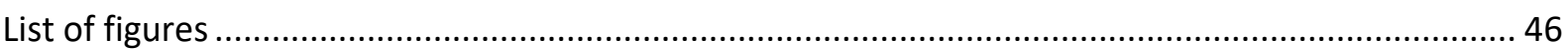

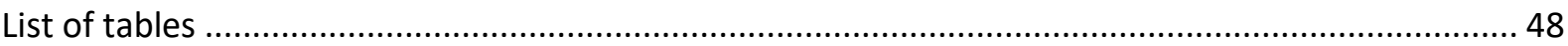




\section{Executive summary}

This document is intended to give an overview of the human subject study in a driving simulator that was conducted by the Chair of Traffic and Transportation Psychology (Verkehrspsychologie - VPSY) of the Technische Universität Dresden (TUD) to provide the Chair of Automotive Engineering (Lehrstuhl Kraftfahrzeugtechnik - LKT) of TUD with the necessary input for the validation of a stochastic traffic simulation, especially for the parameterization, consolidation, and validation of driver behaviour models. VPSY planned, conducted, and analysed a driving simulator study. The main purpose of the study was to analyse driving behaviour and gaze data at intersections in urban areas. Based on relevant literature, a simulated driving environment was created, in which a sample of drivers passed a variety of intersections. Considering different driver states, driving tasks, and traffic situations, the collected data provide detailed information about human gaze and driving behaviour when approaching and crossing intersections. The collected data was transferred to LKT for the development of the stochastic traffic simulation.

\section{Publishable summary}

See above. 


\section{Introduction \& Scope}

\subsection{Purpose and target group}

The purpose of the work done was to deliver reliable results about human drivers' gaze and driving behaviour when approaching, crossing, and exiting intersections. Therefore, the results of the human subject study address developers and engineers, who want to model human driving behaviour as a basis for testing automated driving functions.

\subsection{Contributions of partners}

TABLE 1: CONTRIBUTIONS

\begin{tabular}{|l|l|l|}
\hline Chapter & Partner & Contribution \\
\hline $1,2,3,4,5,6,7,8,9,10,11$ & TUD - VPSY & $\begin{array}{l}\text { Overall responsible for study design, data processing, } \\
\text { results, etc. }\end{array}$ \\
\hline $\begin{array}{l}\text { Methodology, data } \\
\text { processing, results }\end{array}$ & TUD - LKT & $\begin{array}{l}\text { The planning of the study design, the data processing } \\
\text { strategy, and the presentation of results was closely } \\
\text { coordinated with VPSY. }\end{array}$ \\
\hline
\end{tabular}

\subsection{Relation to other activities in the project}

The activities of this study are closely related to the work of TUD - LKT in Supply Chain 10. In addition, the results of the study are further processed by LKT to be considered for the parameterization, consolidation, and validation of driver behaviour models within the stochastic traffic simulation of D6.23b, respectively Task 6.12. 


\section{Theoretical background}

\subsection{Driver gaze behaviour}

Intersections in urban areas are danger points for crashes as the branches bring different traffic flows together. Among others, the causes for accidents to happen are the misinformation of drivers as they fail to sense the relevant information from the environment. Accident analysis of Vollrath et al. (2006) showed that the majority of the analysed severe accidents occurred due to information and goal setting mistakes. They also showed that errors occurring while turning or crossing at intersections are most importantly caused by a lack of perception of existing information. In order to better understand how the driver allocates his or her attention, eye movements of drivers are focus of traffic psychological research. Visual attention of drivers is clearly associated with information processing of relevant road objects. Crundall and Underwood (2011) give an excellent overview of eye movement measurement in driving research. In the following, prominent results of eye movement research with special focus on intersections are described.

Rumar (1990) and Summala et al. (1996) showed that drivers scan the relevant traffic environment not sufficiently enough to detect vulnerable road users and other relevant objects. This suggests that driver develop well-established visual search patterns regarding frequent objects and risks, but miss to detect rarely seen objects.

Shinar (2008) recapped the studies of Mourant and Rockwell (1972; Mourant and Rockwell, 1970) regarding visual search patterns of drivers. In the studies of Mourant and Rockwell, the visual search patterns were compared for scenarios with car following and not, as well as with instructions to attend to various signs. Without car following and no particular instruction to attend to a sign, drivers looked close to the so called 'focus of expansion', the point where all road geometry lines merge, but in general more wide spread. With car following the fixations come down to the rear end of the leading vehicle. In addition, the studies showed that fixations varied by the task the driver had to perform and the second study found that novice and experienced drivers differ in their visual search patterns.

Labett and Langham (2006) installed cameras at two intersections at the university campus of Essex and showed that drivers spent in average 0.5 seconds time to search for hazards at an intersection and that they tend to search in one direction only. In an additional laboratory experiment drivers ( $N=14)$ were confronted with two seconds videos eight times, showing different intersections (6 T-junctions, 1 roundabout). Results of eye movement analysis showed differences regarding driving experience.

A further interesting study regarding visual search behaviour at intersections was performed by Werneke and Vollrath (2012) in a driving simulator study with 40 participants. At several T-junctions drivers had to turn right and give priority to traffic coming from the left branch of the junction (yield sign). Following the SEEV (salience, effort, expectancy, value) model of Wickens et al. (2003), the study varied the top-down factors of attentional allocation expectancy and value and examined their influence on gaze behaviour and attention distribution. Expectancy was operationalized by varying traffic density and value by the presence or absence of a pedestrian at intersections. The presence of a pedestrian led to a self-reported shift in attention distribution to the right. However, the actual frequency of gazes to the left and right was not influenced by this presence. In the junction scenario having a pedestrian and a high traffic density, the mean frequency of looking to the left was increased, although the self-reported attention allocation was not changed between these situations. 
When driving through intersections, the intended driving manoeuvre (left turn, right turn, go straight) influences the gaze behaviour. Literature shows that more head movements and shorter mean fixations occur during right turns compared to going straight and left turns (Hancock et al., 1990; Shinohara and Nishizaki, 2017). More specifically, Robbins et al. (2019) found shorter mean fixation durations when turning right in low demanding driving situations (traffic light controlled traffic environment), but not for medium demanding driving situations (driver had to yield). The head movements were not influenced by the driving manoeuvre. The study of Robbins et al. (2019) found longer fixation durations in low demanding situations (traffic lights regulated and road environment only allows one direction) and shorter fixation durations in medium demanding situations (driver had to wait until it was safe to pull out).

Further important knowledge regarding eye movements at intersections was gained by Plavšić (2010). She analysed several intersections differing regarding the driving manoeuvre, the current regulation of way, time pressure, and the presence of a leading vehicle. She divided the crossing of an intersection into different phases (approaching, decelerating, crossing 1, crossing 2, and leaving). Results showed that time pressure led to much lesser gazes towards the drivers' lane when being in the approach phase, and turning led drivers to look at the lane more closely to their own. In addition, she found that half of the drivers did not foveally look at traffic signs in general. However, nearly all participants focused the stop sign.

\subsection{Task demand at intersections}

In general, intersections are defined as places where two or more roads meet and are mostly located in urban areas. In comparison to driving on highways and rural roads, driving in urban areas is more demanding for drivers as more information needs to be processed (Paxion et al., 2014; de Waard, 1996). As mentioned before, Robbins et al. (2019) found longer mean fixation durations for low demanding driving situations (traffic light controlled road environment so that the driver can only manoeuvre in a certain direction) compared to medium demand driving situations (driver has to decide when to safely pull out of intersection). This finding exemplarily represents the increased number of information that needs to be processed, so that fixation durations decrease and fixation numbers increase. In addition, Fastenmeier (1995) developed a taxonomy for task complexity of 134 different road traffic situations and categorized their complexity regarding two aspects of the driving task information processing and vehicle controlling. His research showed that urban intersections have a high driving task complexity. A further adaptation of Fastenmeier and Gstalter (2007) provided a method to structure driving tasks into subtasks and to rate the complexity and the risk of a driving task. Plavšić (2010) was guided by their work and similarly categorized the driving tasks when crossing an intersection into phases. Plavšić (2010) gave an overview of factors influencing workload and task demand of the driving task (see Figure 1). 


\begin{tabular}{|c|c|c|c|c|}
\hline $\begin{array}{l}\text { Driver Shaping } \\
\text { Factors }\end{array}$ & $\begin{array}{l}\text { Constructional } \\
\text { characteristics }\end{array}$ & $\begin{array}{l}\text { Operating } \\
\text { characteristics }\end{array}$ & $\begin{array}{l}\text { Situational and } \\
\text { environmental } \\
\text { characteristics }\end{array}$ & $\begin{array}{l}\text { Other road } \\
\text { users }\end{array}$ \\
\hline $\begin{array}{l}\text { - permanent } \\
\text { characteristics } \\
\text { - current state } \\
\text { - familiarity with } \\
\text { an intersection } \\
\text { - applied } \\
\text { strategies } \\
\text { - time pressure }\end{array}$ & $\begin{array}{l}\text { - the function of } \\
\text { the streets } \\
\text { - X, T form } \\
\text { - crossing angle } \\
\text { - characteristic of } \\
\text { the streets (width, } \\
\text { number of lanes, } \\
\text { curvature) }\end{array}$ & $\begin{array}{l}\text { - regulation of the } \\
\text { right of the way } \\
\text { - presence of } \\
\text { traffic signs } \\
\text { - street markings } \\
\text { - presence of } \\
\text { lanes for bicycle } \\
\text { - illumination }\end{array}$ & $\begin{array}{l}\text { - clear view } \\
\text { - right of way } \\
\text { - maneuver } \\
\text { - main/minor } \\
\text { street } \\
\text { - weather } \\
\text { - visibility }\end{array}$ & $\begin{array}{l}\text { - traffic density } \\
\text { - presence of } \\
\text { vulnerable } \\
\text { traffic } \\
\text { participants } \\
\text { - behavior of } \\
\text { other traffic } \\
\text { participants }\end{array}$ \\
\hline
\end{tabular}

Figure 1. The MOST RELEVANT FACTORS INFLUENCING WORKLOAD AND TASK DEMAND AT INTERSECTIONS FROM PLAVŠIĆ (2010)

In addition, the EU project INVENT of the German Aerospace Center (Vollrath et al., 2004) analysed driving behaviour at intersections. They focused on the following variations of intersections:

- Driving manoeuvre (right, left, straight)

- Traffic regulation (traffic lights, signs, no regulation, priority to the right)

- Right of way (having, giving)

- Intersection type (X- or T-junction)

- Road lane width

- Driving experience (learning the trip)

- Traffic density (different day times)

\subsection{Workload at intersections}

Considering the task demand when crossing intersections from the perspective of road design, the concept of workload needs to be addressed in this respect. Workload can be differentiated between mental and visual workload. Verwey (2000) wrote that "visual workload is assumed to be associated with the number and complexity of visual information sources. Mental workload is related to the amount of attention required for making decisions." A higher workload is assumed to influence the driving and gaze behaviour. For this reason, the driver's engagement in secondary tasks causing a higher workload, being distracted should be kept in mind when studying the approaching and crossing of intersections. Verwey (1993) analysed the workload in a real driving situation with a secondary task. Four groups were formed:

- Baseline

- Visual digit that has to be orally confirmed

- Visual digit where 12 had to be added (and orally said)

- Auditory digit where 12 had to be added (and orally said)

Participants were instructed 'not to pay attention to the secondary task when that would affect driving performance' (self-paced). The driving scene consisted of a highway and a subsequent drive on a rural road with differing driving manoeuvres (roundabout, right turn, and left turn). Results showed that the performance in the secondary task with visual detection or addition strongly decreases when turning left on the rural road in comparison to driving straight or turning right. However, the performance in the secondary task with auditory addition only decreased for turning left for unexperienced drivers. 
Engström et al. (2005) showed for a motorway drive that visual load, in contrast to cognitive load, increased the lane keeping variation and decreased speed. Furthermore, the gazes directed towards the road centre increased under cognitive load in comparison to a baseline drive. However, no differences in gaze variation occurred for the differing difficulty levels of the auditory secondary task. They reviewed the literature and summarized that visual load led to decreased performance in lane keeping, reduced speed, and decreased performance on detection of critical events. Visual load also reduces the event detection performance and the reaction times when phoning. Further results show that mental workload increases when texting while driving (Lansdown, 2019).

Apart from the primary driving task, also additional secondary tasks play an important role when studying workload and driving behaviour. On the one hand, secondary tasks while driving (e.g. phoning, texting, eating, smoking, talking with the passenger, controlling vehicle infotainment systems, ...) can be distracting and increase the workload, so that it is possible to gain an insight into how strenuous these secondary tasks can be and how they affect driving behaviour. On the other hand, by measuring the performance in a standardized secondary task, it is also possible to gain insight into how demanding the driving task itself is (Jahn et al., 2005). 


\section{Study aim}

Coming up from the theoretical background of the last chapter, several research questions evolve regarding the approaching and crossing of intersections.

First of all, attention allocation at intersections is of high relevance and therefore the driving simulator study aims to analyse gaze behaviour in more detail, regarding causally determined influences of intersection type and priority regulations.

In addition, the influence of a secondary task is relevant for the effects when driving through intersections as they increase the mental workload and can be a fundamental origin for driving errors due to attentional failures. Therefore, the simulator study also aims to analyse the influence of secondary task engagement of driving and gaze behaviour. 


\section{Methodology}

The driving simulator study was conducted at the Chair of Traffic and Transportation Psychology at the Technische Universität Dresden in April and May 2019. In the following chapter a description of the driving simulator, the study design, and the variables are given, as well as descriptions of intersection scenarios, sample, and procedure of the study.

\subsection{Driving simulator and eye tracking software}

The driving simulator of the Chair of Traffic and Transportation Psychology is a static driving simulator based on the program STISIM Drive from Systems Technology Incorporated and is equipped with a half vehicle mock-up (Mercedes-Benz series 169) with driver and passenger seat as well as three monitors with 40 inch screen diagonal each. The displayed viewing area of the monitors together gives 135 degrees. The HED system from Sensomotoric Instruments (SMI) was used for gaze detection. Figure 2 shows on the left side the static driving simulator being used and on the right side the eye tracking system from SMI.
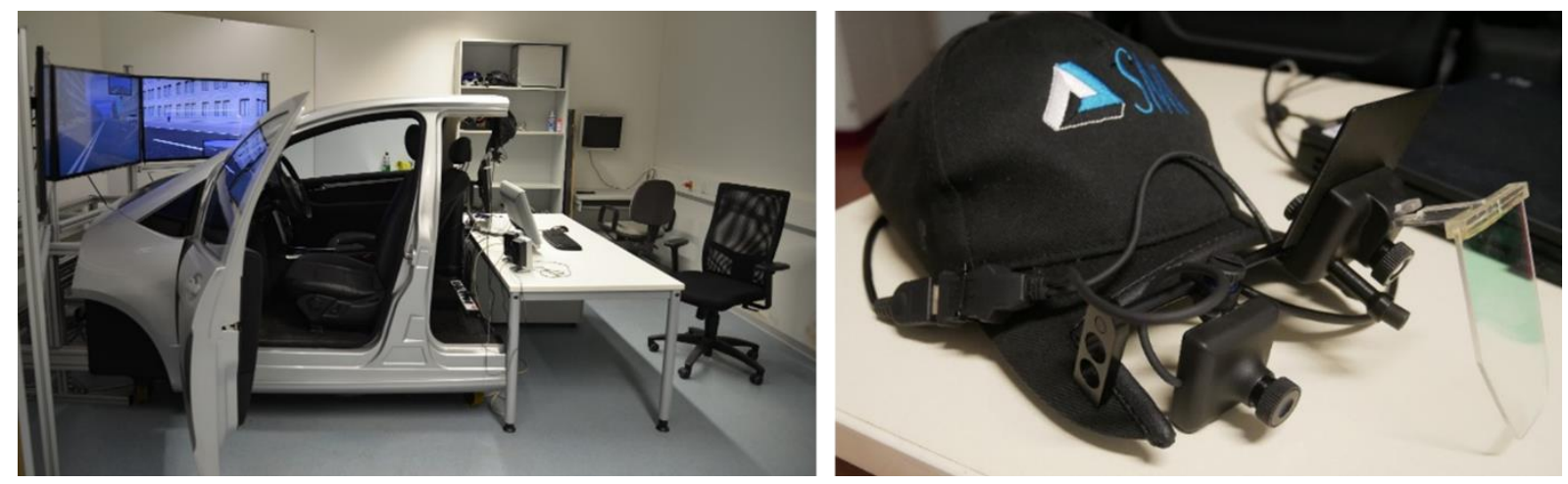

FIGURE 2. StATIC DRIVING SIMULATOR (LEFT) AND EYE TRACKING SYSTEM SMI HED4 (RIGHT)

\subsection{Research design}

According to the literature, various important influencing factors must be taken into account when investigating driving and gaze behaviour at intersections. The following influencing factors (independent variables) were investigated, whereby the individual variations (steps) are shown in the right-hand column (A detailed description of the factors is given in the next chapter):

1. Secondary task:

2. Right of way:

3. Intersection type:

4. Driving manoeuvre:
1) Baseline (no secondary task)

2) with secondary task (focus on task)

3) with secondary task (focus on driving)

1) Having priority with green traffic light

2) Giving priority with yield sign

1) $T$-junction (three way)

2) X-intersection (four way)

1) turn left

2) turn right

3) go straight 
5. Traffic and its' right of way: 1) no traffic

2) irrelevant traffic (no waiting needed)

3) relevant cross traffic

4) relevant cross traffic and oncoming traffic

With respect to the mental workload, a between subjects factor was varied by the presence or absence of a secondary task and therefore, the distraction of the driver was varied. The driver had either no secondary task or a secondary task with focus on the driving task or on the secondary task.

The remaining four factors were within-subjects, i.e. each person should receive every variation of these factors. The combination of the factors with each other resulted in a variety of intersection scenarios that the driver had to pass through. However, certain combinations of factors do not occur in reality, resulting in an incomplete investigation design. For example, driving straight ahead is not possible at a T-junction. Furthermore, in scenarios where the right-of-way was regulated by a green traffic light for the subject, the surrounding traffic is less variable, since the other vehicles have to wait at their red traffic light. Combining right of way, intersection type, driving manoeuvre, and traffic and its' right of way (steps 1-3) resulted in 25 intersection scenarios. In chapter 4.3, a detailed description of the operationalization of the five independent variables is given.

\subsection{Intersections}

In order to better illustrate the resulting intersection scenarios, Figure 3 and Figure 4 show all examined scenarios schematically. Scenarios 1 to 10 represent the right of way "Having priority with green traffic light". Scenarios 11 to 25 represent the right of way "Giving right of way with yield sign". Scenarios 26 and 27 represent an additional variation of traffic for each priority variation.

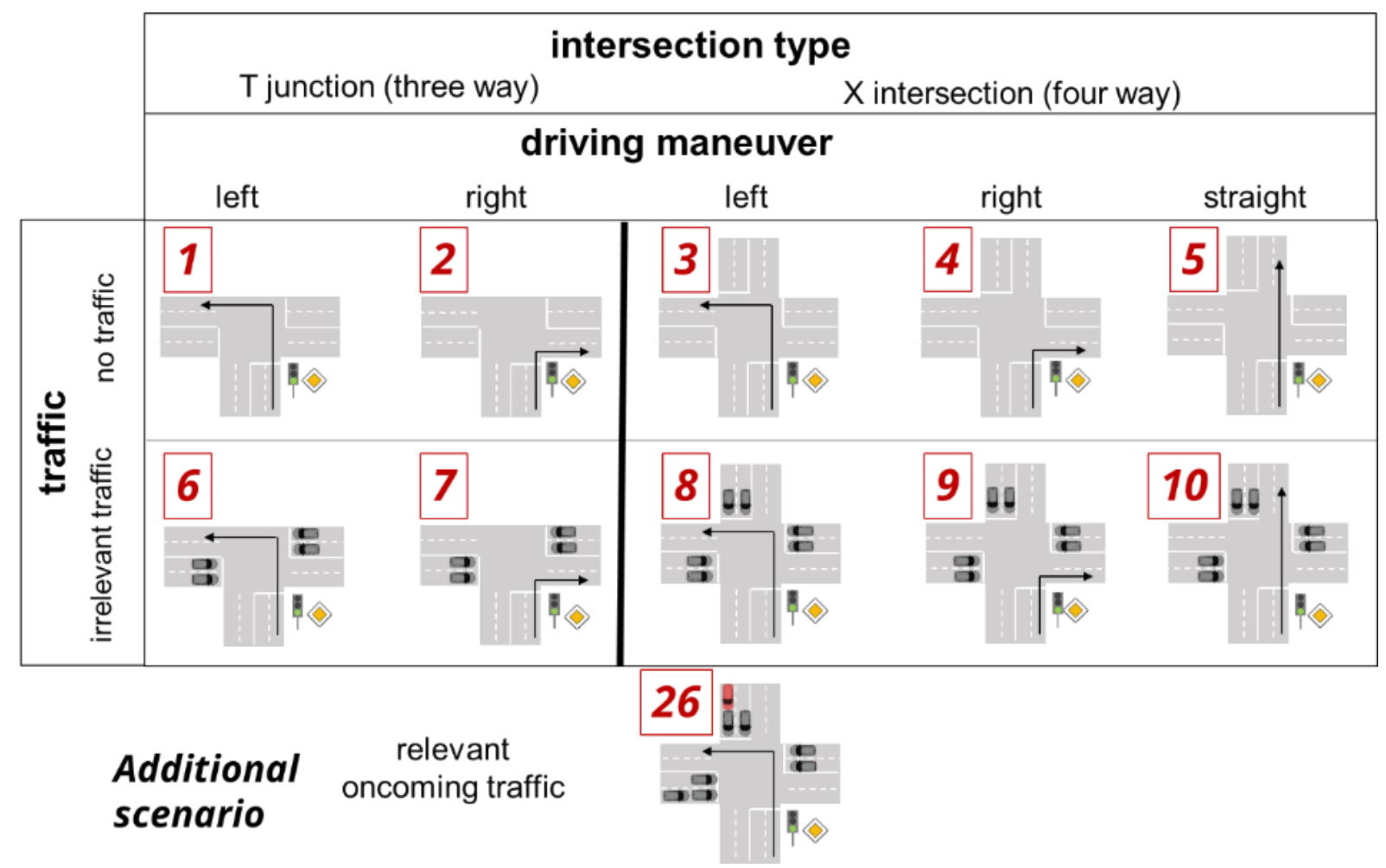

FigURE 3. SCHEMATIC REPRESENTATION OF INTERSECTION SCENARIOS FOR THE RIGHT OF WAY "HAVING PRIORITY WITH GREEN TRAFFIC LIGHT" 


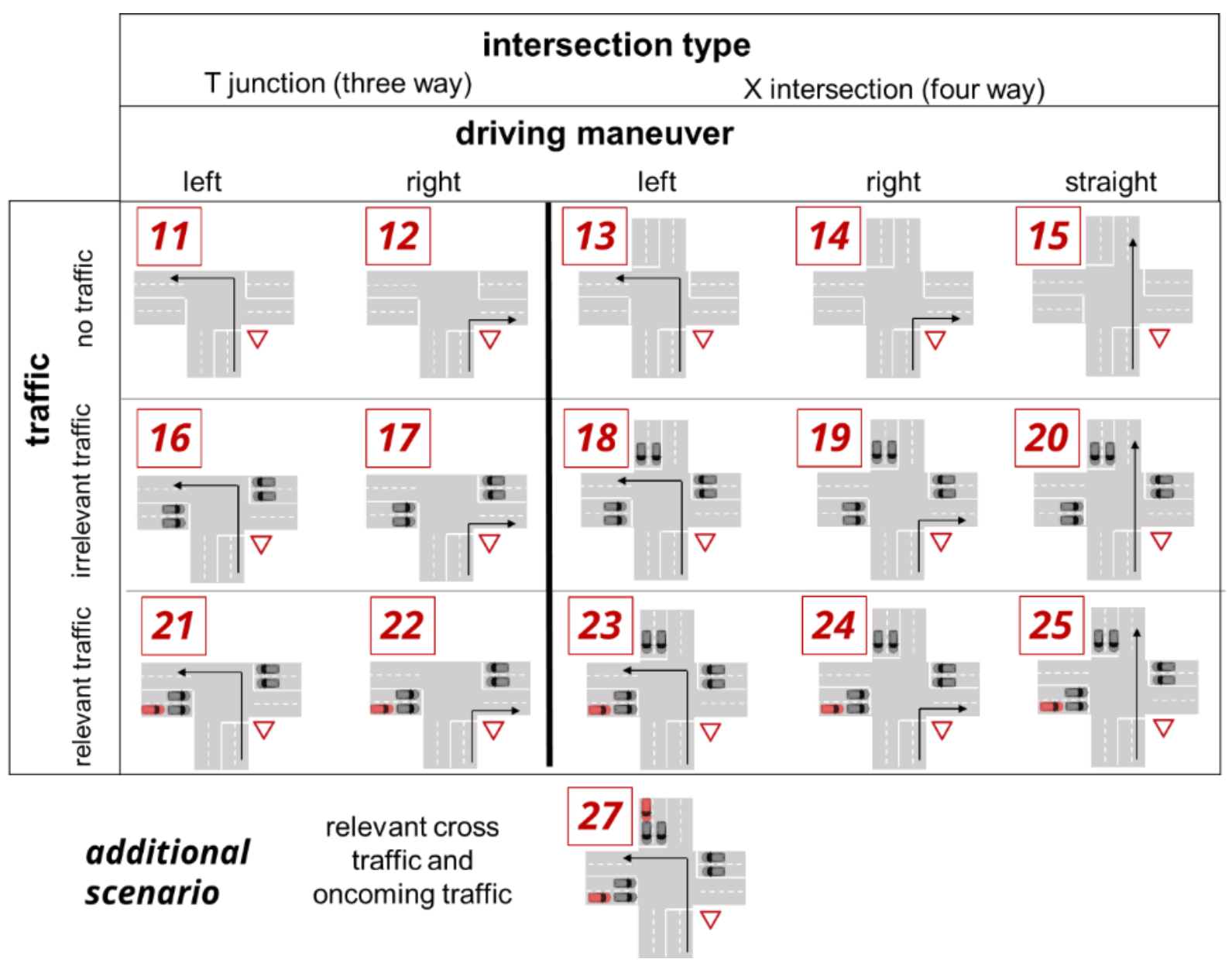

FIGURE 4. SCHEMATIC REPRESENTATION OF INTERSECTION SCENARIOS FOR THE RIGHT OF WAY “GIVING RIGHT OF WAY WITH YIELD SIGN"

In addition, Figure 5 and Figure 6 show screenshots of the driving simulation from the driver's perspective on T-junctions and X-intersections, as well as a bird's eye view on an X-intersection.
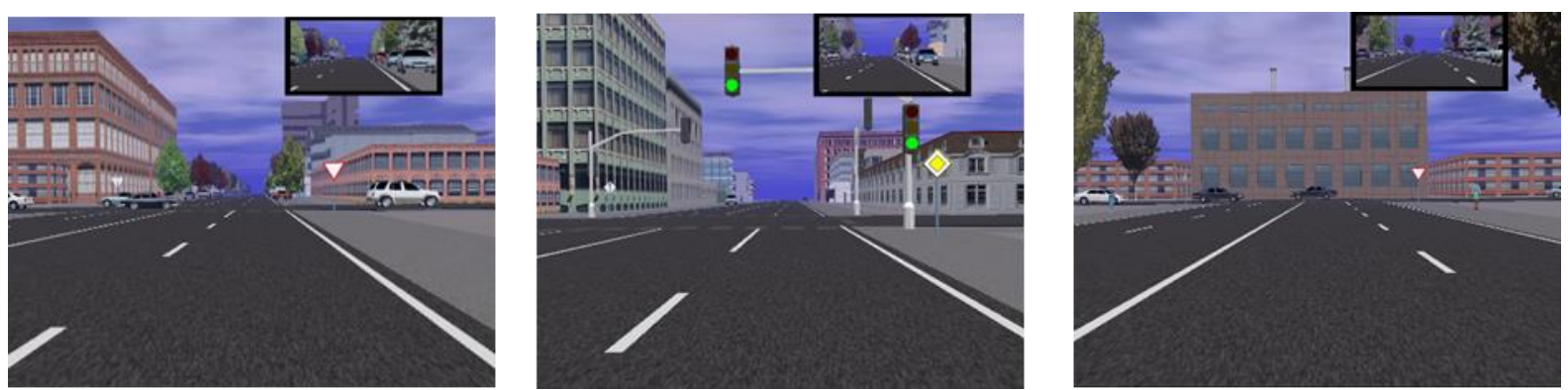

FIGURE 5. A SELECTION OF INTERSECTION SCENARIOS FROM THE DRIVER'S PERSPECTIVE (LEFT - SCENARIO 24, MIDDLE - SCENARIO 5, RIGHT - SCENARIO 16) 

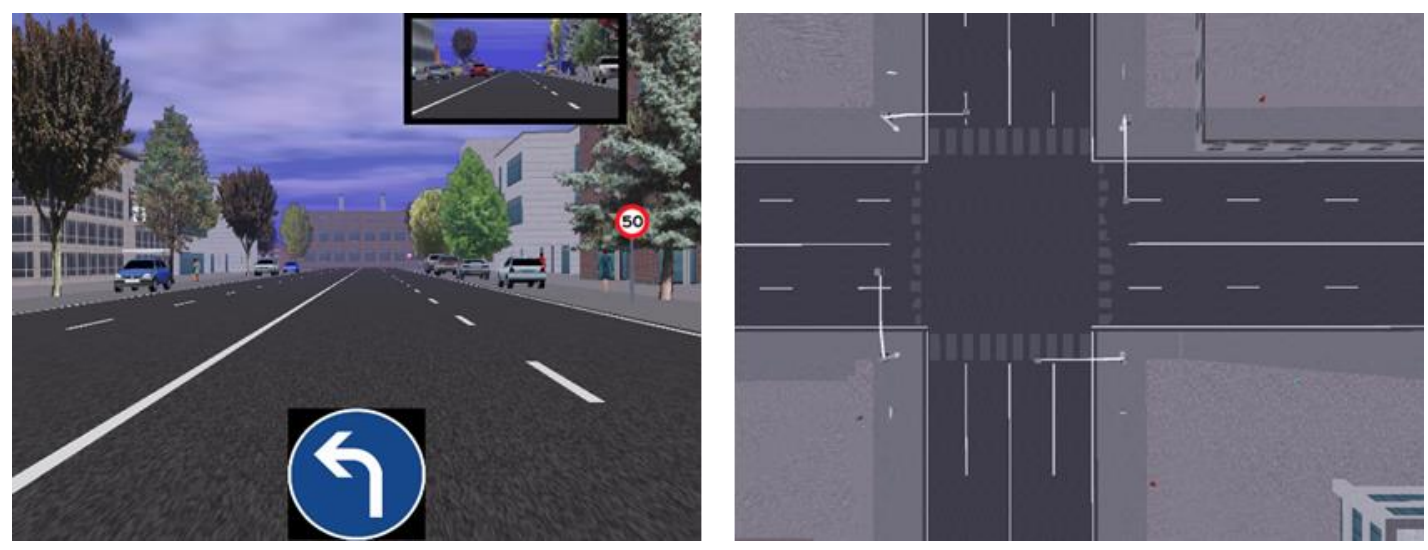

FIGURE 6. T-JUNCTION FROM THE DRIVER'S PERSPECTIVE (LEFT), X-INTERSECTION FROM A BIRD'S EYE VIEW (RIGHT)

\subsubsection{Secondary task}

The secondary task was varied by letting one group of subjects count backward from a certain number in steps of 2 following the serial seven subtraction task being a widely used cognitive load task (Scholey et al., 2001). This secondary task was chosen to achieve an increased mental workload for the driver that corresponds to a cognitive distraction in road traffic. The beginning and ending of the secondary task was shown in the driver's head-up display on the middle monitor of the driving simulator for each intersection ( $120 \mathrm{~m}$ before to $40 \mathrm{~m}$ after the intersection).

\subsubsection{Right of way}

The right of way was varied by adapting the signposting at the intersection and the presence or absence of traffic lights. For the situation of giving right of way, there was the traffic sign of the German traffic sign type 205 "Give way" in the direction of the ego-vehicle and the oncoming traffic, and for the cross traffic the German traffic sign type 306 "Priority road". For the situation of having right of way, the opposite was true: for the ego car and the oncoming traffic, the German traffic sign type 306 "Priority road" was valid and for the cross traffic the German traffic sign type 205 "Give way". In addition, a traffic light system signalled green light to the driver and oncoming traffic and red light to cross traffic.

\subsubsection{Driving manoeuvre}

The driving manoeuvre was signposted to the driver by arrows (left, straight, or right), which were triggered approximately $275 \mathrm{~m}$ before each intersection in the head-up display.

\subsubsection{Intersection type}

The variation of intersection type was achieved by placing a building on the upper branch of the Xintersection so that a T-junction was created. The crossing branches were arranged at right angles for both variations. There were no additional pedestrian fords or similar. Unfortunately, the driving simulation software STISIM formed intersection branches at a 90-degree angle by default and did not allow any further adjustments in terms of road edge design or road edge curvature. Because of this, especially the "right turn" manoeuvre was very difficult for the drivers to handle. Therefore, a 4-lane city road with two lanes per direction was used, allowing the drivers to turn right and keep the tight curve radius without crossing oncoming traffic. 


\subsubsection{Traffic and its right of way}

The traffic and its right of way are strongly dependent on the variation of the first independent variable, the right of way for the ego vehicle. In the variation "no traffic", there were no other vehicles at the intersection. So, if the previous within factors are combined, this variation without surrounding traffic results in ten scenarios (in Figure 3 scenarios 1-5 and in Figure 4 scenarios 11-15).

The variation "irrelevant traffic (no waiting needed)" means that surrounding traffic was present but did not intervene with the ego vehicle. It was implemented differently for the situation "Having priority with green traffic light" and "giving priority with yield sign":

1) Driver has the right of way: The cross traffic was standing at the red traffic light. This means that one vehicle waited on each lane at the left and right branch of the intersection (in Figure 3 scenarios 6-10). Oncoming traffic at X-intersections (scenarios 8-10) cleared the intersection before the subject entered it.

2) Driver gives right of way: Two cars from the left and right branch of the intersection drove over the intersection at a target speed of approx. $12.5 \mathrm{~m} / \mathrm{s}$ in cross traffic and left the intersection as soon as the subject entered the intersection (scenarios 16-20 in Figure 4). Oncoming traffic at $\mathrm{X}$-intersections (scenarios 18-20) cleared the intersection before the subject entered it.

The variation of "relevant traffic" was implemented only for the situation, where the subject had to give right of way. The cross traffic approaching the intersection from the left was increased in addition to the surrounding traffic of the previous step. Three further vehicles drove from the left over the intersection with a distance of $10 \mathrm{~m}$ each and an instructed speed of $12.5 \mathrm{~m} / \mathrm{s}$. This cross-traffic made it unavoidable for the subject to stop at the intersection (scenarios 21-25 in Figure 4).

The variation "relevant cross traffic and oncoming traffic" was implemented for scenarios 26 and 27:

1) Scenario 26 (Driver has the right of way): Only for the scenario of turning left at an Xintersection, the subject would have to give priority to oncoming traffic (scenario 26 in Figure 3). Oncoming vehicles drove over the intersection with $12.5 \mathrm{~m} / \mathrm{s}(45 \mathrm{~km} / \mathrm{h})$ and having intervals of $20 \mathrm{~m}, 20 \mathrm{~m}, 40 \mathrm{~m}, 40 \mathrm{~m}, 60 \mathrm{~m}, 60 \mathrm{~m}, 80 \mathrm{~m}, 80 \mathrm{~m}$, and $100 \mathrm{~m}$ and therefore creating a gap acceptance situation.

2) Scenario 27 (Driver gives right of way): Similar to scenario 26 before, the situation of turning left at an X-intersection was of special interest, where the subject had to give right of way to all other road users before he or she can turn left. Accordingly for an additional 27th scenario, a situation was created, in which the driver had to give right of way to both cross traffic from the left and oncoming traffic by stopping. For this purpose, the oncoming traffic with right of way from scenario 26 was triggered after all vehicles from the left had crossed the intersection.

\subsection{Intersection sequence}

The driving simulation was designed in such a way that an intersection was following every $400 \mathrm{~m}$. The final 27 intersections were divided into five clusters, each having five to six intersections (scenarios) to give the drivers the opportunity for having breaks in between. The sequence of intersections was chosen so that the intersections alternate strongly. The order of the clusters was varied for every driver to avoid that learning and sequential effects have a systematic influence on driving parameters. 


\subsection{Procedure}

The experiment started with the greeting of the subject. After signing the declaration of consent, the subject received detailed instructions on the driving simulator and the driving task, as well as a description of the test procedure and, depending on the group, a description of the secondary task. Afterwards, the subject entered the driving simulator and the experimenter explained the characteristics of the driving simulator and the subsequent training drive. Before the actual training drive began, the eye tracking system was put on. The training drive lasted 5 to 10 minutes and started on a rural road, led via a suburb, and finally into an urban area. Here, the subject had to pass seven intersections and trained the manoeuvres of turning left and turning right. Afterwards, the subject had the opportunity to repeat the training for the urban area in order to feel sufficiently acclimatized. After this training, the actual test drive with the five clusters with five to six intersections each began. This was followed by a demographic questionnaire, including questions about the current state of health and simulator sickness. At the end the test, persons received an expense allowance of $15 €$ and were bid farewell.

\subsection{Sample}

Prerequisites for participation in the experiment were the possession of a driving license and an annual mileage of at least $5,000 \mathrm{~km}$. A total of 75 test persons took part in the study. However, 14 persons aborted because of problems with simulator sickness. Simulator sickness is a subset of motion sickness that is being "defined as the discomfort experienced when perceived motion disturbs the organs of balance. Symptoms may include nausea, vomiting, pallor, cold sweats, hypersalivation, hyperventilation, and headaches" (Loo, 2009)). Another two test persons were excluded due to technical problems with the eye tracking system. Accordingly, 59 complete data sets were left at the end ( 26 women, 33 men). The mean age of these 59 subjects is 38.4 years ( $S D=12.1$ years) and the mean annual mileage is $13,294.9 \mathrm{~km}(\mathrm{SD}=9159.7 \mathrm{~km})$. The randomized group allocation was as follows: 33 persons drove in the control group (without secondary task) and 26 persons drove with a secondary task. 


\section{Data processing and data analysis}

Driving data and gaze data was recorded. Driving data included lateral and longitudinal speed, acceleration, and longitudinal and lateral position of the drivers' car. About $10 \%$ of driving data was unusable due to technical failures of data saving within the simulation software. All clusters and scenarios where equally affected, therefore no adjustment was necessary for data analysis. The driving data was processed with National Instruments DIADEM.

Gaze data was processed regarding the detection and separation of fixations and saccades by SMIs' software BeGaze. A fixation is the maintaining of the gaze on one position. In contrast to this, saccades describe the very quick eye movements in between fixations. The fixations determined by the software BeGaze were used for further gaze data processing. The fixations for all intersections and subjects were manually coded regarding the gaze location given by the areas 'left', 'right', 'straight', 'down', and 'other' (see Figure 7).

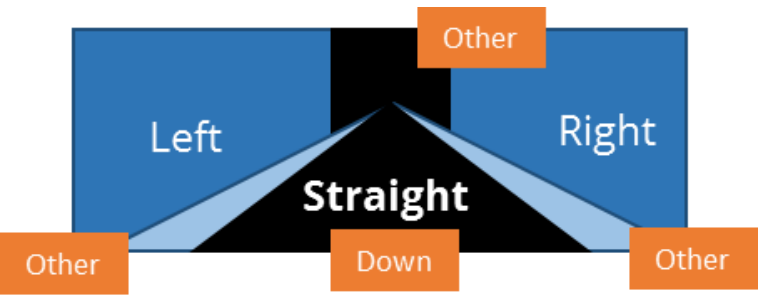

FIGURE 7. GAZE LOCATIONS FOR DATA PROCESSING

For data analysis of driving and gaze data, a segmentation of driving through the intersection was necessary. Five segments were separated (see also Figure 8):

- Segment 1 includes data within the area $75 \mathrm{~m}$ to $50 \mathrm{~m}$ before intersection entry (Approach 1 )

- Segment 2 includes data within the area $50 \mathrm{~m}$ to $25 \mathrm{~m}$ before intersection entry (Approach 2)

- Segment 3 includes data within the area $25 \mathrm{~m}$ before intersection entry until intersection entry (Approach 3)

- Segment 4 includes all data within the dimensions of the intersection (Crossing)

- Segment 5 includes all data from leaving the dimension of the intersection until the driver finishes the manoeuvre and gaze data coding ended (Exit)

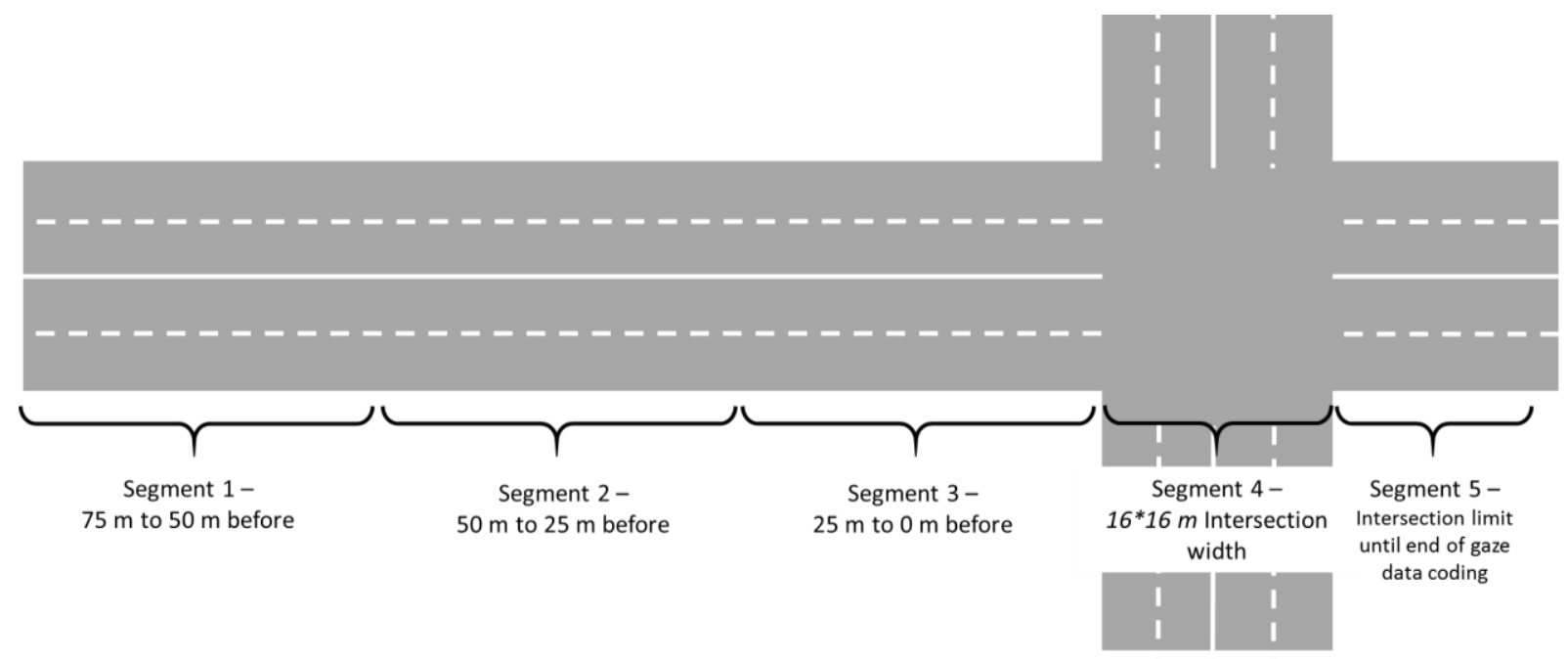

FIGURE 8: SEGMENTATION OF INTERSECTION FOR DATA ANALYSIS 


\section{Results}

The result section is structured as follows: Firstly, the driving characteristics of the segments 1 to 4 are presented in chapter 6.1 to get an overall impression on the different driving behaviour for each scenario. Chapter 6.2 shows the gaze distribution for all scenarios and junction segments in dependence of the influence of traffic and driving manoeuvre. Chapter 6.3 presents the mean fixation durations for all scenarios and junction segments. The results regarding the secondary task engagements are part of chapter 6.4.

\subsection{Driving characteristics}

\subsubsection{Right of way - having priority}

The following results are given for scenarios 1 to 10 and 26 (see Figure 3), in which the driver has the right of way being given by a green traffic light. Table 2 gives an overview of all analysed driving parameters in this regard. For each segment, the duration, the mean speed and its' standard deviation, the entry speed and minimal speed, as well as the mean acceleration are presented. Detailed description of results is given for the segment duration, the mean speed, and the mean acceleration.

\subsubsection{Segment duration}

The duration of driving through the different segments when approaching and crossing the intersection varies strongly for the four presented segments. Results are shown in Figure 9 and Figure 10 , separated for control group and task group (the group having the secondary task), as well as Tjunction and $\mathrm{X}$-intersection. The shortest durations occur for the crossing segment and segment 1 when the driver is 75 to $50 \mathrm{~m}$ away from the intersection. As to be expected, the longest durations occur shortly before crossing in segment 3 ( $25 \mathrm{~m}$ to 0 before intersection entry).

Control group, $\mathrm{T}$ junction

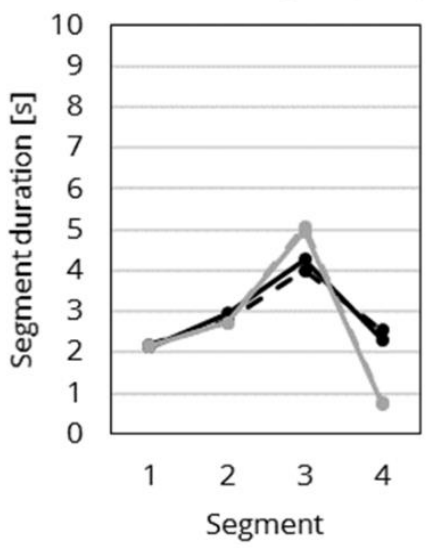

Control group, $\mathrm{X}$ intersection

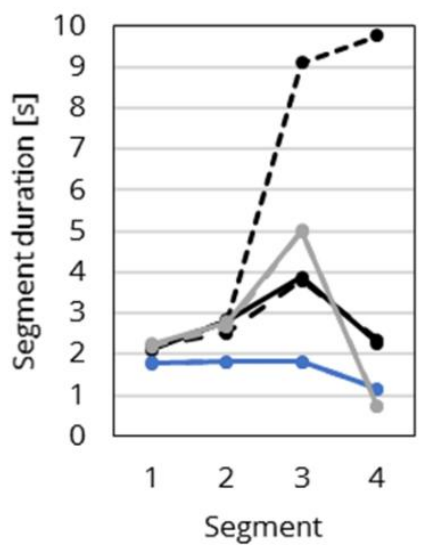

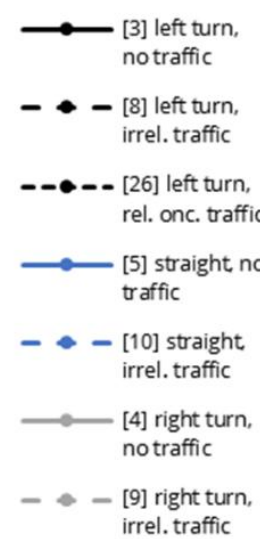

FIGURE 9. SEGMENT DURATIONS FOR SCENARIOS OF CONTROL GROUP WHEN HAVING THE RIGHT OF WAY. BRACKETS PRESENT THE SCENARIO NUMBER. LEFT SHOWS SCENARIOS WITH T-JUNCTION AND RIGHT SHOWS SCENARIOS WITH X-INTERSECTION. 
Task group, $\mathrm{T}$ junction

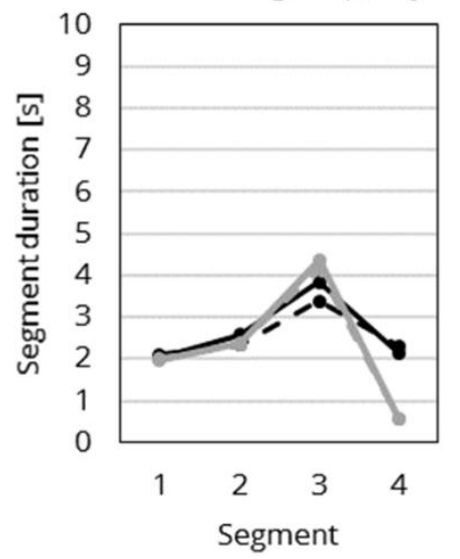

Task group, $\mathrm{X}$ intersection

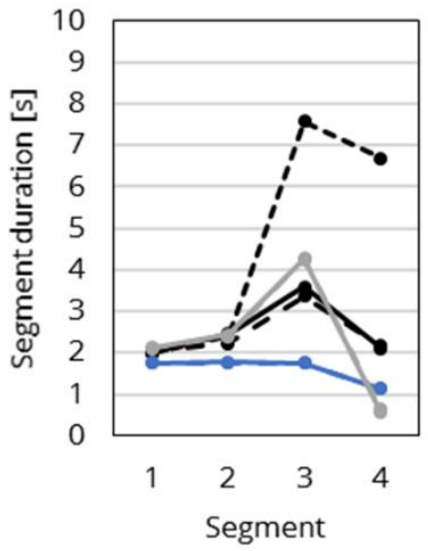

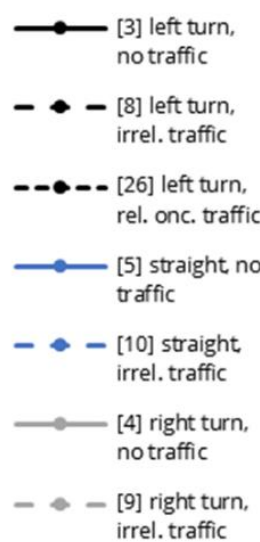

FigURE 10. SEGMENT DURATIONS FOR SCENARIOS OF TASK GROUP WHEN HAVING THE RIGHT OF WAY. BRACKETS PRESENT THE SCENARIO NUMBER. LEFT SHOWS SCENARIOS WITH T-JUNCTION AND RIGHT SHOWS SCENARIOS WITH X-INTERSECTION.

Interestingly, there are no big differences in the duration of the segments between the scenarios with and without irrelevant traffic (except for scenario 26, which is special anyway). In the figures, this would be visible by huge differences between the solid and long dashed lines. This indifference could indicate that driving behaviour is unaffected by the mere presence of traffic, without it being relevant for the drivers' right of way, but a closer look at the velocities is necessary to further evaluate this assumption.

A further aspect relates to the differentiation between control and task group. Differences between control and task group seem small. Some major differences are visible for turning right (grey lines) as the duration of segment 3 ( $25 \mathrm{~m}$ to 0 prior to intersection) is longer in the control group than in the task group. Being distracted might lead to a faster approach towards the intersection. A huge difference is visible for scenario 26 , where the participants had to turn left with dynamic oncoming traffic. When having a secondary task, the drivers did pass the segment way faster.

\subsubsection{Mean segment speed}

The mean speeds when driving through the four segments while approaching and crossing the intersection having a green traffic light are shown in Figure 11 and Figure 12, again separated for control and task group, as well as T-junction and X-intersection.

Control group, $\mathrm{T}$ junction

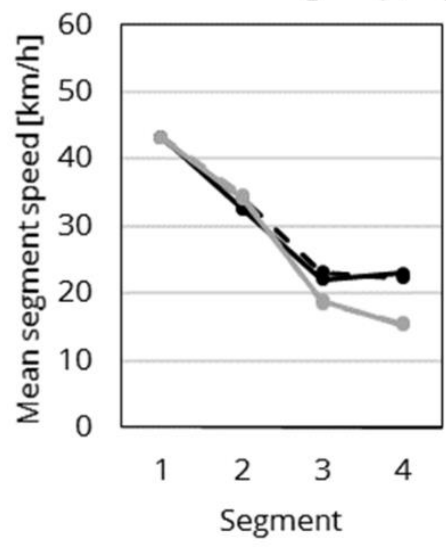

\section{Control group, $\mathrm{X}$ intersection}

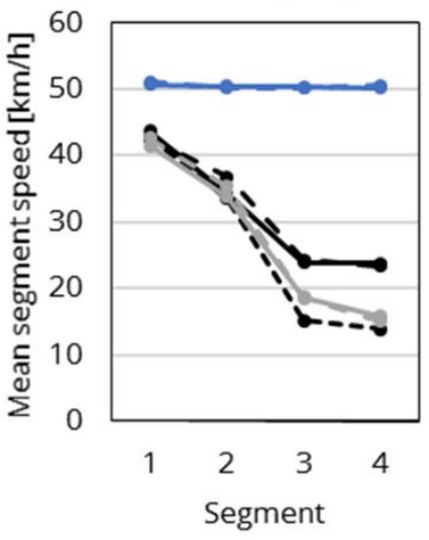

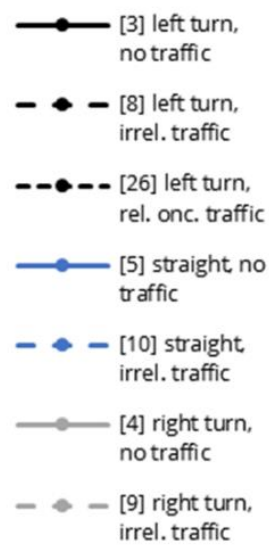

FIGURE 11. MEAN SEGMENT SPEED FOR SCENARIOS OF CONTROL GROUP WHEN HAVING THE RIGHT OF WAY. BRACKETS PRESENT THE SCENARIO NUMBER. LEFT SHOWS SCENARIOS WITH T-JUNCTION AND RIGHT SHOWS SCENARIOS WITH X-INTERSECTION. 
Task group, T junction

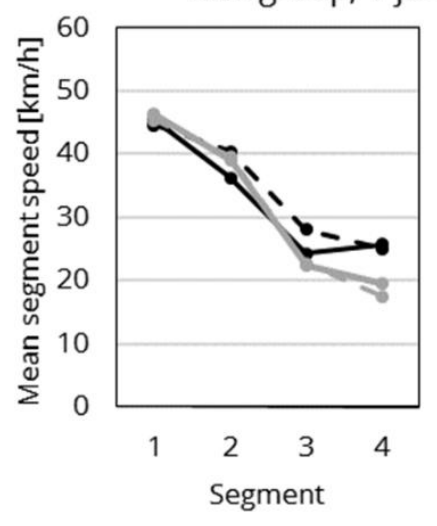

Task group, $\mathrm{X}$ intersection

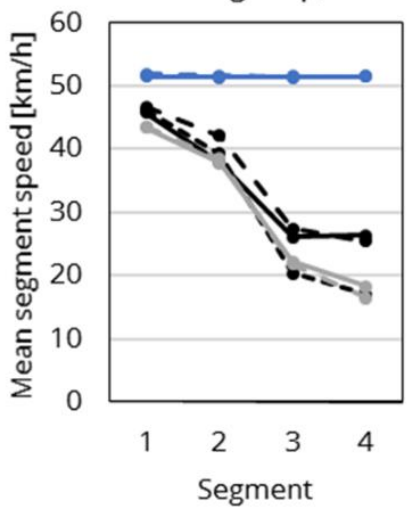

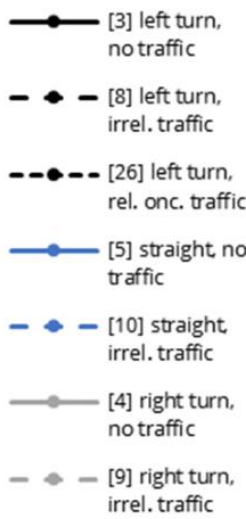

FIGURE 12. MEAN SEGMENT SPEED FOR SCENARIOS OF TASK GROUP WHEN HAVING THE RIGHT OF WAY. BRACKETS PRESENT THE SCENARIO NUMBER. LEFT SHOWS SCENARIOS WITH T-JUNCTION AND RIGHT SHOWS SCENARIOS WITH X-INTERSECTION.

Firstly, going straight at an X-intersection having priority that is signalized by a green traffic light causes virtually no change in speed while driving through the individual segments when approaching and crossing the intersection (see blue lines in figures). The mean speeds are about $50 \mathrm{~km} / \mathrm{h}$ for the control group and about $51 \mathrm{~km} / \mathrm{h}$ for the task group (drivers having a secondary task). In addition, these speeds are the highest values being found in all scenarios and segments.

However, when turning right or left (black and grey lines in the figures), it can be seen by the numbers and the figures that the speed decreases from segment 1 to segment 3 independently of the presence or absence of traffic. This was to be expected because the drivers had to reduce their speeds to get around the corner. In the first segment ( $75 \mathrm{~m}$ to $50 \mathrm{~m}$ before intersection entry), the mean speed was about $45 \mathrm{~km} / \mathrm{h}$ when planning to turn left or right. In the second segment $(50 \mathrm{~m}$ to $25 \mathrm{~m}$ before intersection entry), the mean speed for planning to turn right or left varies from 30 to $40 \mathrm{~km} / \mathrm{h}$. Higher values of mean speed in segment 2 can be found for drivers having a secondary task. This means that the drivers might not reduce their speed as much as in the situation without a secondary task. In segment 3 ( $25 \mathrm{~m}$ to 0 before intersection entry), the mean speeds for turning left or right vary between 15 and $28 \mathrm{~km} / \mathrm{h}$. A first visual difference in graphs can be found for segment 3 between control and task group: mean speeds for drivers having a secondary task are higher than for drivers without. A second difference in segment 3 is visible from the number and figures for $\mathrm{X}$-intersections between turning left (without scenario 26) and turning right: mean speeds for turning left are descriptively higher than for turning right. This difference becomes stronger in segment 4 , the phase of crossing the intersection. The figures show greater differences between mean speeds for turning left (without scenario 26) and turning right. The scenario 26 , which was turning left and waiting for oncoming traffic, is more comparable to right turns in its course of mean speeds.

\subsubsection{Mean segment acceleration}

The mean acceleration values when driving through the four segments while approaching and crossing the intersection having a green traffic light are shown Figure 13 and Figure 14 . The variation in acceleration is smallest for driving straight ahead (blue lines in figures), which is comparable to the consistently high mean speeds shown in the section before. This means that drivers did not adapt their speed when driving straight at a prioritized intersection. 
Control group, $\mathrm{T}$ junction

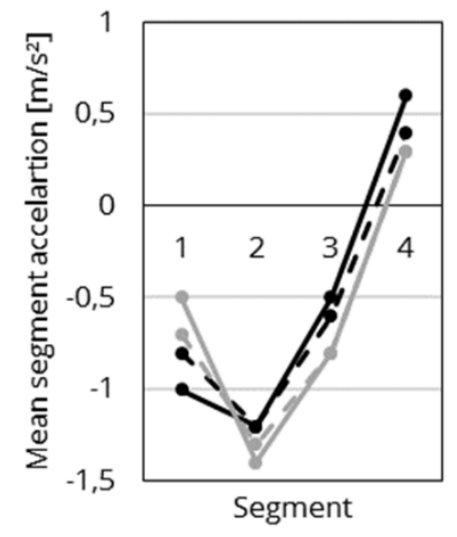

Control group, $\mathrm{X}$ intersection

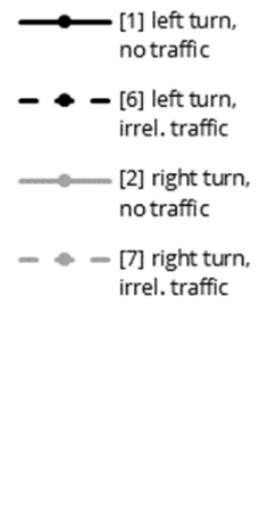

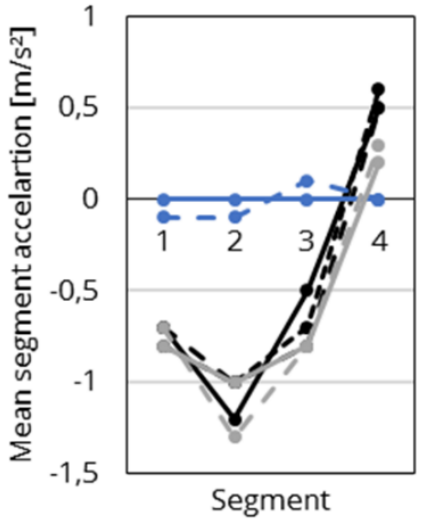

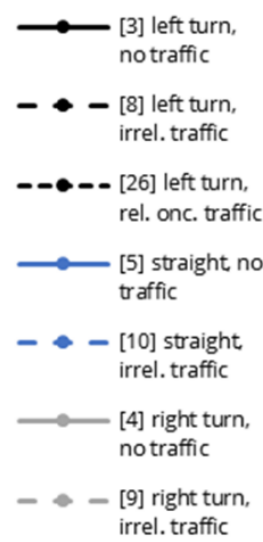

FIGURE 13. MEAN SEGMENT ACCELERATION FOR SCENARIOS OF CONTROL GROUP WHEN HAVING THE RIGHT OF WAY. LEFT SHOWS SCENARIOS WITH T-JUNCTION AND RIGHT SHOWS SCENARIOS WITH X-INTERSECTION. [ ] IS THE SCENARIO NUMBER.

Task group, $\mathrm{T}$ junction

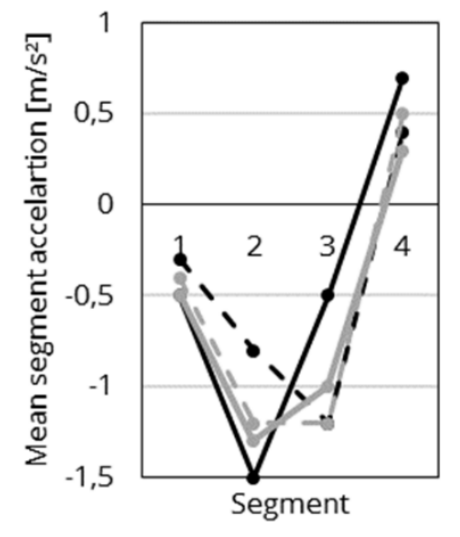

Task group, $\mathrm{X}$ intersection

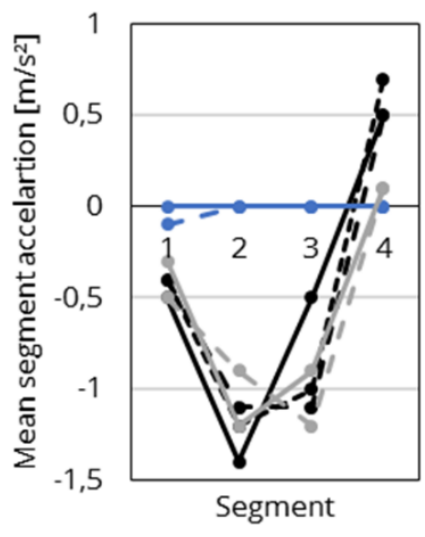

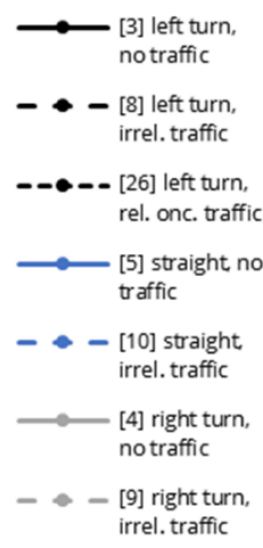

FIGURE 14. MEAN SEGMENT ACCELERATION FOR SCENARIOS OF TASK GROUP WHEN HAVING THE RIGHT OF WAY. LEFT SHOWS SCENARIOS WITH T-JUNCTION AND RIGHT SHOWS SCENARIOS WITH X-INTERSECTION. [ ] IS THE SCENARIO NUMBER.

When turning left or right, the lowest values for acceleration (highest values for deceleration) can be seen for the control group in segment 2 and for the task group in segment 2 as wells as segment 3 . In general, the acceleration values are negative in segment 1,2 , and 3 . Only in segment 4 , i.e. when the intersection is already being driven through, the values of acceleration become positive. For segment 1 , the deceleration is stronger in the control group than in the task group. This is reversed in segment 2 and 3, where the task group decelerates more. This is again consistently with the changes in speed found in chapter 6.1.1.2. Drivers without secondary task decelerated earlier when planning a right or left turn. The further variation in acceleration for turning right and left in dependence of presence and absence of traffic as well as secondary task is highly inconsistent. In contrast to mean speeds, from the visual inspection of the figures no general patterns can be found. There are some scenarios showing strongest deceleration in segment 2 (e.g. scenario 1 and 3 - left turn without traffic) and smaller values in the other segments. However, other scenarios (e.g. scenario 8 and 9 - right and left turn with traffic at $X$-intersection) have a high deceleration in segment 2 and segment 3 . These high variations in acceleration suggest that driver adapt the driving behaviour in consequence of the individual intersection scenario that has to be performed. 


\subsubsection{Right of way - giving priority}

The following results are given for scenarios 11 to 25 (see Figure 4), in which the driver must give right of way being signalized with a yield sign. Table 3 gives an overview of all analysed driving parameters in this regard, also for scenario 27 . For each segment, the duration, the mean speed and its' standard deviation, the entry speed, and minimal speed, as well as the mean acceleration are presented. Detailed description of results is following for the segment duration, the mean speed, and the mean acceleration.

\subsubsection{Segment duration}

Results for the segment duration are shown in Figure 15 and Figure 16, separated for control group and task group (the group having the secondary task), as well as T-junction and X-intersection. The figures do not present scenario 27.
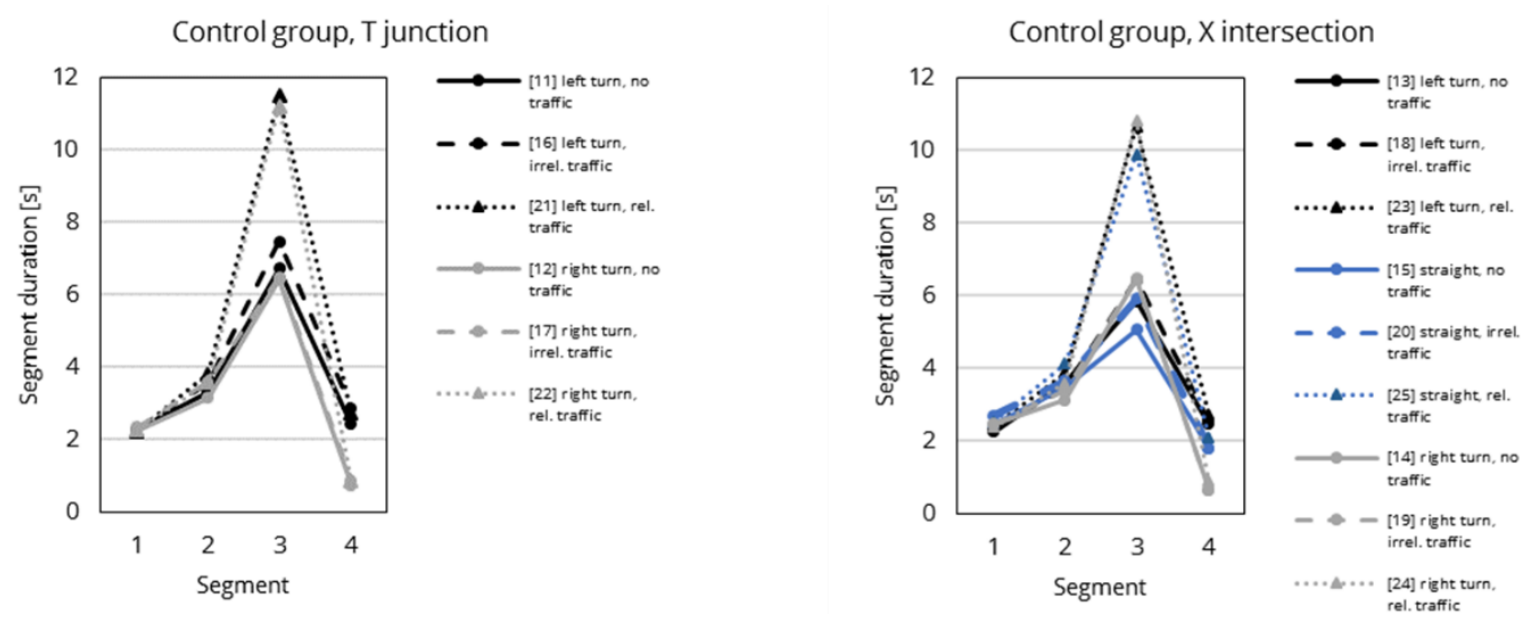

FIGURE 15. SEGMENT DURATIONS FOR SCENARIOS OF CONTROL GROUP WHEN GIVING THE RIGHT OF WAY. BRACKETS PRESENT THE SCENARIO NUMBER. LEFT SHOWS SCENARIOS WITH T-JUNCTION AND RIGHT SHOWS SCENARIOS WITH X-INTERSECTION.

Taskgroup, T junction

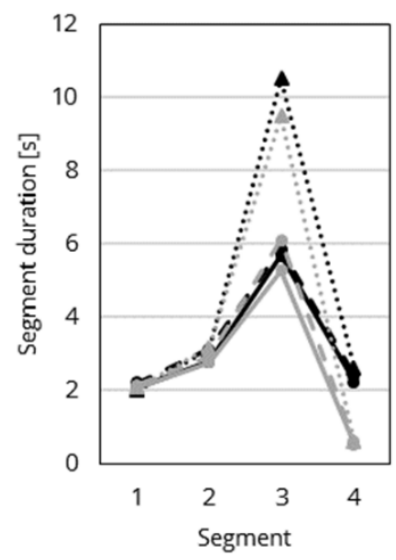

Task group, $\mathrm{X}$ intersection

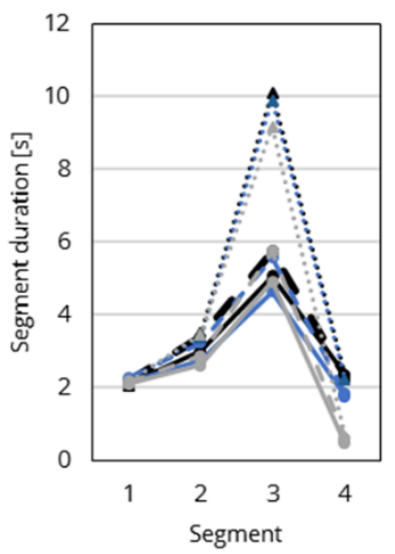

FIGURE 16. SEGMENT DURATIONS FOR SCENARIOS OF TASK GROUP WHEN GIVING THE RIGHT OF WAY. BRACKETS PRESENT THE SCENARIO NUMBER. LEFT SHOWS SCENARIOS WITH T-JUNCTION AND RIGHT SHOWS SCENARIOS WITH X-INTERSECTION.

The longest durations of $9 \mathrm{~s}$ to $12 \mathrm{~s}$ are given for segment 3 ( $25 \mathrm{~m}$ to 0 before intersection entry), showing that the drivers took their time there before crossing the intersection. As to be expected, the scenarios with relevant surrounding traffic that forces the driver to hold and give way provide the longest durations of $9 \mathrm{~s}$ to $12 \mathrm{~s}$ in average. The major visible differences between scenarios having relevant traffic and scenarios having irrelevant or no traffic consist in the duration of segments. This is 
interesting in such a way that the presence of relevant traffic might only be important in this segment, $25 \mathrm{~m}$ to 0 before the intersection boundary begins. A further look at the speed should further substantiate this.

A difference for drivers having a secondary task in comparison to drivers without can be seen in segment 3: Drivers having a secondary task passed the $25 \mathrm{~m}$ before intersection entry a little faster than drivers without secondary task. For all other segments, the durations are comparable from visual inspection of data. A further aspect is the driving manoeuvre: turning left, turning right, or going straight had comparable durations in the different segments.

\subsubsection{Mean segment speed}

The results for the mean segment speed for all scenarios in which the driver had to give priority are shown in Figure 17 and Figure 18. In contrast to the mean speeds when having the priority (see chapter 6.1.1.2), the speed when giving way decreases while approaching the intersection for all scenarios, even when going straight without further traffic (blue solid line).
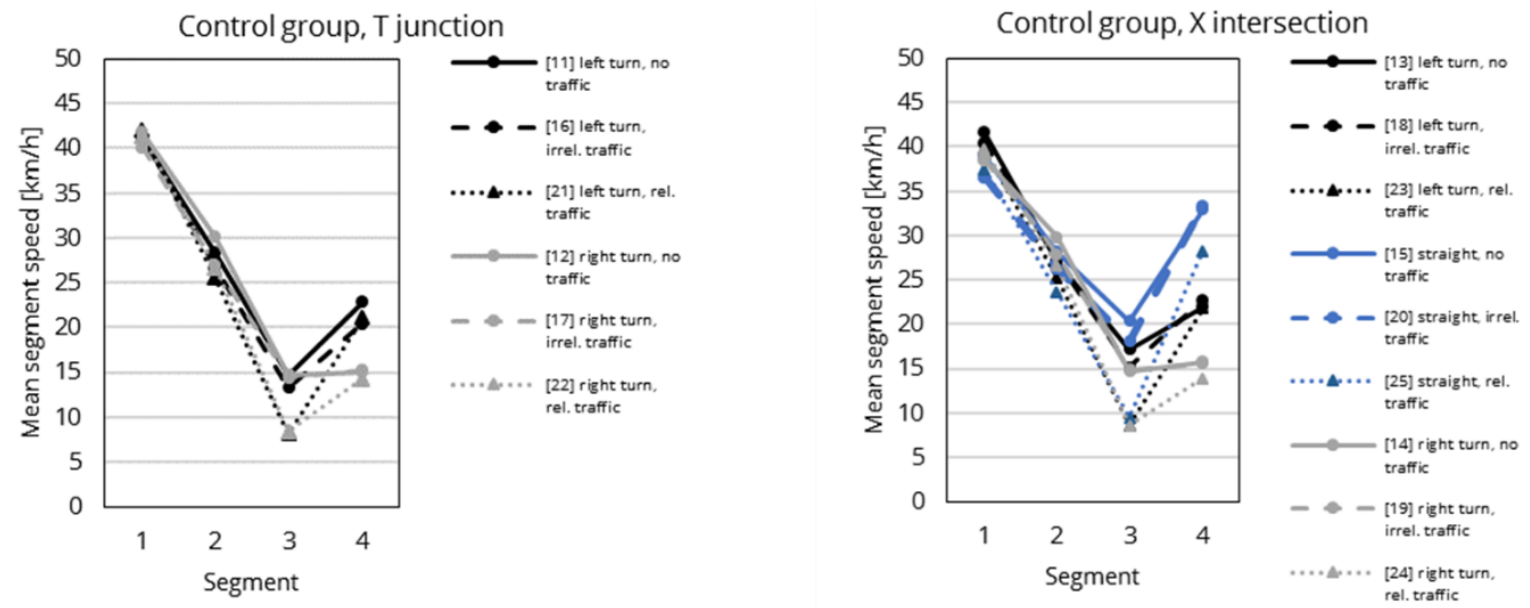

FigURE 17. MEAN SEGMENT SPEED FOR SCENARIOS OF CONTROL GROUP WHEN GIVING THE RIGHT OF WAY. BRACKETS PRESENT THE SCENARIO NUMBER. LEFT SHOWS SCENARIOS WITH T-JUNCTION AND RIGHT SHOWS SCENARIOS WITH X-INTERSECTION.
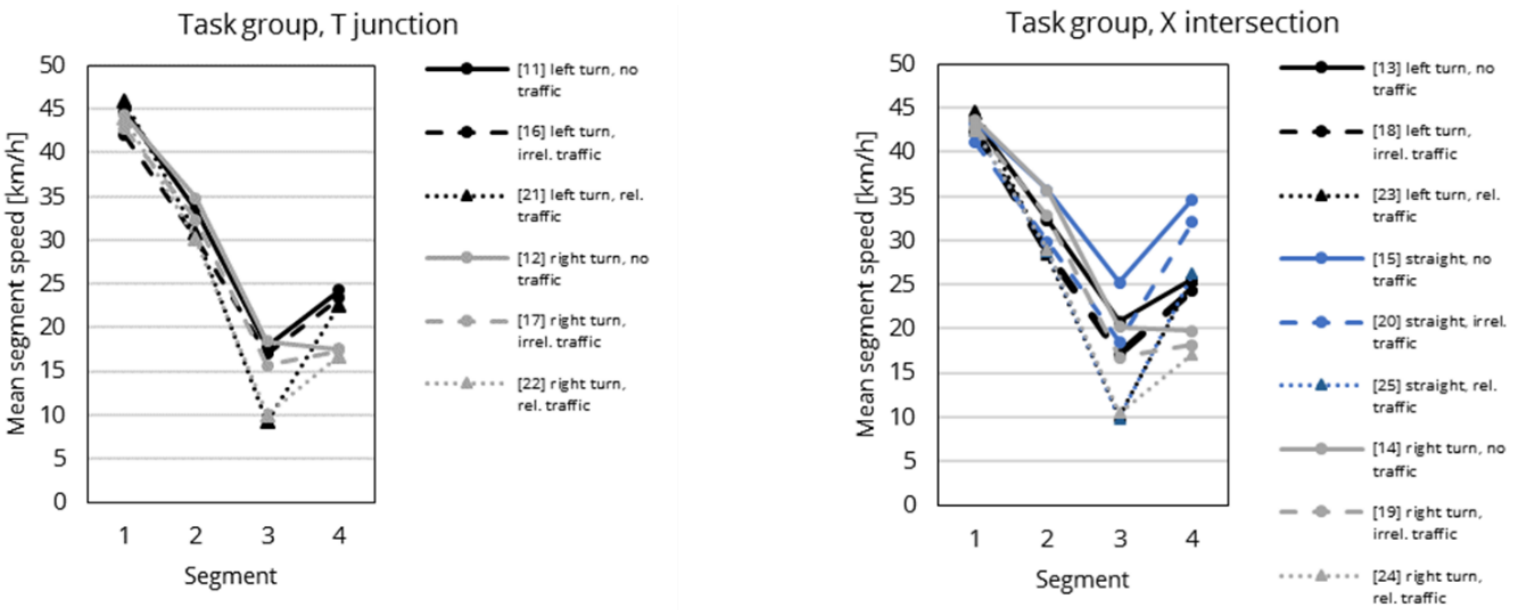

FiguRE 18. MEAN SEGMENT SPEED FOR SCENARIOS OF TASK GROUP WHEN GIVING THE RIGHT OF WAY. BRACKETS PRESENT THE SCENARIO NUMBER. LEFT SHOWS SCENARIOS WITH T-JUNCTION AND RIGHT SHOWS SCENARIOS WITH X-INTERSECTION.

In segment 1 ( $75 \mathrm{~m}$ to $50 \mathrm{~m}$ before intersection entry), the mean speeds range from $40 \mathrm{~km} / \mathrm{h}$ to $45 \mathrm{~km} / \mathrm{h}$ for most of the scenarios. However, when approaching X-intersections without having a secondary task, the mean speeds in segment 1 are slower and range from $36 \mathrm{~km} / \mathrm{h}$ to $42 \mathrm{~km} / \mathrm{h}$. The 
descriptive difference between scenarios being passed with and without secondary task is also present in further approaching segments 2 and 3 . The mean speeds when driving with the secondary task are for all approaching segments about $5 \mathrm{~km} / \mathrm{h}$ higher than when driving without a secondary task. In segment 2 ( $50 \mathrm{~m}$ to $25 \mathrm{~m}$ before intersection), the mean speeds range from $25 \mathrm{~km} / \mathrm{h}$ to $36 \mathrm{~km} / \mathrm{h}$ and in segment 3 ( $25 \mathrm{~m}$ to 0 before intersection) from $8 \mathrm{~km} / \mathrm{h}$ to $25 \mathrm{~km} / \mathrm{h}$. In segment 3 , the variation in mean speed is caused by the specific scenario variation. Scenarios, in which the driver had to stand and wait for relevant cross traffic, show the lowest speeds independently of the planned driving manoeuvre. When passing the intersection without traffic or with irrelevant traffic, mean speeds in segment 3 are comparable for turning left and right. However, when going straight, mean speeds are somewhat higher $(2-5 \mathrm{~km} / \mathrm{h})$.

The crossing segment shows stronger variations in speed regarding the driving manoeuvre than the approaching segment. As to be expected, when turning right, the mean speeds are slower (about $16 \mathrm{~km} / \mathrm{h}$ ) than when turning left (about $23 \mathrm{~km} / \mathrm{h}$ ) and when going straight (about $31 \mathrm{~km} / \mathrm{h}$ ).

\subsubsection{Mean segment acceleration}

The mean acceleration values when driving through the four segments while approaching and crossing an intersection when having to give priority are shown Figure 19 and Figure 20. For all driving manoeuvres (left turn, right turn, going straight) similar patterns across the segments in acceleration were found.
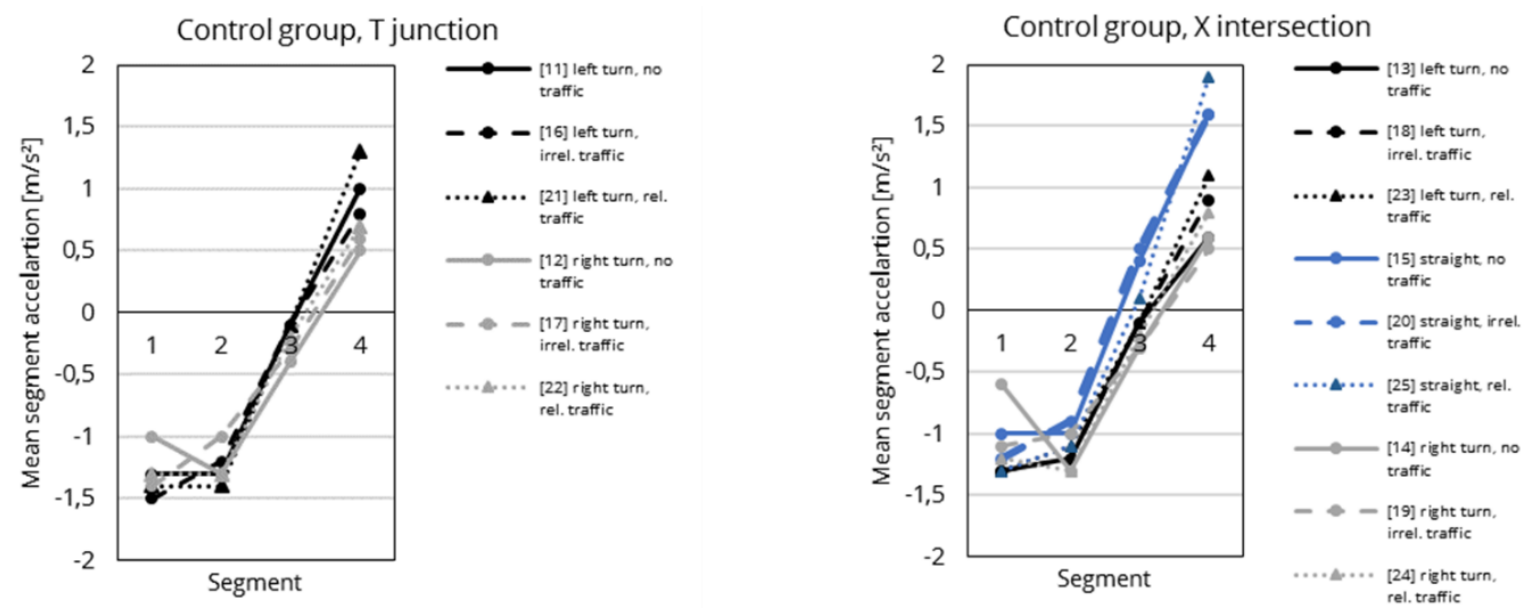

FIGURE 19. MEAN SEGMENT ACCELERATION FOR SCENARIOS OF CONTROL GROUP WHEN GIVING THE RIGHT OF WAY. BRACKETS PRESENT THE SCENARIO NUMBER. LEFT SHOWS SCENARIOS WITH T-JUNCTION AND RIGHT SHOWS SCENARIOS WITH X-INTERSECTION. 

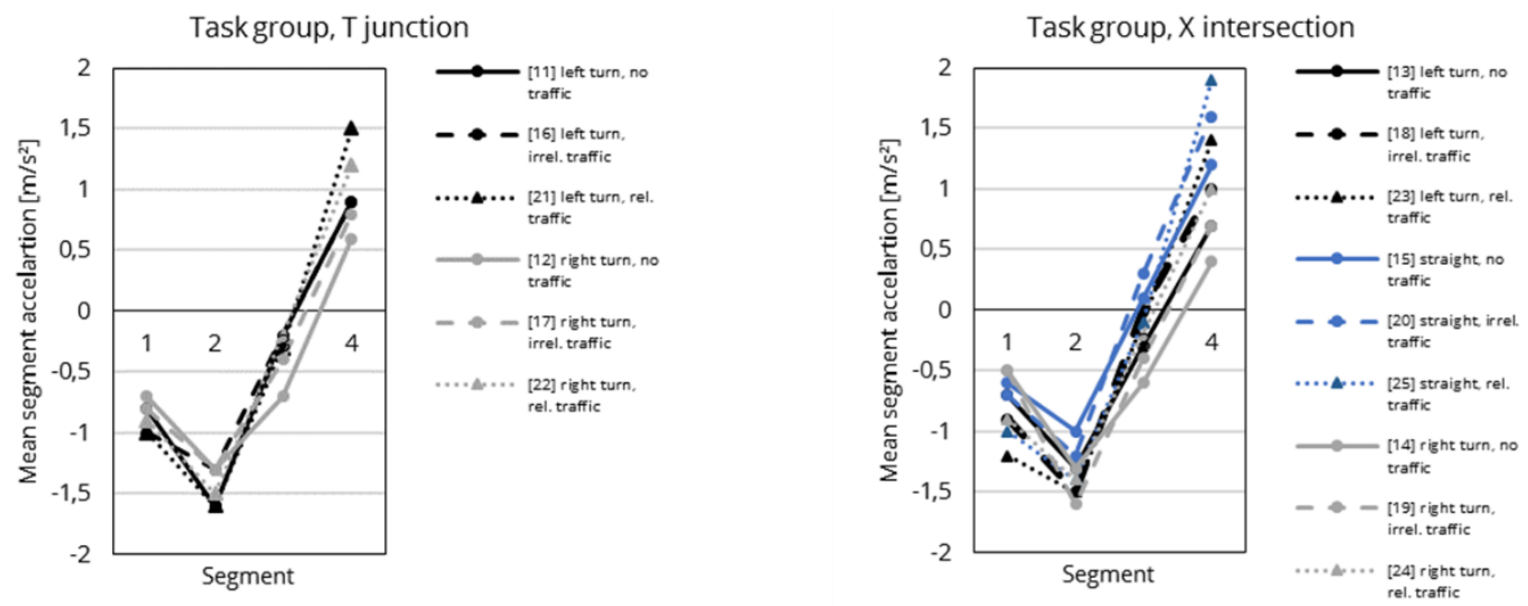

FIGURE 20. MEAN SEGMENT ACCELERATION FOR SCENARIOS OF TASK GROUP WHEN HAVING THE RIGHT OF WAY. BRACKETS PRESENT THE SCENARIO NUMBER. LEFT SHOWS SCENARIOS WITH T-JUNCTION AND RIGHT SHOWS SCENARIOS WITH X-INTERSECTION.

The lowest values for acceleration (highest values for deceleration) for the control group occurred in segment 1 and 2. However, for the drivers having a secondary task, the deceleration was only highest in segment 2. This represents the fact that drivers without secondary task reduced their speed earlier while approaching the intersection and had consequently slower mean speeds as shown in the section above. From segment 2 on, acceleration was higher for scenarios in which the driver had to go straight than when turning left or right, independently of the current traffic situation. This result is again transferable to the results regarding the mean speeds: When going straight at an X-intersection, the drivers decelerated less strongly in segment 2 ( $50 \mathrm{~m}$ to $25 \mathrm{~m}$ before intersection) and accelerated more strongly in segment 3 ( $25 \mathrm{~m}$ to 0 before intersection) and segment 4 (crossing), which results in slightly higher mean speeds in comparison to right and left turn.

Interestingly, the variation of surrounding traffic showed no strong influences on acceleration when approaching the intersection. In contrast, the mean speeds in segment 3 were slower when having relevant crossing traffic. This difference between speed and acceleration in segment 3 can be reasoned in the time standing and waiting at the intersection. Those seconds of having a very low speed weighed stronger for the calculation of mean speed than for the calculation of acceleration, where the values before were about $0 \mathrm{~m} / \mathrm{s}^{2}$ all the time.

\subsection{Gaze locations}

As described in chapter 5, the fixations of eye tracking data were summed regarding five gaze locations: 'left', 'right', 'straight', 'down', and 'other'. The results of the distribution of fixations regarding those gaze locations are summarized in Table 4 and Table 5. Table 4 shows the results for the scenarios in which the driver had the right of way and Table 5 show the results for the scenarios in which the driver had to give priority. In each table, the percentage shares of fixations towards the five gaze locations within one segment are presented. For instance, in Table 4 first line: 27 drivers without secondary task (control group) in scenario 1 (turning left at T-junction with green traffic light without surrounding traffic) in the area of $75 \mathrm{~m}$ to $50 \mathrm{~m}$ before intersection entry looked on average from all fixations $0.7 \%$ down, $71.5 \%$ straight, $16.1 \%$ left, $11.7 \%$ right, and $0 \%$ in other directions. The different sample size for each scenario are reasoned in the usual misses in eye tracking data (blinks and loss of focus) and in some cases because the segment duration was so short that no fixations occurred. 
For better interpretation of gaze data, subsequent figures show single results of the proportion of fixations for the gaze locations 'straight', 'left', and 'right'. Results are separated for scenarios in which the driver had priority and scenarios in which the driver had to give priority. In addition, figures are separated for control and task group, as well as intersection type. The additional scenarios 26 and 27 are missing for reasons of space.

\subsubsection{Right of way - having priority}

\section{T-junction}

First, the fixation distribution is presented for scenarios in which the driver had the right of way. Figure 21 and Figure 22 show the distribution of fixations towards the locations 'straight', 'left', and 'right' for scenarios having a T-junction (see figure right), once for the group without a secondary task and once for scenarios having a secondary task.

- [1] left turn, no traffic $\Xi[6]$ left turn, irrel. traffic $\square$ [2] right turn, no traffic $\boxminus$ [7] right turn, irrel. traffic

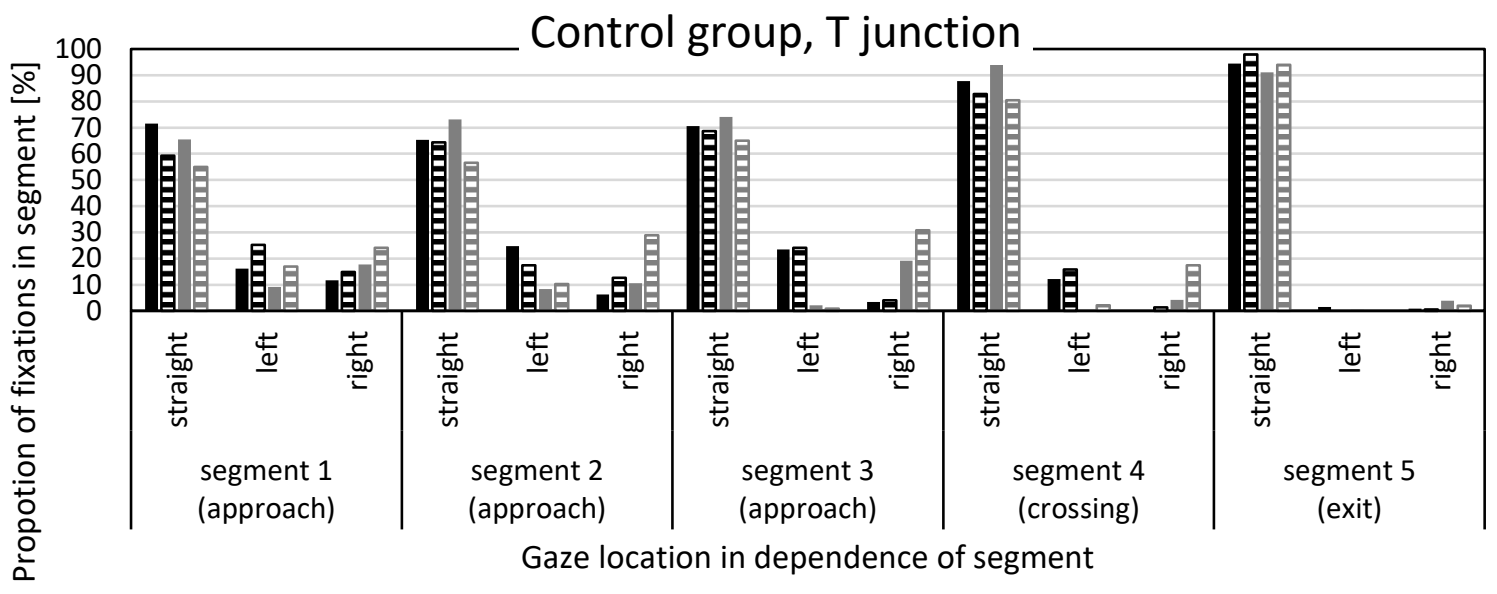

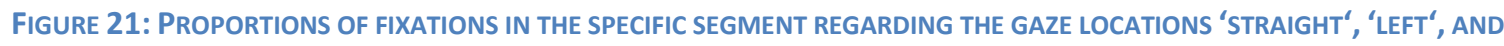
'RIGHT' FOR T-JUNCTIONS OF CONTROL GROUP WHEN HAVING THE RIGHT OF WAY. BRACKETS PRESENT THE SCENARIO NUMBER.

口[1] left turn, no traffic $\boxminus[6]$ left turn, irrel. traffic $\square$ [2] right turn, no traffic $\boxminus$ [7] right turn, irrel. traffic

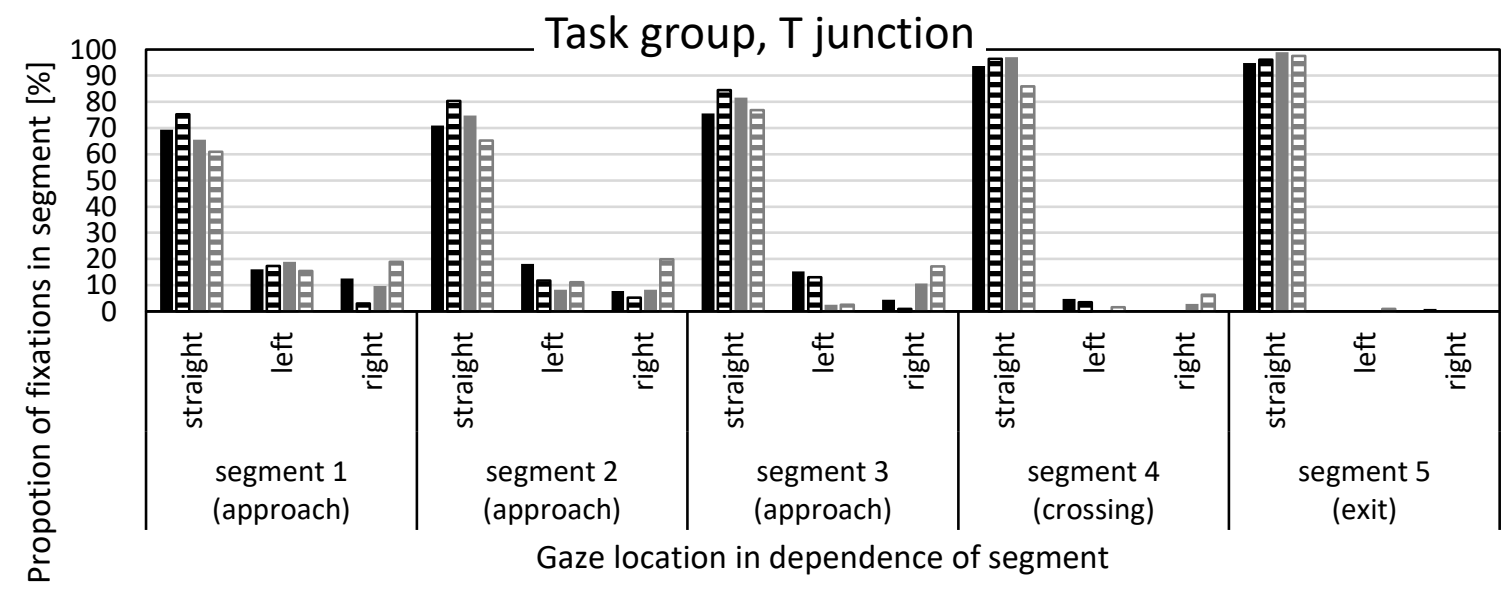

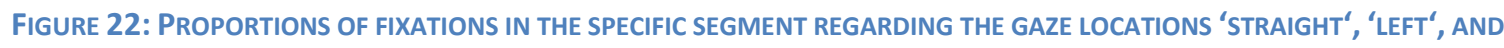
'RIGHT' FOR T-JUNCTIONS OF TASK GROUP WHEN HAVING THE RIGHT OF WAY. BRACKETS PRESENT THE SCENARIO NUMBER. 
The fixations are mostly located towards the road centre (gaze location 'straight'). However, the proportions of fixations regarding the road centre start from about $60 \%$ in segment 1 and slightly increase towards $80 \%$ when crossing and $90 \%$ when leaving the intersection. This shows that drivers scan the outer areas of the field of view and road centre mostly while approaching (segment 1-3). While crossing the signalized intersection, a few fixations to the left or right occur. When leaving the intersection, the glances stay at the 'straight' gaze location.

Interestingly, in the segments of approaching the intersection, the glances towards 'left' and 'right' are more frequent for the control group than for the task group and in turn glances towards the road centre are less frequent. This indicates that drivers having a secondary task locate their fixations less likely outside the middle of the road and could therefore might miss the identification of relevant traffic objects.

The planned driving manoeuvre (turn left or right) affects the distribution of fixations mostly in segment 2 and 3 while approaching the intersection. In segment 1, when being around $75 \mathrm{~m}$ to $50 \mathrm{~m}$ before intersection entry, the fixations tend similarly to 'right' and 'left'. But when being $50 \mathrm{~m}$ to 0 before the intersection, the intended driving manoeuvre has a one-to-one effect on the glances: When planning to go left (black bars), the glances towards the left areas of sight increase, when going to the right (grey bars), the glances towards the right increase. This descriptive difference is also evident in segment 4 when crossing the intersection.

A further aspect is the variation of traffic. When no traffic is present (bars filled), the fixations in the approaching segments go more likely to the road centre and less likely to the left or right areas. However, when traffic is present by standing at the red traffic light (striped bars), drivers' fixations go less likely to the road centre and more likely to the left or right areas when approaching the green signalized T-junction. One exception for this is the left turn when having a secondary task. 


\section{$X$-intersection}

Figure 23 and Figure 24 show the distribution of fixations towards the gaze locations 'straight', 'left', and 'right' for scenarios having an X-intersection (see figure right), once for the group without a secondary task and once for scenarios having a secondary task.

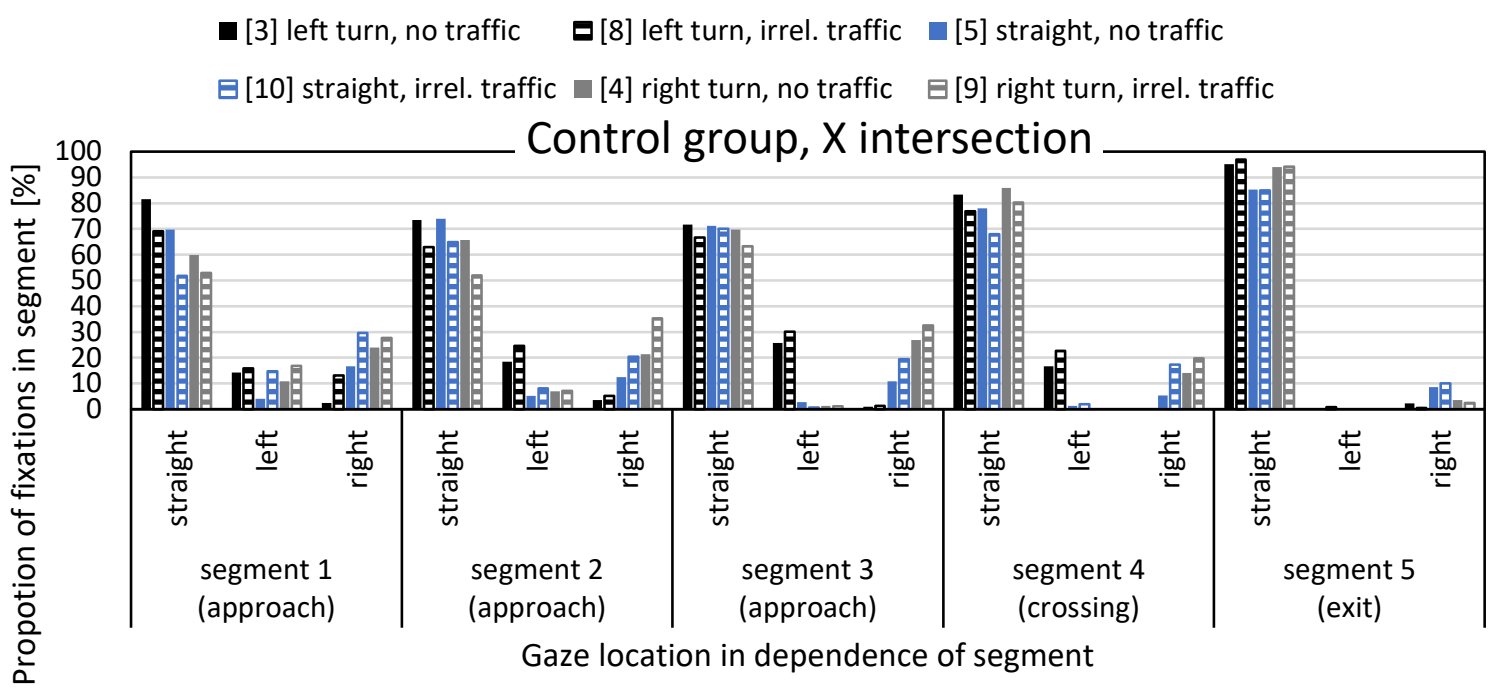

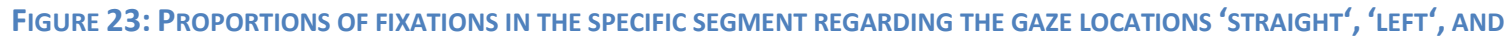
'RIGHT' FOR X-INTERSECTIONS OF CONTROL GROUP WHEN HAVING THE RIGHT OF WAY. BRACKETS PRESENT THE SCENARIO NUMBER.

[3] left turn, no traffic $\quad \boxminus[8]$ left turn, irrel. traffic $\quad \square[5]$ straight, no traffic

$\boxminus[10]$ straight, irrel. traffic $\square[4]$ right turn, no traffic $\boxminus[9]$ right turn, irrel. traffic

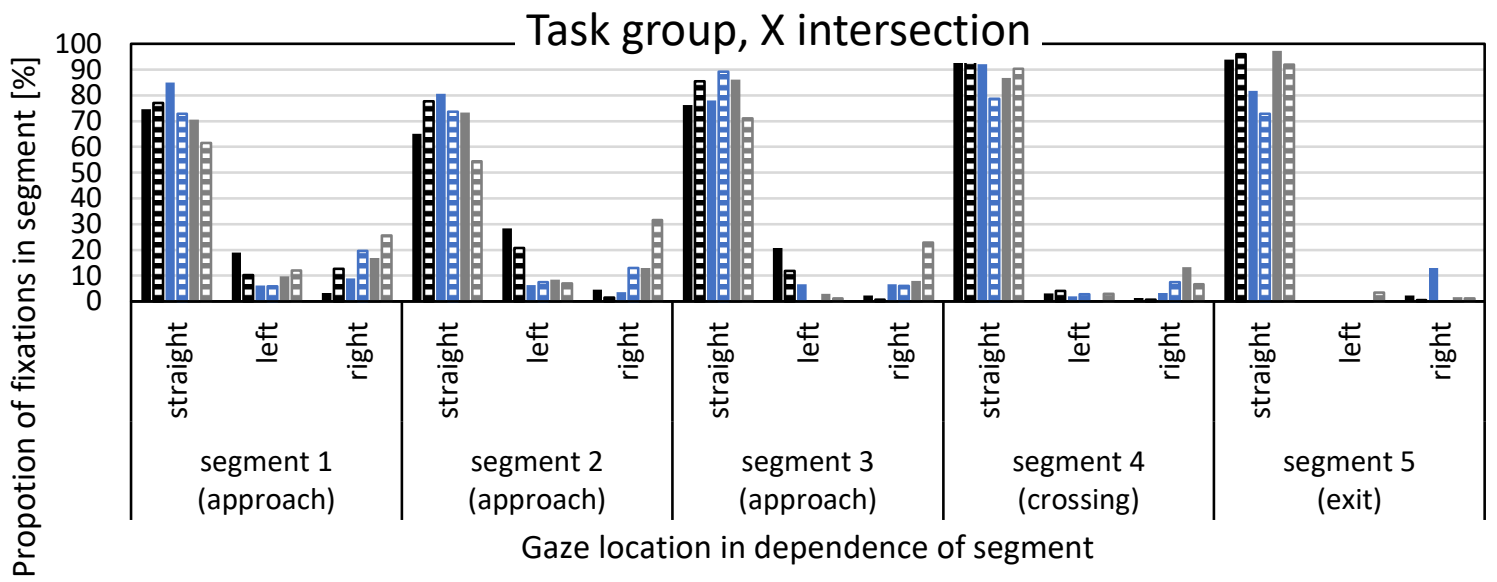

Figure 24: PROPORTIONS OF FiXATIONS IN THE SPECIFIC SEGMENT REgARDING THE GAZE LOCATIONS 'STRAight', 'LEFT', AND 'RIGHT' FOR X-INTERSECTIONS OF TASK GROUP WHEN HAVING THE RIGHT OF WAY. BRACKETS PRESENT THE SCENARIO NUMBER.

In these scenarios in which the driver had the right of way, the fixations are again mostly located towards the road centre (gaze location 'straight'). As seen before, fixations towards the road centre (gaze location 'straight') have a higher proportion when having a secondary task than when driving without a secondary task. This differences are visible for all segments of approaching (1-3) and the crossing of the X-intersection. Especially in segment 3, the fixations towards the road centre make up an about $10 \%$ higher proportion when driving while counting back numbers in steps of 2 than when driving without. This shows again that drivers fixations concentrate on the road centre when having a secondary task. 
Interesting results are given for the three driving manoeuvres. When approaching the $\mathrm{X}$-intersection and planning to turn left, the side glances went mainly to the left as already seen for T-junctions. However, when planning to turn right and when planning to go straight, the side glances for the approaching segments went mainly to the right.

The presence of traffic standing at the $\mathrm{X}$-intersection has no clear share in the variation of the fixation distribution, especially for the separation of control and task group. In contrast to T-junctions, at Xintersections the glances might distribute independently of the standing traffic, because the upper branch of the intersection can be seen.

\subsubsection{Right of way - giving priority}

\section{T-junction}

The results of the fixation distribution for scenarios in which the driver had to give priority are given in this chapter. Figure 25 and Figure 26 show the distribution of fixations towards the locations 'straight', 'left', and 'right' for scenarios having a T-junction (see figure right), separated for control group and task group.

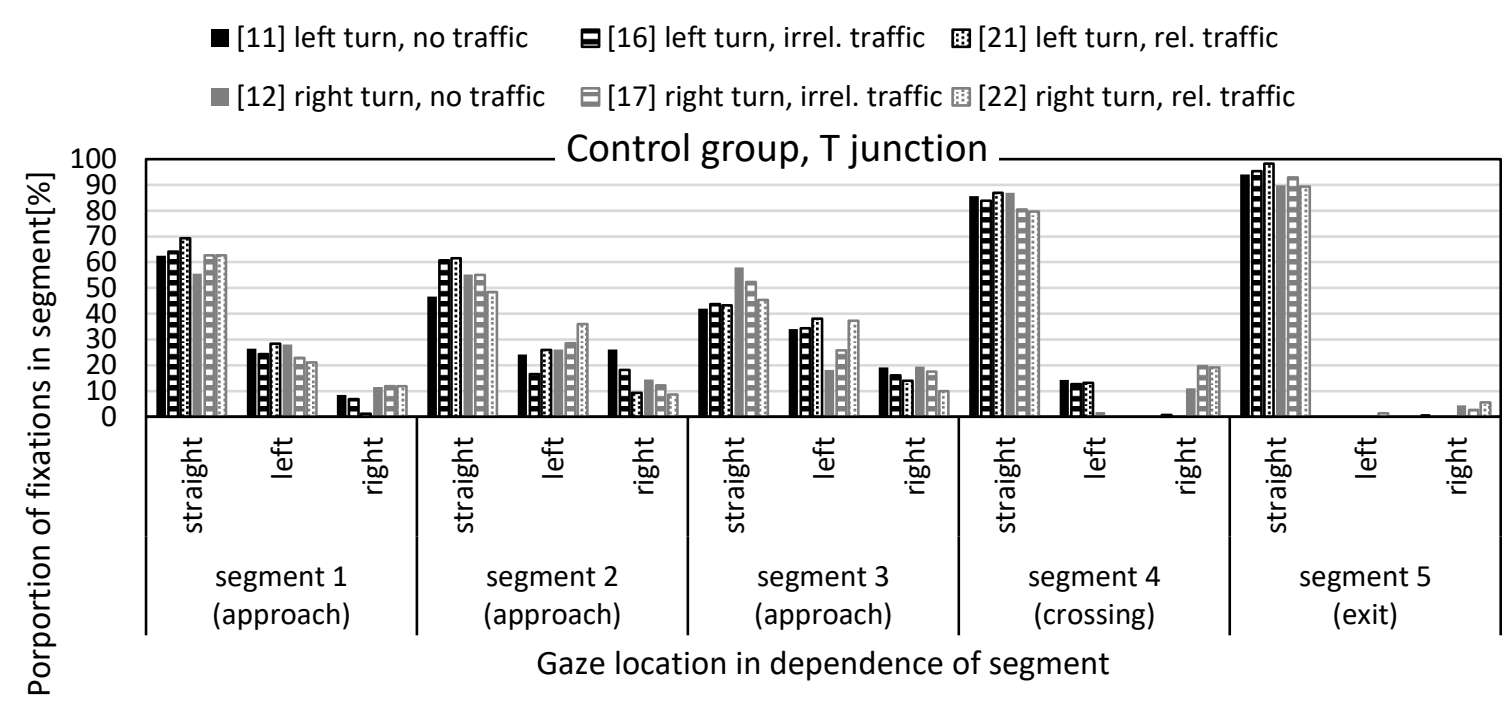

Figure 25: Proportions of FiXATIONS IN THE SPECIFIC SEGMENT REgARDING THE GAZE LOCATIONS 'STRAight', 'LEFT', AND 'RIGHT' FOR T-JUNCTIONS OF CONTROL GROUP WHEN GIVING THE RIGHT OF WAY. BRACKETS PRESENT THE SCENARIO NUMBER. 
- [11] left turn, no traffic $\quad$ [16] left turn, irrel. traffic

[12] right turn, no traffic $\square[17]$ right turn, irrel. traffic ${ }^{3}[22]$ right turn, rel. traffic

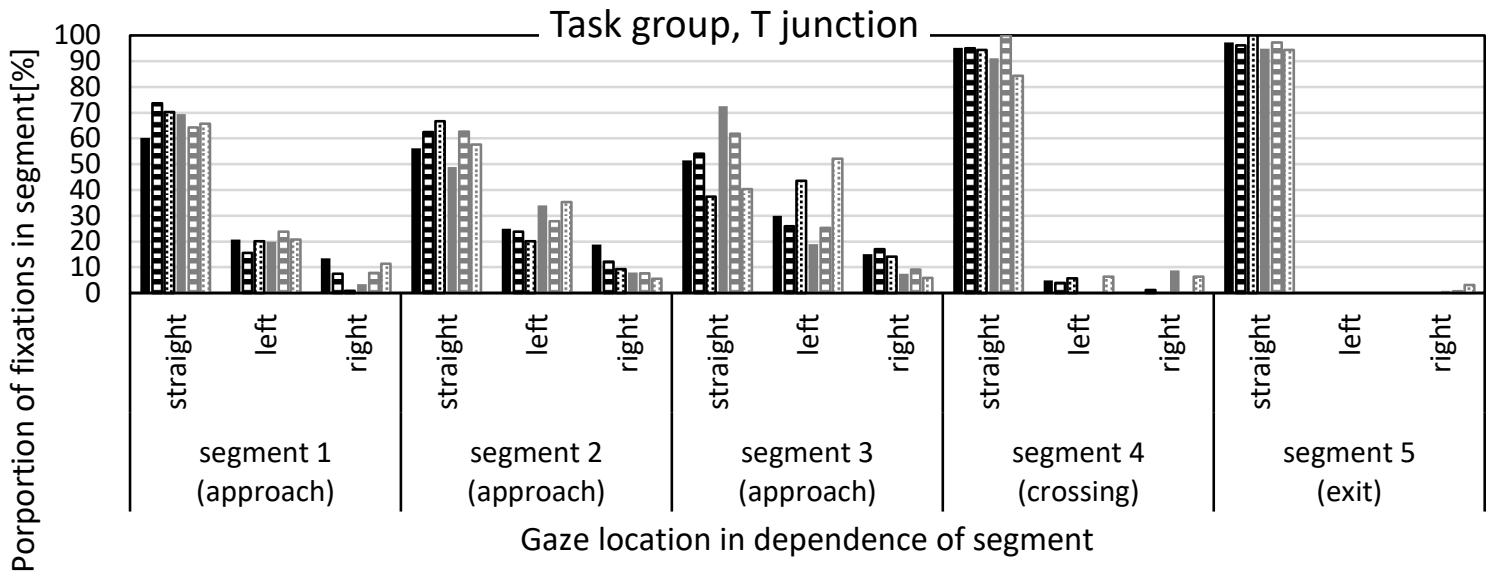

Figure 26: Proportions of Fixations In the SPECIFIC SEgMENT Regarding the GAZE LOCATIONS 'STRAight', 'LEFT', AND 'RIGHT' FOR T-JUNCTIONS OF TASK GROUP WHEN GIVING THE RIGHT OF WAY. BRACKETS PRESENT THE SCENARIO NUMBER.

The fixations in these scenarios of giving way scatter much more between the gaze locations during the approach segments than when having way. More concrete, in segment 1 when being $75 \mathrm{~m}$ to $50 \mathrm{~m}$ before intersection entry, the fixations towards the road centre make up in average about $60 \%$ of all fixations in this segment. In segment 2 (50 $\mathrm{m}$ to $25 \mathrm{~m}$ before intersection) it decreases towards about $52 \%$ and in segment 3 ( $25 \mathrm{~m}$ to 0 before intersection) to about $45 \%$. In return, the glances to the side increase while approaching the intersection. This shows a major difference of gaze behaviour between having and giving way when approaching intersections. Similarly to scenarios in which the driver had the right of way, while crossing the unsignalized intersection, a few fixations to the left or right occur. When leaving the intersection, the fixations stay at the 'straight' gaze location.

The presence or absence of a secondary task shows smaller differences in the descriptive distribution of fixations than for scenarios in which the driver had the right of way (section above). Only in segment 3 , shortly before entering the intersection and in the crossing segment, the fixations towards the road centre (gaze location 'straight') are more frequent when having a secondary task. This suggests that the presence of a secondary task has a different degree of influence on attention allocation, depending on whether the drivers have right of way or not when approaching and crossing a T-junction.

The planned driving manoeuvre shows no clear difference in the distribution of fixations (black vs. grey bars). However, as to be expected, the presence of relevant traffic (dotted bars), i.e. cross traffic that forces the driver to stop, ensures that side glances increase in segment 3 ( $25 \mathrm{~m}$ to 0 before intersection entry). It concerns thereby the glances to the left, the place from which the cross traffic comes. Unfortunately, the mere presence of cross traffic without forcing the driver to stop (irrelevant traffic, striped bars) has no clear share in changing the distribution of fixations. 


\section{$X$ intersection}

Figure 27 and Figure 28 show the distribution of fixations towards the locations 'straight', 'left', and 'right' for scenarios having an X-intersection (see figure right), once for the group without a secondary task and once for scenarios having a secondary task.

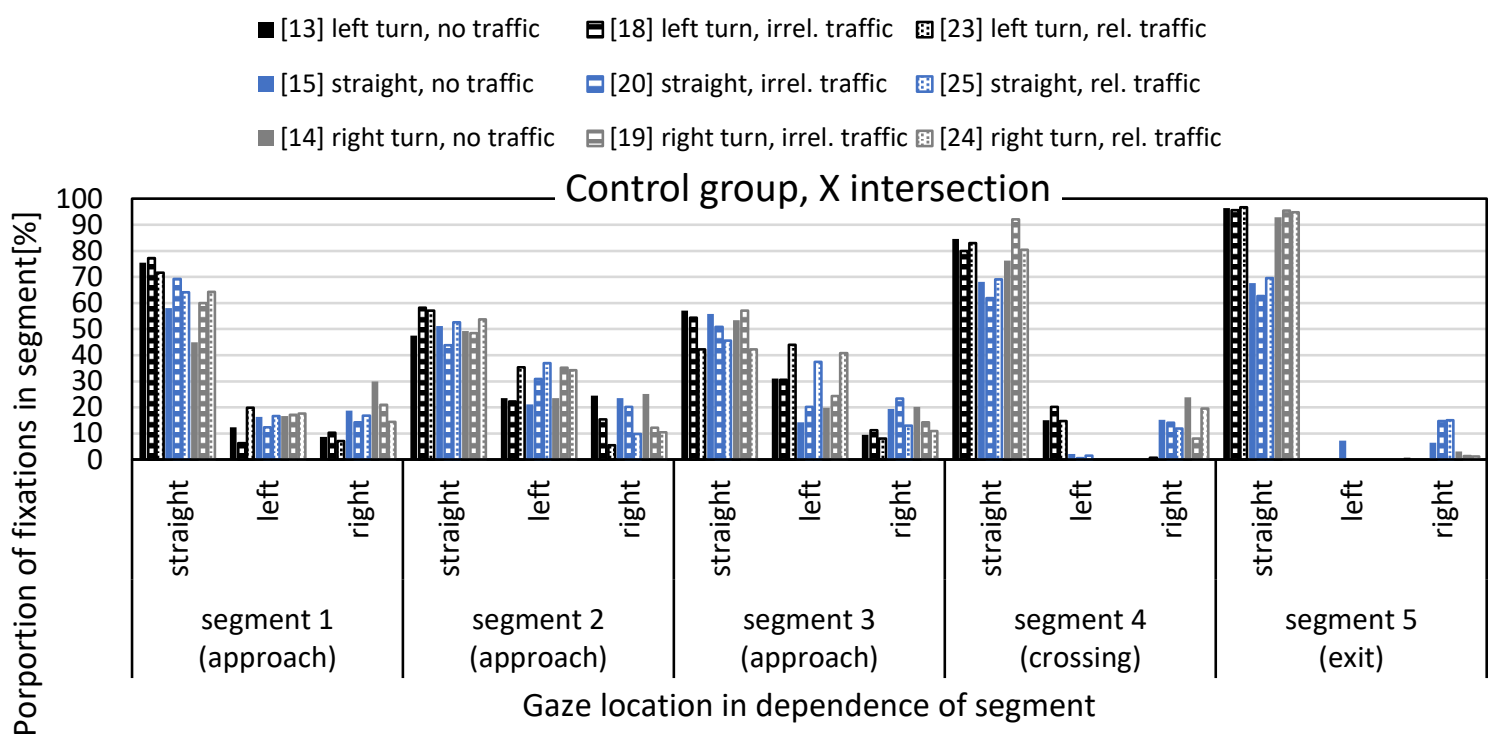

FigURE 27: Proportions of FiXATIONS IN THE SPECIFIC SEGMENT REgARDING THE GAZE LOCATIONS 'STRAight', 'LEFT', AND 'RIGHT' FOR X-INTERSECTIONS OF CONTROL GROUP WHEN GIVING THE RIGHT OF WAY. BRACKETS PRESENT THE SCENARIO NUMBER.
- [13] left turn, no traffic
日[18] left turn, irrel. traffic
[15] straight, no traffic
$\boxminus[20]$ straight, irrel. traffic [25] straight, rel. traffic
[14] right turn, no traffic

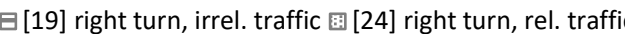

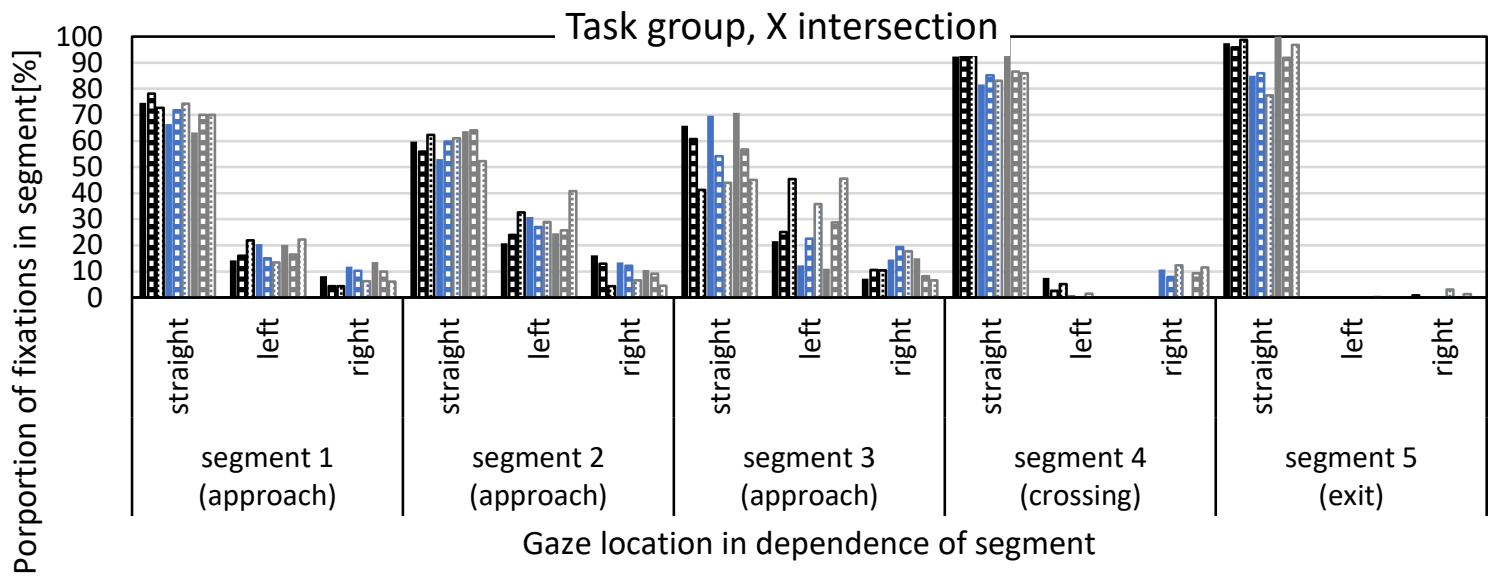

FigURE 28: PROPORTIONS OF FIXATIONS IN THE SPECIFIC SEgMENT REgARDING THE GAZE LOCATIONS 'STRAIGHT', 'LEFT', AND 'RIGHT' FOR X-INTERSECTIONS OF TASK GROUP WHEN GIVING THE RIGHT OF WAY. BRACKETS PRESENT THE SCENARIO NUMBER.

The result of secondary task engagement, which has already appeared more frequently, can also be seen in part for these intersections. In segment 2, 3, and 4, the fixations towards the road centre occur on average more often when driving with a secondary task than when driving without. However, the descriptive differences are very small for segment 2 and 3 . Only for the crossing segment the glances towards the road centre make up about $10 \%$ more. Nonetheless, the impression is strengthened that 
the secondary task engagement leads drivers to allocate their attention more to the road centre, especially when being close to the intersections and when crossing them.

Again, the planned driving manoeuvre showed no clear influence on fixation distribution. The segments show different shares of fixating the road centre. For instance, the fixations towards the road centre were descriptively higher when planning to turn left in segment 1 of approaching than planning to go straight or to turn right. However, when crossing and leaving the intersection, the fixations towards the road centre where similar when turning left and right, but fewer when going straight.

Nonetheless, there was a clear share of relevant cross traffic in changing the glances to the left areas beside the road in segment 3 .

\subsection{Fixation duration}

The fixation durations can be found in Table 6 for scenarios in which drivers had the right of way and in Table 7 for scenarios in which the driver had to give the right of way. It is noticeable that the number of values being basis for the individual calculation of means $(n)$ is often very small. For this reason, a further comparison of fixation durations regarding variations of driving manoeuvre, traffic, or group treatment is futile. However, the individual fixation durations stand for their own and are applicable for the validation of the driver behaviour models of the stochastic traffic simulation. Results are transferred to the Chair of Automobile Engineering and are further processes there. 
TABLE 2: DRIVING CHARACTERISTICS FOR EVERY SEGMENT FOR SCENARIOS WITH PRIORITY FOR THE DRIVER $(1-10,26)$. RELEVANT ONC. STANDS FOR RELEVANT ONCOMING TRAFFIC. SEGMENT 1 - 75 M TO 50 M BEFORE INTERSECTION. SEGMENT 2 - 50 M TO 25 M BEFORE INTERSECTION. SEGMENT 3 - 25 M TO 0 BEFORE INTERSECTION. SEGMENT 4 - CROSSING THE INTERSECTION. N - SUBSAMPLE.

\begin{tabular}{|c|c|c|c|c|c|c|c|c|c|c|c|c|c|c|c|c|c|c|c|c|c|c|c|c|c|c|c|c|c|}
\hline \multirow[t]{2}{*}{ group } & \multirow[t]{2}{*}{ junction } & \multirow[t]{2}{*}{$\begin{array}{l}\text { driving } \\
\text { maneuver }\end{array}$} & \multirow[t]{2}{*}{ traffic } & \multirow[t]{2}{*}{$\begin{array}{l}\text { scenario } \\
\text { no. }\end{array}$} & \multirow[t]{2}{*}{$n$} & \multicolumn{4}{|c|}{$\begin{array}{l}\text { Segment duration }[\mathrm{s}] \text { of } \\
\text { segment 1-4 }\end{array}$} & \multicolumn{4}{|c|}{$\begin{array}{c}\text { Mean speed of total } \\
\text { segment }[\mathrm{km} / \mathrm{h}] \text { of segment } \\
1-4\end{array}$} & \multicolumn{4}{|c|}{$\begin{array}{c}\text { Standard deviation of } \\
\text { mean speed of } \\
\text { segments 1-4 [km/h] }\end{array}$} & \multicolumn{4}{|c|}{$\begin{array}{c}\text { Mean speed of segment } \\
\text { entry }[\mathrm{km} / \mathrm{h}] \text { of segment } 1- \\
4\end{array}$} & \multicolumn{4}{|c|}{$\begin{array}{l}\text { Mean of minimal velocity of } \\
\text { segment } 1-4[\mathrm{~km} / \mathrm{h}]\end{array}$} & \multicolumn{4}{|c|}{$\begin{array}{l}\text { Mean acceleration of } \\
\text { segment 1-4 }\left[\mathrm{m} / \mathrm{s}^{2}\right]\end{array}$} \\
\hline & & & & & & 1 & 2 & 3 & 4 & 1 & 2 & 3 & 4 & 1 & 2 & 3 & 4 & 1 & 2 & 3 & 4 & 1 & 2 & 3 & 4 & 1 & 2 & 3 & 4 \\
\hline \multirow{11}{*}{ control } & \multirow{4}{*}{$\begin{array}{l}\text { T-junction } \\
\text { (three way) }\end{array}$} & \multirow{2}{*}{ left } & no & 1 & 27 & 2.13 & 2.96 & 4.28 & 2.32 & 43.2 & 32.6 & 22.0 & 22.9 & 2.3 & 3.8 & 3.3 & 1.4 & \begin{tabular}{|l|}
46.5 \\
\end{tabular} & 38.9 & 27.4 & 20.7 & 38.9 & 26.9 & 18.0 & 20.7 & $\begin{array}{l}-1.0 \\
\end{array}$ & $\begin{array}{l}-1.2 \\
\end{array}$ & -0.5 & 0.6 \\
\hline & & & irrelevant & 6 & 26 & 2.18 & 2.78 & 4.01 & 2.53 & \begin{tabular}{|l|}
43.1 \\
\end{tabular} & 34.1 & 23.1 & 22.3 & 2.3 & 3.6 & 3.2 & 1.2 & \begin{tabular}{|l|}
46.1 \\
\end{tabular} & 39.4 & 28.8 & 20.6 & 39.3 & 28.3 & 19.2 & 20.5 & -0.8 & -1.2 & -0.6 & 0.4 \\
\hline & & \multirow[b]{2}{*}{ right } & no & 2 & 30 & 2.16 & 2.72 & 4.95 & 0.75 & \begin{tabular}{|l|}
43.1 \\
\end{tabular} & 34.2 & 18.9 & 15.3 & 1.4 & 4.7 & 4.6 & 0.3 & \begin{tabular}{|l|}
45.4 \\
\end{tabular} & 41.0 & 27.6 & 15.0 & 40.7 & 26.9 & 13.4 & 14.9 & -0.5 & -1.4 & -0.8 & 0.3 \\
\hline & & & irrelevant & 7 & 29 & 2.14 & 2.73 & 5.07 & 0.79 & \begin{tabular}{|l|}
43.2 \\
\end{tabular} & 34.7 & 18.5 & 15.5 & 1.9 & 4.1 & 4.6 & 0.2 & 46.0 & 40.5 & 28.1 & 15.1 & 40.4 & 27.9 & 13.4 & 15.1 & -0.7 & $\begin{array}{l}-1.3 \\
\end{array}$ & -0.8 & 0.3 \\
\hline & \multirow{7}{*}{$\begin{array}{l}\text { X- } \\
\text { intersection } \\
\text { (four way) }\end{array}$} & \multirow{3}{*}{ left } & no & 3 & 30 & 2.10 & 2.81 & 3.88 & 2.28 & 43.7 & 34.1 & 23.9 & 23.7 & 1.6 & 3.8 & 3.2 & 1.3 & 46.0 & 40.6 & 29.2 & 22.0 & 40.6 & 28.2 & 20.0 & 21.8 & -0.7 & -1.2 & -0.5 & 0.5 \\
\hline & & & irrelevant & 8 & 26 & 2.18 & 2.52 & 3.80 & 2.36 & 42.5 & 36.7 & 24.3 & 23.3 & 1.9 & 2.8 & 3.7 & 1.2 & \begin{tabular}{|l|}
45.4 \\
\end{tabular} & 40.0 & 31.7 & 21.7 & 39.7 & 31.4 & 20.3 & 21.5 & -0.7 & -1.0 & -0.8 & 0.5 \\
\hline & & & $\begin{array}{l}\text { relevant } \\
\text { onc. }\end{array}$ & 26 & 31 & 2.16 & 2.83 & 9.09 & 9.75 & 42.7 & 33.5 & 15.1 & 13.8 & 2.2 & 3.3 & 6.5 & 4.7 & 45.6 & 38.8 & 29.0 & 11.6 & 38.8 & 28.3 & 7.6 & 8.6 & -0.8 & -1.0 & -0.7 & 0.6 \\
\hline & & \multirow{2}{*}{ straight } & no & 5 & 27 & 1.79 & 1.81 & 1.81 & 1.16 & 50.7 & 50.4 & 50.3 & 50.1 & 0.2 & 0.2 & 0.2 & 0.1 & 50.8 & 50.5 & 50.3 & 50.2 & 50.3 & 50.1 & 50.0 & 50.0 & 0.0 & 0.0 & 0.0 & 0.0 \\
\hline & & & irrelevant & 10 & 27 & 1.78 & 1.81 & 1.81 & 1.15 & 51.0 & 50.2 & 50.2 & 50.5 & 0.3 & 0.2 & 0.2 & 0.1 & \begin{tabular}{|l|}
51.3 \\
\end{tabular} & 50.5 & 50.1 & 50.4 & 50.5 & 49.8 & 50.0 & 50.3 & -0.1 & -0.1 & 0.1 & 0.0 \\
\hline & & \multirow{2}{*}{ right } & no & 4 & 27 & 2.25 & 2.78 & 5.00 & 0.73 & 41.5 & 33.8 & 18.7 & 15.8 & 2.0 & 3.1 & 4.6 & 0.3 & \begin{tabular}{|l|l}
44.7 \\
\end{tabular} & 38.5 & 28.8 & 15.5 & 38.3 & 28.5 & 13.7 & 15.4 & -0.8 & -1.0 & -0.8 & 0.2 \\
\hline & & & irrelevant & 9 & 28 & 2.19 & 2.66 & 5.01 & 0.75 & 42.6 & 35.3 & 18.6 & 15.0 & 1.8 & 3.7 & 4.6 & 0.3 & \begin{tabular}{|l|}
44.9 \\
\end{tabular} & 40.1 & 28.4 & 14.7 & 39.7 & 28.2 & 13.0 & 14.5 & -0.7 & -1.3 & -0.8 & 0.3 \\
\hline \multirow{11}{*}{$\begin{array}{l}\text { secondary } \\
\text { task }\end{array}$} & \multirow{4}{*}{$\begin{array}{l}\text { T-junction } \\
\text { (three way) }\end{array}$} & & no & 1 & 26 & 2.04 & 2.57 & 3.84 & 2.15 & 45.4 & 36.2 & 24.3 & 25.7 & 1.1 & 4.5 & 3.1 & 1.6 & \begin{tabular}{|l|}
47.1 \\
\end{tabular} & 43.3 & 30.0 & 23.3 & 43.3 & 29.6 & 20.6 & 23.3 & -0.5 & -1.5 & -0.5 & 0.7 \\
\hline & & left & irrelevant & 6 & 22 & 2.10 & 2.33 & 3.38 & 2.31 & 44.5 & 40.4 & 28.1 & 25.0 & 0.8 & 2.3 & 4.5 & 1.1 & \begin{tabular}{|l|}
45.4 \\
\end{tabular} & 43.4 & 36.4 & 24.2 & 43.0 & 36.2 & 22.5 & 23.4 & -0.3 & -0.8 & -1.2 & 0.4 \\
\hline & & & no & 2 & 26 & 1.99 & 2.38 & 4.36 & 0.55 & 46.2 & 39.0 & 22.3 & 19.5 & 1.0 & 3.8 & 5.1 & 0.3 & \begin{tabular}{|l|}
47.6 \\
\end{tabular} & 44.4 & 32.9 & 19.1 & 44.3 & 32.8 & 16.9 & 19.1 & -0.5 & \begin{tabular}{|l|}
-1.3 \\
\end{tabular} & -1.0 & 0.3 \\
\hline & & right & irrelevant & 7 & 23 & 2.03 & 2.34 & 4.14 & 0.58 & 45.4 & 39.6 & 22.7 & 17.5 & 0.9 & 3.1 & 6.0 & 0.3 & \begin{tabular}{|l|}
46.3 \\
\end{tabular} & 43.9 & 34.2 & 17.1 & 43.6 & 34.0 & 15.6 & 17.0 & -0.4 & -1.2 & -1.2 & 0.5 \\
\hline & & & no & 3 & 24 & 2.02 & 2.45 & 3.59 & 2.10 & 45.7 & 37.9 & 26.1 & 26.4 & 1.2 & 3.9 & 2.9 & $\begin{array}{l}1.2 \\
\end{array}$ & \begin{tabular}{|l|}
47.3 \\
\end{tabular} & 43.6 & 31.5 & 24.6 & 43.4 & 31.2 & 22.7 & 24.6 & -0.5 & $\begin{array}{l}-1.4 \\
\end{array}$ & -0.5 & 0.5 \\
\hline & & left & irrelevant & 8 & 22 & 2.02 & 2.22 & 3.37 & 2.16 & 46.6 & 42.1 & 27.4 & 25.4 & 1.0 & 3.0 & 4.5 & 1.2 & 48.0 & 45.2 & 36.5 & 23.8 & 45.0 & 36.0 & 22.1 & 23.6 & -0.4 & -1.1 & -1.1 & 0.5 \\
\hline & & Tert & $\begin{array}{l}\text { relevant } \\
\text { onc. }\end{array}$ & 26 & 25 & 1.99 & 2.39 & 7.57 & 6.69 & 46.1 & 39.2 & 20.4 & 17.0 & 0.9 & 3.5 & 6.5 & 4.5 & 47.3 & 44.4 & 33.6 & 14.6 & 44.3 & 33.5 & 12.4 & 11.8 & -0.4 & -1.2 & -1.0 & 0.7 \\
\hline & & & no & 5 & 23 & 1.76 & 1.77 & 1.76 & 1.13 & \begin{tabular}{|l|}
51.4 \\
\end{tabular} & 51.3 & 51.3 & 51.4 & 0.2 & 0.2 & 0.2 & 0. & \begin{tabular}{|l|l|}
51.4 \\
\end{tabular} & $\begin{array}{l}51.3 \\
\end{array}$ & 51.3 & 51.4 & \begin{tabular}{|l|l|}
51.1 \\
\end{tabular} & 51.0 & 51.0 & 51.2 & 0.0 & 0.0 & 0.0 & 0.0 \\
\hline & & & irrelevant & 10 & 21 & 1.75 & 1.76 & 1.76 & 1.13 & 51.8 & 51.6 & 51.5 & 51.5 & 0.2 & 0.2 & 0.2 & 0.1 & 52.0 & 51.6 & 51.6 & 51.5 & 51.5 & 51.3 & 51.3 & 51.4 & -0.1 & 0.0 & 0.0 & 0.0 \\
\hline & & & & 4 & 26 & 2.12 & 2.43 & 4.25 & 0.56 & 43.4 & 37.8 & 22.2 & 18.3 & 1.0 & 3.4 & 5.0 & 0.4 & 44.6 & 42.4 & 31.8 & 18.2 & 41.8 & 31.7 & 16.5 & 17.7 & -0.3 & -1.2 & -0.9 & 0.1 \\
\hline & & $\mathrm{rig}$ & irrel & 9 & \begin{tabular}{|l|}
23 \\
\end{tabular} & 2.10 & 2.39 & 4.27 & 0.65 & 43.5 & 38.4 & 21.8 & 16.5 & \begin{tabular}{|l|l|}
1.1 \\
\end{tabular} & 2.4 & 5.9 & 0.4 & \begin{tabular}{|l|}
45.2 \\
\end{tabular} & 41.7 & 33.8 & 16.6 & 41.5 & 33.7 & 15.0 & 16.0 & -0.5 & -0.9 & -1.2 & 0.1 \\
\hline
\end{tabular}


TABLE 3: DRIVING CHARACTERISTICS FOR EVERY SEGMENT FOR SCENARIOS WHERE DRIVERS GAVE PRIORITY $(11-25,27)$. RELEVANT ONC. STANDS FOR RELEVANT ONCOMING TRAFFIC. SEGMENT 1 - 75 M TO 50 M BEFORE INTERSECTION. SEGMENT 2- 50 M TO 25 M BEFORE INTERSECTION. SEGMENT 3 - 25 M TO 0 BEFORE INTERSECTION. SEGMENT 4 - CROSSING THE INTERSECTION. N - SUBSAMPLE.

\begin{tabular}{|c|c|c|c|c|c|c|c|c|c|c|c|c|c|c|c|c|c|c|c|c|c|c|c|c|c|c|c|c|c|}
\hline \multirow[t]{2}{*}{ group } & \multirow[t]{2}{*}{ junction } & \multirow[t]{2}{*}{$\begin{array}{l}\text { driving } \\
\text { maneu } \\
\text { ver }\end{array}$} & \multirow[t]{2}{*}{ traffic } & \multirow[t]{2}{*}{$\begin{array}{c}\text { scenario } \\
\text { no. }\end{array}$} & \multirow[t]{2}{*}{$n$} & \multicolumn{4}{|c|}{$\begin{array}{l}\text { Segment duration [s] of } \\
\text { segment 1-4 }\end{array}$} & \multicolumn{4}{|c|}{$\begin{array}{c}\text { Mean speed of total } \\
\text { segment }[\mathrm{km} / \mathrm{h}] \text { of segment } \\
1-4\end{array}$} & \multicolumn{4}{|c|}{$\begin{array}{c}\text { Standard deviation of mean } \\
\text { speed of segments 1-4 } \\
{[\mathrm{km} / \mathrm{h}]}\end{array}$} & \multicolumn{4}{|c|}{$\begin{array}{l}\text { Mean speed of segment } \\
\text { entry }[\mathrm{km} / \mathrm{h}] \text { of segment 1-4 }\end{array}$} & \multicolumn{4}{|c|}{$\begin{array}{l}\text { Mean of minimal velocity of } \\
\text { segment 1-4 }[\mathrm{km} / \mathrm{h}]\end{array}$} & \multicolumn{4}{|c|}{$\begin{array}{l}\text { Mean acceleration of } \\
\text { segment } 1-4\left[\mathrm{~m} / \mathrm{s}^{2}\right]\end{array}$} \\
\hline & & & & & & 1 & 2 & 3 & 4 & 1 & 2 & 3 & 4 & 1 & 2 & 3 & 4 & 1 & 2 & 3 & 4 & 1 & 2 & 3 & 4 & 1 & 2 & 3 & 4 \\
\hline \multirow{16}{*}{ control } & \multirow{6}{*}{$\begin{array}{l}\text { T-junction } \\
\text { (three way) }\end{array}$} & \multirow{3}{*}{ left } & no & 11 & 28 & 2.28 & 3.33 & 6.72 & 2.42 & 41.1 & 28.4 & 14.6 & 22.9 & 3.2 & 4.2 & 4.1 & 2.6 & 46.0 & 35.6 & 22.0 & 18.7 & 35.6 & 21.8 & 9.2 & 18.5 & -1.3 & -1.3 & -0.1 & 1.0 \\
\hline & & & irrelevant & 16 & 27 & 2.27 & 3.55 & 7.47 & 2.87 & 41.4 & 26.7 & 13.3 & 20.5 & 4.0 & 4.5 & 3.9 & 2.3 & \begin{tabular}{|l|}
47.1 \\
\end{tabular} & 34.6 & 20.4 & 16.6 & 34.5 & 19.8 & 8.0 & 16.6 & -1.5 & -1.2 & -0.1 & 0.8 \\
\hline & & & relevant & 21 & 29 & 2.24 & 3.82 & 11.47 & 2.72 & 42.0 & 25.5 & 8.2 & 21.1 & 3.6 & 5.5 & 5.5 & 3.5 & 46.8 & 35.4 & 18.9 & 15.0 & 35.3 & 17.7 & 1.0 & 15.0 & -1.4 & $\begin{array}{l}-1.4 \\
\end{array}$ & -0.1 & 1.3 \\
\hline & & \multirow{3}{*}{ right } & no & 12 & 29 & 2.24 & 3.16 & 6.43 & 0.75 & 41.8 & 30.1 & 14.7 & 15.1 & 2.5 & 4.6 & 4.1 & 0.4 & 45.5 & 37.6 & 23.7 & 14.5 & 37.4 & 23.1 & 9.6 & 14.5 & -1.0 & $\begin{array}{l}-1.3 \\
\end{array}$ & -0.4 & 0.5 \\
\hline & & & irrelevant & 17 & 27 & 2.34 & 3.59 & 6.48 & 0.88 & 40.1 & 26.9 & 14.5 & 15.3 & 3.8 & 4.0 & 4.2 & 0.6 & \begin{tabular}{|l|l|}
45.4 \\
\end{tabular} & 33.6 & 21.9 & 14.5 & 33.3 & 20.9 & 9.2 & 14.5 & -1.4 & -1.0 & -0.3 & 0.6 \\
\hline & & & $\begin{array}{l}\text { relevant } \\
\end{array}$ & 22 & 28 & 2.28 & 3.57 & 11.21 & 0.86 & 41.4 & 26.7 & 8.4 & 14.3 & 3.4 & 4.5 & 5.7 & 0.6 & 46.2 & 35.4 & 20.5 & 13.3 & 35.4 & 20.0 & 0.9 & 13.3 & -1.3 & -1.3 & -0.2 & 0.7 \\
\hline & \multirow{10}{*}{$\begin{array}{l}\text { X- } \\
\text { intersection } \\
\text { (four way) }\end{array}$} & & no & 13 & 29 & 2.26 & 3.60 & 5.84 & 2.48 & 41.6 & 27.0 & 17.2 & 22.0 & 3.3 & 4.5 & 2.9 & 1.6 & 45.9 & 35.7 & 21.7 & 19.5 & 35.4 & 20.5 & 13.4 & 19.5 & $\begin{array}{l}-1.3 \\
\end{array}$ & -1.2 & -0.1 & 0.6 \\
\hline & & & irrelevant & 18 & 28 & 2.33 & 3.49 & 6.45 & 2.55 & 40.5 & 27.2 & 15.2 & 22.8 & 3.5 & 4.3 & 4.1 & 2.2 & 45.3 & 34.5 & 21.5 & 18.9 & 34.4 & 21.1 & 9.9 & 18.9 & $\begin{array}{l}-1.3 \\
\end{array}$ & -1.2 & -0.1 & 0.9 \\
\hline & & left & relevant & 23 & 30 & 2.42 & 3.88 & 10.66 & 2.73 & 39.7 & 25.3 & 8.6 & 21.8 & 3.7 & 4.8 & 5.9 & 3.0 & 44.6 & 33.8 & 19.4 & 16.7 & 33.2 & 18.1 & 1.2 & 16.7 & -1.3 & -1.1 & -0.1 & 1.1 \\
\hline & & & $\begin{array}{l}\text { relevant } \\
\text { onc. } \\
\end{array}$ & 27 & 29 & 2.30 & 3.71 & 39.08 & 6.24 & 40.9 & 26.4 & 4.3 & 17.6 & 3.6 & 4.6 & 4.2 & 4.3 & 45.9 & 34.6 & 20.1 & 12.1 & 34.6 & 19.1 & 1.7 & 11.1 & -1.3 & -1.2 & -0.1 & 1.1 \\
\hline & & & no & 15 & 26 & 2.46 & 3.46 & 5.07 & 1.82 & 38.9 & 28.2 & 20.4 & 33.0 & 2.5 & 3.8 & 4.3 & 3.1 & 42.5 & 34.5 & 23.0 & 27.7 & 34.2 & 22.2 & 14.8 & 27.7 & -1.0 & -1.0 & 0.4 & 1.6 \\
\hline & & straight & irrelevant & 20 & 30 & 2.70 & 3.66 & 5.91 & 1.81 & 36.6 & 26.3 & 18.1 & 33.4 & 3.8 & 3.8 & 5.6 & 3.2 & 42.9 & 31.7 & 21.1 & 27.8 & 30.8 & 20.0 & 10.9 & 27.8 & -1.2 & -0.9 & 0.5 & 1.6 \\
\hline & & & relevant & 25 & 27 & 2.54 & 4.13 & 9.89 & 2.11 & 37.5 & 23.7 & 9.5 & 28.3 & 3.8 & 4.8 & 6.1 & 4.3 & 43.3 & 31.5 & 17.6 & 21.0 & 31.3 & 16.1 & 1.7 & 21.0 & -1.3 & -1.1 & 0.1 & 1.9 \\
\hline & & & no & 14 & 26 & 2.47 & 3.14 & 6.44 & 0.66 & 38.5 & 29.9 & 14.7 & 15.8 & 1.7 & 4.5 & 4.5 & 0.4 & 41.1 & 36.2 & 22.3 & 15.2 & 35.6 & 22.2 & 8.9 & 15.2 & -0.6 & -1.3 & -0.3 & 0.6 \\
\hline & & right & irrelevant & 19 & 30 & 2.45 & 3.39 & 6.47 & 0.67 & 38.6 & 27.9 & 14.9 & 15.6 & 3.1 & 3.7 & 4.4 & 0.4 & 43.3 & 33.8 & 23.0 & 15.0 & 33.5 & 22.4 & 9.3 & 15.0 & -1.1 & -1.0 & -0.3 & 0.5 \\
\hline & & & relevant & 24 & 26 & 2.39 & 3.60 & 10.81 & 0.91 & 39.7 & 26.7 & 8.6 & 13.9 & 3.3 & 4.7 & 5.2 & 0.7 & \begin{tabular}{|l|}
45.2 \\
\end{tabular} & 34.7 & 19.9 & 12.7 & 34.6 & 19.4 & 1.9 & 12.7 & -1.2 & -1.3 & -0.2 & 0.8 \\
\hline & & & no & 11 & 23 & 2.06 & 2.80 & 5.67 & 2.23 & 44.7 & 33.5 & 17.8 & 24.3 & 1.7 & 4.8 & 4.1 & 2.2 & 47.2 & 41.4 & 26.0 & 20.5 & 41.3 & 25.9 & 13.0 & 20.5 & -0.8 & -1.6 & -0.2 & 0.9 \\
\hline & & left & irrelevant & 16 & 26 & 2.21 & 3.14 & 5.86 & 2.40 & 42.0 & 30.3 & 17.0 & 23.4 & 2.6 & 4.5 & 4.4 & 2.3 & 45.3 & 37.3 & 23.4 & 19.6 & 37.2 & 22.9 & 11.3 & 19.6 & -1.0 & -1.3 & -0.2 & 0.9 \\
\hline & & & relevant & 21 & 23 & 2.00 & 3.12 & 10.50 & 2.63 & 45.9 & 30.8 & 9.2 & 22.6 & 2.3 & 5.4 & 6.7 & 4.1 & 48.9 & 41.2 & 23.9 & 15.3 & 41.1 & 23.3 & 1.3 & 15.3 & -1.0 & -1.6 & -0.3 & 1.5 \\
\hline & ay) & & no & 12 & 23 & 2.06 & 2.77 & 5.28 & 0.53 & 44.3 & 34.8 & 18.4 & 17.6 & 1.8 & 3.7 & 4.8 & 0.4 & 46.5 & 41.1 & 28.5 & 17.0 & 40.9 & 27.9 & 12.5 & 17.0 & -0.7 & -1.3 & -0.7 & 0.6 \\
\hline & & right & irrelevant & 17 & 26 & 2.16 & 2.91 & 6.11 & 0.60 & 42.7 & 32.3 & 15.7 & 17.4 & 2.2 & 4.1 & 4.9 & 0.5 & 45.5 & 38.9 & 25.9 & 16.5 & 38.7 & 25.6 & 9.3 & 16.5 & -0.8 & -1.3 & -0.4 & 0.8 \\
\hline & & & relevant & 22 & 23 & 2.09 & 3.17 & 9.48 & 0.61 & 43.9 & 30.1 & 10.0 & 16.8 & 2.1 & 5.0 & 6.1 & 0.8 & 46.1 & 39.2 & 22.9 & 15.6 & 39.2 & 22.6 & 2.2 & 15.6 & -0.9 & -1.5 & -0.2 & 1.2 \\
\hline & & & no & 13 & 23 & 2.12 & 3.01 & 5.07 & 2.37 & 43.6 & 32.3 & 20.8 & 25.6 & 1.8 & 4.6 & 3.7 & 2.6 & 46.3 & 40.4 & 26.8 & 22.6 & 40.3 & 26.3 & 15.8 & 20.9 & -0.7 & $\begin{array}{l}-1.3 \\
\end{array}$ & -0.3 & 0.7 \\
\hline & & & irrelevant & 18 & 23 & 2.20 & 3.39 & 5.75 & 2.32 & 42.4 & 28.6 & 17.1 & 24.4 & 2.5 & 5.6 & 3.6 & 2.4 & 45.5 & 37.9 & 21.3 & 20.5 & 37.7 & 20.1 & 11.9 & 20.5 & -0.9 & -1.5 & 0.0 & 1.0 \\
\hline & & left & $\begin{array}{l}\text { relevant } \\
\end{array}$ & 23 & 26 & 2.06 & 3.50 & 10.09 & 2.33 & 44.7 & 28.4 & 10.1 & 25.6 & 2.8 & 5.7 & 6.1 & 3.9 & 48.2 & 39.0 & 21.5 & 18.6 & 39.0 & 20.5 & 2.4 & 18.2 & -1.2 & -1.5 & -0.1 & 1.4 \\
\hline & & & $\begin{array}{l}\text { relevant } \\
\text { onc. }\end{array}$ & 27 & 23 & 2.06 & 3.66 & 26.68 & 4.40 & 45.0 & 28.1 & 6.5 & 18.5 & 2.4 & 6.8 & 4.9 & 4.5 & 48.2 & 40.3 & 20.5 & 12.1 & 40.2 & 19.2 & 2.3 & 11.3 & -1.0 & -1.7 & -0.1 & 1.3 \\
\hline & & & no & 15 & 22 & 2.16 & 2.74 & 4.64 & 1.78 & 43.3 & 35.7 & 25.3 & 34.6 & 1.7 & 3.5 & 4.1 & 2.5 & 45.8 & 40.8 & 30.4 & 30.3 & 40.6 & 30.0 & 20.3 & 30.3 & -0.6 & -1.0 & 0.1 & 1.2 \\
\hline & & straight & irrelevant & 20 & 25 & 2.27 & 3.23 & 5.58 & 1.86 & 41.1 & 29.9 & 18.5 & 32.1 & 1.9 & 4.4 & 5.6 & 3.4 & 43.6 & 37.5 & 24.4 & 26.3 & 37.3 & 23.3 & 11.3 & 26.3 & -0.7 & -1.2 & 0.3 & 1.6 \\
\hline & & & relevant & 25 & 26 & 2.20 & 3.38 & 9.88 & 2.23 & 42.4 & 28.8 & 9.9 & 26.2 & 2.7 & 4.7 & 6.4 & 4.5 & 45.8 & 37.3 & 22.4 & 18.6 & 37.2 & 21.8 & 2.4 & 18.6 & -1.0 & -1.4 & -0.1 & 1.9 \\
\hline & & & no & 14 & 22 & 2.11 & 2.62 & 4.91 & 0.47 & 43.7 & 35.7 & 20.2 & 19.8 & 1.3 & 3.9 & 4.6 & 0.3 & \begin{tabular}{|l|}
45.5 \\
\end{tabular} & 41.4 & 28.9 & 19.5 & 41.2 & 28.8 & 14.9 & 19.4 & -0.5 & -1.3 & -0.6 & 0.4 \\
\hline & & right & irrelevant & 19 & 26 & 2.17 & 2.88 & 5.74 & 0.6 & 42.8 & 32.8 & 16.8 & 18.2 & 1.2 & 5.0 & 4.7 & 0.5 & \begin{tabular}{|l|l}
44.2 \\
\end{tabular} & 40.3 & 25.1 & 17.4 & 40.2 & 24.5 & 10.8 & 17.4 & -0.5 & -1.6 & -0.4 & 0.7 \\
\hline & & & relevant & 24 & 22 & 2.17 & 3.46 & 9.17 & 0.66 & 42.4 & 29.0 & 10.5 & 17.1 & 2.3 & 5.3 & 6.1 & 0.7 & 45.6 & 38.1 & 22.4 & 15.9 & 38.0 & 21.0 & 2.8 & 15.9 & -0.9 & -1.4 & -0.2 & 1.0 \\
\hline
\end{tabular}


TABLE 4: MEAN FIXATION PROPORTIONS FOR GAZE LOCATIONS WHEN HAVING PRIORITY WITH GREEN TRAFFIC LIGHT. RELEVANT ONC. STANDS FOR RELEVANT ONCOMING TRAFFIC. N - SUBSAMPLE.

\begin{tabular}{|c|c|c|c|c|c|c|c|c|c|c|c|c|c|c|c|c|c|c|c|c|c|c|c|c|c|c|c|c|c|c|c|c|c|c|}
\hline \multirow[b]{2}{*}{ group } & \multirow{3}{*}{ junction } & \multirow{4}{*}{$\begin{array}{l}\begin{array}{l}\text { driving } \\
\text { manoeuvre }\end{array} \\
\text { left }\end{array}$} & \multirow{3}{*}{ traffic } & \multirow{3}{*}{$\begin{array}{l}\begin{array}{l}\text { scenario } \\
\text { no. }\end{array} \\
1\end{array}$} & \multicolumn{6}{|c|}{ Segment 1 ( $75 \mathrm{~m}$ to $50 \mathrm{~m}$ ) } & \multicolumn{6}{|c|}{ Segment 2 (50 $\mathrm{m}$ to $25 \mathrm{~m}$ ) } & \multicolumn{6}{|c|}{ Segment $3(25 \mathrm{~m}$ to $0 \mathrm{~m})$} & \multicolumn{6}{|c|}{ Segment 4 (crossing) } & \multicolumn{6}{|c|}{ Segment 5 (exit) } \\
\hline & & & & & $n$ & down & it & left & right & other & $n$ & down & straight & left & right $c$ & other & $n$ & dow & ht & left & right & other & $n$ & down & raig & left & right & other & $n$ & dov & straigh & left & right & other \\
\hline \multirow{11}{*}{ control } & & & & & 27 & 0.7 & 71.5 & 16.1 & 11.7 & 0.0 & 27 & 3.2 & 65.3 & 24.7 & 6.3 & 0.6 & 27 & 1.4 & 70.5 & 23.5 & 3.4 & 1.2 & 26 & 0.0 & 87.8 & 12.2 & 0.0 & 0.0 & 27 & 0.3 & 94.5 & 1.5 & 0.9 & 2.8 \\
\hline & \multirow{3}{*}{$\begin{array}{l}\text { T-junction } \\
\text { (three way) }\end{array}$} & & irrelevant & 6 & 26 & 0.8 & 59.2 & 25.2 & 14.8 & 0.0 & 26 & 4.3 & 64.4 & 17.4 & 12.7 & 1.3 & 26 & 2.0 & 68.6 & 24.1 & 4.1 & 1.3 & 26 & 0.0 & 82.9 & 15.8 & 1.3 & 0.0 & 24 & 1.4 & 98.0 & 0.0 & 0.6 & 0.0 \\
\hline & & \multirow{2}{*}{ right } & no & 2 & 30 & 7.6 & 65.5 & 9.1 & 17.7 & 0.0 & 30 & 5.9 & 73.1 & 8.4 & 10.5 & 2.0 & 30 & 0.7 & 74.1 & 2.1 & 19.2 & 3.9 & 24 & 0.0 & 95.8 & 0.0 & 4.2 & 0.0 & 30 & 1.9 & 91.1 & 0.6 & 3.9 & 2.6 \\
\hline & & & irrelevant & 7 & 29 & 4.1 & 54.9 & 17.0 & 24.1 & 0.0 & 29 & 4.4 & 56.5 & 10.2 & 28.9 & 0.0 & 29 & 1.1 & 65.0 & 0.9 & 30.8 & 2.2 & 23 & 0.0 & 80.4 & 2.2 & 17.4 & 0.0 & 29 & 0.9 & 94.0 & 0.0 & 2.0 & 3.1 \\
\hline & \multirow{7}{*}{$\begin{array}{l}\text { X- } \\
\text { intersection } \\
\text { (four way) }\end{array}$} & \multirow{3}{*}{ left } & no & 3 & 30 & 1.8 & 81.6 & 14.2 & 2.4 & 0.0 & 30 & 3.9 & 73.5 & 18.4 & 3.6 & 0.7 & 30 & 0.6 & 71.6 & 25.7 & 1.0 & 1.0 & 30 & 0.0 & 83.3 & 16.7 & 0.0 & 0.0 & 25 & 1.8 & 95.2 & 0.0 & 2.2 & 0.7 \\
\hline & & & irrelevant & 8 & 26 & 1.9 & 69.1 & 15.8 & 13.1 & 0.0 & 26 & 3.7 & 62.9 & 24.6 & 5.2 & 3.6 & 26 & 1.3 & 66.7 & 30.1 & 1.3 & 0.6 & 26 & 0.0 & 76.9 & 22.7 & 0.0 & 0.4 & 24 & 0.5 & 96.9 & 0.8 & 0.5 & 1.3 \\
\hline & & & relevant onc. & 26 & 31 & 3.9 & 82.4 & 3.6 & 5.8 & 4.4 & 31 & 1.8 & 81.0 & 12.1 & 3.5 & 1.6 & 31 & 0.1 & 85.4 & 10.9 & 2.7 & 0.9 & 30 & 1.2 & 81.2 & 15.4 & 1.0 & 1.2 & 18 & 1.1 & 97.7 & 0.0 & 0.0 & 1.2 \\
\hline & & \multirow{2}{*}{ straight } & no & 5 & 27 & 8.1 & 69.7 & 4.1 & 16.7 & 1.5 & 27 & 6.7 & 74.0 & 5.1 & 12.5 & 1.9 & 27 & 13.2 & 71.2 & 2.8 & 10.9 & 2.0 & 26 & 9.6 & 77.9 & 1.3 & 5.3 & 6.0 & 15 & 5.5 & 85.3 & 0.0 & 8.5 & 0.7 \\
\hline & & & irrelevant & 10 & 27 & 2.8 & 51.7 & 14.7 & 29.6 & 1.2 & 27 & 5.2 & 64.8 & 8.1 & 20.4 & 1.5 & 27 & 8.3 & 70.1 & 0.7 & 19.4 & 1.5 & 25 & 2.7 & 68.0 & 2.0 & 17.3 & 10.0 & 11 & 4.1 & 85.0 & 0.0 & 10.0 & 0.8 \\
\hline & & \multirow{2}{*}{ right } & no & 4 & 27 & 2.6 & 59.9 & 10.9 & 23.9 & 2.7 & 27 & 4.4 & 65.7 & 6.9 & 21.3 & 1.6 & 27 & 0.6 & 69.8 & 1.3 & 26.9 & 1.4 & 22 & 0.0 & 85.9 & 0.0 & 14.1 & 0.0 & 25 & 0.8 & 94.0 & 0.0 & 3.6 & 1.6 \\
\hline & & & irrelevant & 9 & 28 & 0.5 & 52.9 & 16.8 & 27.7 & 2.1 & 28 & 5.8 & 51.9 & 7.1 & 35.2 & 0.0 & 28 & 0.4 & 63.3 & 1.2 & 32.5 & 2.6 & 24 & 0.0 & 80.2 & 0.0 & 19.8 & 0.0 & 27 & 0.5 & 94.2 & 0.0 & 2.4 & 2.8 \\
\hline \multirow{11}{*}{$\begin{array}{l}\text { secondary } \\
\text { task }\end{array}$} & \multirow{4}{*}{$\begin{array}{l}\text { T-junction } \\
\text { (three way) }\end{array}$} & \multirow{2}{*}{ lef } & no & 1 & 26 & 2.1 & 69.4 & 16.0 & 12.6 & 0.0 & 26 & 1.9 & 70.9 & 18.1 & 7.8 & 1.2 & 26 & 1.5 & 75.6 & 15.2 & 4.4 & 3.2 & 25 & 1.0 & 94.2 & 4.8 & 0.0 & 0.0 & 22 & 1.5 & 94.8 & 0.0 & 0.9 & 2.7 \\
\hline & & & irrelevant & 6 & 22 & 2.6 & $\begin{array}{l}75.2 \\
\end{array}$ & 17.3 & 3.0 & 1.8 & 22 & 0.9 & 80.3 & $\begin{array}{l}11.7 \\
\end{array}$ & 5.3 & 1.8 & 22 & 1.4 & 84.5 & 13.1 & 1.0 & 0.0 & 21 & 0.0 & 96.5 & 3.5 & 0.0 & 0.0 & 17 & 2.2 & 96.2 & 0.0 & 0.0 & 1.6 \\
\hline & & & no & 2 & 26 & 2.9 & 65.6 & 19.0 & 9.7 & 2.8 & 26 & 1.9 & 74.8 & 8.2 & 8.3 & 6.7 & 26 & 0.8 & 81.7 & 2.6 & 10.6 & 4.2 & 17 & 0.0 & 97.1 & 0.0 & 2.9 & 0.0 & 25 & 0.0 & 99.0 & 0.0 & 0.0 & 1.0 \\
\hline & & & irrelevant & 7 & 23 & 4.7 & 60.9 & 15.4 & 19.0 & 0.0 & 23 & 3.6 & 65.3 & 11.2 & 19.9 & 0.0 & 22 & 0.0 & 76.8 & 2.6 & 17.2 & 3.5 & 16 & 0.0 & 85.9 & 1.6 & 6.3 & 6.3 & 22 & 1.2 & 97.6 & 0.9 & 0.0 & 0.3 \\
\hline & & & no & 3 & 24 & 1.7 & $\begin{array}{l}74.7 \\
\end{array}$ & 19.0 & 3.3 & 1.4 & 24 & 0.8 & 65.0 & 28.3 & 4.5 & 1.4 & 24 & 0.0 & 76.3 & 20.8 & 2.3 & 0.6 & 24 & 0.0 & 95.6 & 3.1 & 1.4 & 0.0 & 22 & 2.3 & 93.9 & 0.0 & 2.3 & 1.5 \\
\hline & & le & irrelevant & 8 & 22 & 0.0 & 77.0 & 10.3 & 12.7 & 0.0 & 22 & 0.0 & 77.7 & 20.8 & 1.5 & 0.0 & 22 & 0.8 & 85.4 & 11.9 & 0.6 & 1.3 & 22 & 0.0 & 95.3 & 4.1 & 0.6 & 0.0 & 20 & 3.6 & 95.9 & 0.0 & 0.5 & 0.0 \\
\hline & $x-$ & & relevant onc. & 26 & 25 & 4.0 & 81.5 & 5.4 & 9.1 & 0.0 & 25 & 0.0 & 90.9 & 6.9 & 1.5 & 0.8 & 25 & 1.8 & 88.6 & 7.8 & 1.1 & 0.8 & 23 & 0.0 & 94.9 & 4.6 & 0.0 & 0.4 & 12 & 2.5 & 97.5 & 0.0 & 0.0 & 0.0 \\
\hline & & & no & 5 & 23 & 0.0 & 84.9 & 6.2 & 8.9 & 0.0 & 23 & 9.4 & 80.6 & 6.4 & 3.6 & 0.0 & 23 & 8.7 & 78.0 & 6.7 & 6.7 & 0.0 & 18 & 2.8 & 92.1 & 1.9 & 3.2 & 0.0 & 9 & 3.7 & 81.7 & 0.0 & 13.0 & 1.6 \\
\hline & (four way) & aignt & irrelevant & 10 & 21 & 1.6 & 72.9 & 5.9 & 19.6 & 0.0 & 21 & 6.0 & 73.7 & 7.5 & 12.9 & 0.0 & 21 & 3.2 & 89.2 & 0.0 & 6.0 & 1.6 & 18 & 11.1 & 78.7 & 2.8 & 7.4 & 0.0 & 11 & 22.6 & 72.8 & 0.0 & 0.0 & 4.5 \\
\hline & & & no & 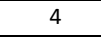 & 26 & 2.1 & 70.5 & 9.7 & 16.9 & 0.8 & 26 & 1.0 & 73.4 & 8.5 & 13.0 & 4.1 & 26 & 0.6 & 86.1 & 3.0 & 7.9 & 2.4 & 15 & 0.0 & 86.7 & 0.0 & 13.3 & 0.0 & 26 & 0.0 & 97.3 & 0.0 & 1.6 & 1.1 \\
\hline & & & & 9 & 23 & 0.0 & 61.5 & 12.0 & 25.6 & 0.9 & 23 & 3.1 & 54.4 & 7.0 & 31.6 & 3.9 & 23 & 2.0 & 71.0 & 1.2 & 22.9 & 2.9 & 20 & 0.0 & 90.3 & 3.0 & 6.7 & 0.0 & 23 & 0.0 & 92.0 & 3.5 & 1.1 & 3.4 \\
\hline
\end{tabular}


TABLE 5: MEAN FIXATION PROPORTIONS FOR GAZE LOCATIONS WHEN GIVING PRIORITY WITH YIELD SIGN. RELEVANT ONC. STANDS FOR RELEVANT ONCOMING TRAFFIC. N - SUBSAMPLE.

\begin{tabular}{|c|c|c|c|c|c|c|c|c|c|c|c|c|c|c|c|c|c|c|c|c|c|c|c|c|c|c|c|c|c|c|c|c|c|c|}
\hline \multirow[b]{2}{*}{ group } & \multirow[b]{2}{*}{ junction } & \multirow{3}{*}{$\begin{array}{l}\text { driving } \\
\text { manoeuvre }\end{array}$} & \multirow{3}{*}{ traffic } & \multirow{3}{*}{$\begin{array}{c}\begin{array}{c}\text { scenario } \\
\text { no. }\end{array} \\
11\end{array}$} & \multicolumn{6}{|c|}{ Segment 1 ( $75 \mathrm{~m}$ to $50 \mathrm{~m}$ ) } & \multicolumn{6}{|c|}{ Segment 2 (50 $\mathrm{m}$ to $25 \mathrm{~m}$ ) } & \multicolumn{6}{|c|}{ Segment $3(25 \mathrm{~m}$ to $0 \mathrm{~m})$} & \multicolumn{6}{|c|}{ Segment 4 (crossing) } & \multicolumn{6}{|c|}{ Segment 5 (exit) } \\
\hline & & & & & $n$ & d & 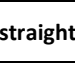 & 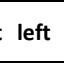 & & other & $n$ & & straigh & $t$ left $r$ & right 0 & er & $n$ & c & straight & & & other & $n$ & down & straight & & r & her & $\mathrm{n}$ & down & straight & ft & right & other \\
\hline \multirow{16}{*}{ control } & \multirow{6}{*}{$\begin{array}{l}\text { T-junction } \\
\text { (three way) }\end{array}$} & & & & 28 & 0.8 & 62.5 & 26.5 & 8.4 & 1.7 & 28 & 0.8 & 46.7 & 24.1 & 26.1 & 2.3 & 28 & 0.0 & 42.0 & 34.1 & 19.2 & 4.7 & 28 & 0.0 & $\begin{array}{ll}85.7 \\
\end{array}$ & 14.3 & 0.0 & 0.0 & 23 & 2.7 & 94.0 & 0.0 & 1.0 & 2.3 \\
\hline & & \multirow[t]{2}{*}{ left } & irrelevant & 16 & 27 & 2.5 & 64.1 & 24.3 & 6.9 & 2.2 & 27 & 1.4 & 60.8 & 16.5 & 18.2 & 3.0 & 27 & 0.2 & 43.7 & 34.4 & 16.0 & 5.7 & 27 & 0.0 & 83.9 & 12.7 & 0.7 & 2.7 & 24 & 1.9 & 95.3 & 0.0 & 0.0 & 2.8 \\
\hline & & & relevant & 21 & 29 & 1.1 & 69.3 & 28.3 & 1.2 & 0.0 & 29 & 0.6 & 61.5 & 25.9 & 9.2 & 2.8 & 29 & 0.4 & 43.2 & 38.1 & 13.9 & 4.4 & 28 & 0.0 & 86.9 & 13.1 & 0.0 & 0.0 & 25 & 0.8 & 98.2 & 0.0 & 0.0 & 1.0 \\
\hline & & \multirow{3}{*}{ right } & no & 12 & 29 & 1.3 & 55.6 & 28.1 & 11.6 & 3.5 & 29 & 1.0 & 55.2 & 26.1 & 14.5 & 3.3 & 29 & 0.4 & 58.0 & 18.1 & 19.5 & 4.0 & 27 & 0.0 & 87.0 & 1.9 & 11.1 & 0.0 & 28 & 0.8 & 89.8 & 0.0 & 4.5 & 4.8 \\
\hline & & & irrelevant & 17 & 27 & 0.0 & 62.6 & 22.9 & 11.8 & $\begin{array}{l}2.7 \\
\end{array}$ & 27 & 0.9 & 55.1 & 28.6 & 12.2 & 3.2 & 27 & 0.0 & 52.3 & 25.8 & 17.6 & 4.3 & 20 & 0.0 & 80.4 & 0.0 & 19.6 & 0.0 & 27 & 0.8 & 93.0 & 1.3 & 2.6 & 2.3 \\
\hline & & & relevant & 22 & 28 & 3.4 & 62.7 & 21.1 & 11.9 & 0.9 & 28 & 2.4 & 48.5 & 35.9 & 8.7 & 4.4 & 28 & 0.0 & 45.3 & 37.2 & 9.9 & 7.6 & 23 & 0.0 & 79.7 & 0.0 & 19.2 & 1.1 & 27 & 0.4 & 89.3 & 0.0 & 5.5 & 4.8 \\
\hline & \multirow{10}{*}{$\begin{array}{l}\text { X- } \\
\text { intersection } \\
\text { (four way) }\end{array}$} & & no & 13 & 29 & 2.5 & 75.4 & 12.3 & 8.6 & 1.1 & 29 & 1.0 & 47.5 & 23.5 & 24.5 & 3.4 & 29 & 0.8 & 57.0 & 31.1 & 9.4 & 1.8 & 29 & 0.0 & 84.6 & 15.0 & 0.0 & 0.5 & 21 & 0.8 & 96.4 & 0.0 & 0.7 & 2.1 \\
\hline & & & irrelevant & 18 & 28 & 6.4 & 77.2 & 6.2 & 10.2 & 0.0 & 28 & 3.2 & 58.2 & 22.3 & 15.4 & 0.8 & 28 & 0.8 & 54.3 & 30.5 & 11.2 & 3.2 & 28 & 0.0 & 79.9 & 20.1 & 0.0 & 0.0 & 23 & 3.4 & 95.6 & 0.0 & 0.0 & 1.0 \\
\hline & & left & relevant & 23 & 30 & 1.4 & 71.6 & 19.8 & 7.1 & 0.0 & 30 & 1.6 & 57.1 & 35.4 & 5.4 & 0.5 & 30 & 0.3 & 42.3 & 44.0 & 8.0 & 5.4 & 29 & 0.8 & 83.0 & 14.7 & 0.7 & 0.9 & 21 & 1.3 & 96.7 & 0.0 & 0.0 & 2.1 \\
\hline & & & relevant c & 27 & 29 & 4.2 & 66.4 & 22.4 & 7.0 & 0.0 & \begin{tabular}{|l|}
29 \\
\end{tabular} & 0.8 & 54.6 & 37.2 & 6.6 & 0.7 & 29 & 0.2 & 72.8 & 19.2 & 4.2 & 3.5 & 28 & 0.0 & 86.5 & 12.6 & 0.7 & 0.2 & \begin{tabular}{|l|}
18 \\
\end{tabular} & 1.9 & 97.2 & 0.0 & 0.0 & 0.9 \\
\hline & & & no & 15 & 26 & 1.3 & 58.1 & 16.4 & 18.8 & 5.4 & 26 & 0.7 & 51.1 & 21.1 & 23.6 & 3.5 & 26 & 9.0 & 55.8 & 14.3 & 19.3 & 1.6 & 24 & 11.1 & 68.1 & 2.1 & 15.3 & 3.4 & 15 & 16.3 & 67.7 & 7.2 & 6.5 & 2.2 \\
\hline & & straight & irrelevant & 20 & 30 & 3.1 & 69.3 & 12.4 & 14.2 & 1.0 & 30 & 2.6 & 43.8 & 30.9 & 20.1 & 2.6 & 30 & 2.7 & 50.8 & 20.2 & 23.3 & 2.9 & 30 & 13.9 & 61.8 & 0.5 & 14.1 & 9.7 & 18 & 14.3 & 62.7 & 0.0 & 14.7 & 8.3 \\
\hline & & & relevant & 5 & 27 & 2.5 & 64.1 & 16.6 & 16.8 & 0.0 & 27 & 0.0 & 52.6 & 36.9 & 9.8 & 0.7 & 27 & 0.0 & 45.6 & 37.4 & 13.0 & 4.1 & 27 & 111.1 & 69.1 & 1.5 & 11.8 & 6.4 & 21 & 13.0 & 69.5 & 0.0 & 15.0 & 2.5 \\
\hline & & & no & 14 & 26 & 2.1 & 44.9 & 16.7 & 30.0 & 6.3 & 26 & 0.5 & 49.2 & 23.6 & 25.1 & 1.6 & 26 & 0.0 & 53.4 & 19.9 & 20.2 & 6.4 & 20 & 0.0 & 76.3 & 0.0 & 23.8 & 0.0 & 24 & 2.4 & 92.9 & 0.0 & 3.1 & 1.6 \\
\hline & & right & irrelevant & 19 & 30 & 1.4 & 60.0 & 17.1 & 21.0 & 0.6 & 30 & 1.5 & 48.4 & 35.2 & $\begin{array}{l}12.2 \\
\end{array}$ & 2.8 & 30 & 0.2 & 57.0 & 24.3 & 14.2 & $\begin{array}{l}4.3 \\
\end{array}$ & 22 & 0.0 & 92.0 & 0.0 & 8.0 & 0.0 & 30 & 0.0 & 95.4 & 0.0 & 1.3 & 3.4 \\
\hline & & & relevant & 24 & 26 & 3.6 & 64.3 & 17.6 & 14.5 & 0.0 & 26 & 1.5 & 53.7 & 34.3 & 10.4 & 0.0 & 26 & 0.2 & 42.3 & 40.8 & 10.9 & 5.8 & 23 & 0.0 & 80.4 & 0.0 & 19.6 & 0.0 & 26 & 0.0 & 94.8 & 0.0 & 1.2 & 4.0 \\
\hline & & & no & 11 & 23 & 2.6 & 60.2 & 20.8 & 13.5 & 2.9 & \begin{tabular}{|l|}
23 \\
\end{tabular} & 0.0 & 56.2 & 25.0 & 18.8 & 0.0 & 23 & 0.0 & 51.5 & 30.0 & 15.1 & 3.4 & 22 & 0.0 & 95.1 & 4.9 & 0.0 & 0. & 21 & 1.9 & 97.3 & 0.0 & 0.0 & 0.8 \\
\hline & & left & irrelevant & 6 & 26 & 1.9 & 73.6 & 15.5 & 7.4 & 1.5 & 26 & 1.5 & 62.5 & 23.8 & 12.2 & 0.0 & 26 & 0.4 & 54.1 & 25.9 & 17.0 & 2.7 & 26 & 0.0 & 95.0 & 3.9 & 1.1 & 0.0 & 21 & 2.1 & 96.2 & 0.0 & 0.0 & 1.6 \\
\hline & & & relevant & , & 23 & 7.0 & 70.3 & 20.1 & 0.9 & 1.7 & 23 & 3.3 & 66.7 & 20.1 & 9.3 & 0.6 & 23 & 0.0 & 37.4 & 43.6 & 14.1 & 4.9 & 20 & 0.0 & 94.3 & 5.7 & 0.0 & 0.0 & 20 & 0.0 & 100.0 & 0.0 & 0.0 & 0.0 \\
\hline & & & no & 12 & 23 & 4.3 & 69.5 & 19.9 & 3.4 & 2.8 & $23 \mid$ & 3.8 & 48.9 & 34.0 & 7.9 & 5.4 & 23 & 0.0 & 72.5 & 18.9 & 7.4 & 1.3 & \begin{tabular}{|l|}
17 \\
\end{tabular} & 0.0 & 91.2 & 0.0 & 8.8 & 0.0 & 22 & 1.2 & 94.8 & 0.0 & 0.8 & 3.2 \\
\hline & & right & irrelevant & 17 & 26 & 1.1 & 64.2 & 23.8 & 7.8 & 3.2 & 26 & 1.7 & 62.7 & 27.9 & 7.7 & 0.0 & 26 & 0.0 & 61.8 & 25.2 & 9.1 & 3.8 & 18 & 0.0 & 100.0 & 0.0 & 0.0 & 0.0 & 25 & 0.0 & 97.3 & 0.0 & 0.7 & 2.0 \\
\hline & & & relevant & 22 & 23 & 0.0 & 65.7 & 20.8 & 11.3 & 2.2 & 23 & 0.0 & 57.7 & 35.3 & 5.5 & 1.4 & 23 & 0.2 & 40.3 & 52.1 & 5.8 & 1.5 & 16 & 3.1 & 84.4 & 6.3 & 6.3 & 0.0 & 20 & 0.0 & 94.4 & 0.0 & 3.1 & 2.6 \\
\hline & & & no & 13 & 23 & 2.9 & 74.6 & 14.3 & 8.2 & 00 & 23 & 2.0 & 59.7 & 20.8 & 16.1 & 15 & 23 & 0.0 & 65.8 & 21.6 & 7.2 & 5.4 & 22 & ת0 & 92.4 & 7.6 & 0.0 & 0.0 & 16 & 1.8 & 97.4 & 0.0 & 0.0 & 0.8 \\
\hline & & & irrelevant & 18 & 23 & 0.9 & 78.1 & 16.0 & 4.3 & 0.7 & \begin{tabular}{|l|}
23 \\
\end{tabular} & 3.2 & 55.9 & 24.0 & 12.9 & 3.9 & \begin{tabular}{|l|}
23 \\
\end{tabular} & 0.0 & 60.8 & 25.1 & 10.5 & 3.5 & 23 & 0.0 & 95.7 & 2.6 & 0.0 & 1.7 & \begin{tabular}{|l|}
19 \\
\end{tabular} & 2.6 & 95.9 & 0.0 & 0.8 & 0.8 \\
\hline & & left & relevant & 23 & 26 & 1.1 & 72.7 & 21.9 & 4.3 & 0.0 & 26 & 0.0 & 62.3 & 32.6 & 4.4 & 0.8 & \begin{tabular}{|l|}
26 \\
\end{tabular} & 0.0 & 41.2 & 45.4 & 10.4 & 3.0 & \begin{tabular}{|l|}
25 \\
\end{tabular} & 0.0 & 92.8 & 5.2 & 0.0 & 2.0 & \begin{tabular}{|l|}
22 \\
\end{tabular} & 1.3 & 98.7 & 0.0 & 0.0 & 0.0 \\
\hline & & & relevant onc. & 27 & 23 & 0.9 & 74.6 & 21.5 & 2.0 & 1.1 & 23 & 2.1 & 47.4 & 44.2 & 6.3 & 0.0 & 23 & 0.1 & 69.2 & 24.8 & 4.3 & 1.7 & 23 & 0.0 & 93.2 & 6.8 & 0.0 & 0.0 & 15 & 0.0 & 98.3 & 0.0 & 0.0 & 1.7 \\
\hline & & & no & 15 & 22 & 1.1 & 66.5 & 20.5 & 11.8 & 0.0 & 22 & 1.3 & 53.0 & 30.8 & 13.4 & 1.5 & 22 & 2.5 & 69.7 & 12.3 & 14.5 & 1.0 & 21 & 6 & 81.7 & 1.0 & 10.7 & 0. & 8 & 6.3 & 85.0 & 0.0 & 0.0 & 8.8 \\
\hline & & straight & irrelevant & 20 & 25 & 1.3 & 71.7 & 15.0 & 10.2 & 1.7 & 25 & 0.0 & 59.8 & 27.0 & 12.1 & 1.0 & 25 & 1.2 & 54.2 & 22.5 & 19.3 & 2.9 & 25 & 3. & 85.1 & 0.0 & 7.9 & 3.7 & 10 & 14.0 & 86.0 & 0.0 & 0.0 & 0.0 \\
\hline & & & relevant & 25 & 26 & 4.6 & 74.3 & 13.5 & 6.3 & 1.3 & 26 & 1.3 & 61.1 & 29.0 & 6.5 & 2.1 & 26 & 0.0 & 43.9 & 35.8 & 17.7 & 2.7 & 24 & 1.0 & 83.1 & 1.4 & 12.3 & 2.1 & \begin{tabular}{|l|}
8 \\
\end{tabular} & 10.0 & 77.5 & 0.0 & 3.1 & 9.4 \\
\hline & & & no & 14 & 22 & 0.0 & 63.3 & 20.2 & 13.6 & 3.0 & 22 & 0.0 & 63.7 & 24.7 & 10.6 & 1.0 & 22 & 0.0 & 70.8 & 11.1 & 15.0 & 3.1 & 12 & 0.0 & 100.0 & 0.0 & 0.0 & 0.0 & 21 & 0.0 & 100.0 & 0.0 & 0.0 & 0.0 \\
\hline & & right & irrelevant & 19 & 26 & 0.0 & 70.0 & 16.5 & 9.9 & 3.6 & 26 & 0.0 & 64.1 & 25.8 & 9.2 & 1.0 & 26 & 0.5 & 56.8 & 28.8 & 8.2 & 5.7 & 18 & 0.0 & 86.6 & 0.0 & 9.3 & 4.2 & 25 & 0.4 & 91.9 & 0.2 & 1.3 & 6.2 \\
\hline & & & relevant & 24 & \begin{tabular}{|l|}
22 \\
\end{tabular} & 0.0 & 70.0 & 22.3 & 6.1 & 1.5 & \begin{tabular}{|l|}
22 \\
\end{tabular} & 1.1 & 52.2 & 40.7 & 4.5 & 1.4 & \begin{tabular}{|l|}
22 \\
\end{tabular} & 0.0 & 45.1 & 45.6 & 6.5 & 2.8 & \begin{tabular}{|l|}
13 \\
\end{tabular} & 0.0 & 85.9 & 0.0 & 11.5 & 2.6 & \begin{tabular}{|l|}
22 \\
\end{tabular} & 2.3 & 96.8 & 0.0 & 0.0 & \\
\hline
\end{tabular}


TABle 6: MEAN FixATION DURATIONS FOR DIFFERENT GAZE LOCATIONS WHEN HAVING PRIORITY WITH GREEN TRAFFIC LIGHT. RELEVANT ONC. STANDS FOR RELEVANT ONCOMING TRAFFIC. N - SUBSAMPLE.

\begin{tabular}{|c|c|c|c|c|c|c|c|c|c|c|c|c|c|c|c|c|c|c|c|c|c|c|c|c|c|c|c|c|c|c|}
\hline \multirow{3}{*}{ group } & \multirow[b]{2}{*}{ junction } & \multirow{2}{*}{\begin{tabular}{|l|l}
$\begin{array}{l}\text { driving } \\
\text { maneuver }\end{array}$ \\
\end{tabular}} & \multirow[b]{2}{*}{ traffic } & \multirow{2}{*}{\multicolumn{2}{|c|}{$\begin{array}{l}\text { scenario } \\
\text { no. }\end{array}$}} & \multicolumn{5}{|c|}{ Segment $1(75 \mathrm{~m}$ to $50 \mathrm{~m})$} & \multicolumn{5}{|c|}{ Segment $2(50 \mathrm{~m}$ to $25 \mathrm{~m}$ ) } & \multicolumn{5}{|c|}{ Segment $3(25 \mathrm{~m}$ to $0 \mathrm{~m})$} & \multicolumn{5}{|c|}{ Segment 4 (crossing) } & \multicolumn{5}{|c|}{ Segment 5 (exit) } \\
\hline & & & & & & \multicolumn{3}{|c|}{ down straight left } & & other & down & straight & left & right & other & down s & straight & left & right & other & down & straight & left & right & other & down & straight & $t$ left & right & other \\
\hline & & & & & $\mathrm{n}$ & 1 & 27 & 13 & & 0 & 4 & 27 & 16 & 8 & 2 & 2 & 26 & 14 & 7 & 3 & 0 & 25 & 6 & 0 & 0 & 1 & 27 & 2 & 1 & \\
\hline & & & no & 1 & mean & 125.2 & 387.7 & 371.1 & 269.7 & & 250.3 & 309.4 & 245.9 & 283.0 & 310.6 & 204.2 & 322.2 & 198.6 & 170.1 & 192.8 & & 356.4 & 325.5 & & & 200.4 & 632.5 & 230.5 & 167.7 & 7228.0 \\
\hline & & left & & & $\mathrm{n}$ & 1 & 23 & 21 & 13 & 0 & 5 & 26 & 16 & 16 & 3 & 4 & 25 & 18 & 7 & 3 & 0 & 25 & 7 & 2 & 0 & 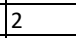 & 24 & 0 & & 0 \\
\hline & & & & & mean & 395.7 & 366.4 & 318.9 & 350.6 & & 210.4 & 317.8 & 274.5 & 275.4 & 266.1 & 150.3 & 311.0 & 458.5 & 221.6 & 266.3 & & 415.8 & 266.6 & 508.4 & & 201.4 & 469.9 & & 271.0 & \\
\hline & & & & 2 & $\mathrm{n}$ & 7 & 29 & 8 & 15 & 0 & 6 & 30 & 10 & 10 & 3 & 2 & 29 & 5 & 12 & 6 & 0 & 23 & 0 & 1 & 0 & 2 & 30 & 1 & & 5 \\
\hline & & & & 2 & mean & 623.2 & 389.6 & 327.0 & 496.4 & & \begin{tabular}{|l|l|}
174.1 \\
\end{tabular} & 418.6 & 289.6 & 286.6 & 177.8 & 493.4 & 378.5 & 391.2 & 332.5 & 281.5 & & 449.8 & & 278.0 & & 279.9 & 516.6 & 245.5 & 236.8 & 8304.5 \\
\hline & & & & & $\mathrm{n}$ & 3 & 29 & -17 & 21 & 0 & 4 & 29 & 12 & 24 & 0 & 3 & 25 & 3 & 21 & 4 & 0 & 19 & 1 & 5 & 0 & 1 & 29 & 0 & 4 & 4 \\
\hline & & & & 7 & mean & 154.5 & 329.2 & 276.4 & 347.8 & & 292.1 & 313.2 & 226.0 & 282.9 & & 449.0 & 331.2 & 477.9 & 299.1 & 214.9 & & 334.7 & 279.6 & 332.9 & & 172.6 & 397.4 & & 324.3 & 3236.8 \\
\hline & & & & & $n$ & 3 & 30 & 13 & 4 & 0 & 5 & 30 & 20 & 5 & 1 & 1 & 30 & 22 & 3 & 2 & 0 & 28 & 8 & 0 & 0 & 2 & 25 & 0 & 2 & 1 \\
\hline & & & $n$ & 3 & mean & 263.9 & 378.6 & 336.9 & 359.3 & & 216.0 & 279.0 & 232.7 & 254.7 & 300.5 & 115.1 & 350.0 & 247.7 & 150.4 & \begin{tabular}{|l|}
158.7 \\
\end{tabular} & & 387.0 & 305.3 & & & 263.8 & 529.5 & & 268.0 & 215.5 \\
\hline & & & & & $\mathrm{n}$ & 2 & 26 & 17 & 16 & 0 & 3 & 25 & 18 & 6 & 3 & 2 & 24 & 16 & 3 & 2 & 0 & 23 & 8 & 0 & 1 & 1 & 24 & 1 & 1 & 2 \\
\hline & & le & irrelevant & & mean & 431.5 & 331.7 & 285.2 & 223.1 & & 242.2 & 437.6 & 238.8 & 187.1 & 206.0 & 214.1 & 329.0 & 389.6 & 237.2 & 243.1 & & 429.4 & 434.0 & & 210.5 & 175.0 & 561.2 & 936.8 & 3270.6 & 5421.9 \\
\hline & & & relevan & & $n$ & 3 & 30 & 5 & 8 & 3 & 3 & 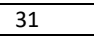 & 17 & 6 & 2 & 1 & 31 & 20 & 8 & 5 & 2 & 30 & 14 & 5 & 3 & 1 & 18 & 0 & 0 & 1 \\
\hline & & & & 26 & mean & 217.6 & 402.3 & 250.0 & 237.1 & 355.3 & 141.2 & 35 & 227.6 & 249.1 & 341.8 & 130.3 & 439.4 & 241.1 & 208.3 & 241.6 & 230.9 & 374.0 & 292.4 & 143.5 & 218.2 & 287.9 & 513.2 & & & 283.1 \\
\hline & & & & & $n$ & 5 & 27 & 5 & 13 & 2 & 5 & 26 & 4 & 10 & 2 & 8 & 26 & 2 & 7 & 2 & 4 & 26 & 1 & 4 & 3 & 4 & 14 & 0 & 3 & 1 \\
\hline & & & no & 5 & mean & 206.4 & 353.3 & 264.0 & 315.1 & 158.9 & 239.3 & 403. & 205.6 & 314.9 & 205.5 & 214.8 & 463.1 & 180.2 & 316.9 & 226.5 & 218.6 & 392.0 & 380.7 & 329.4 & 245.2 & 310.7 & 393.8 & & 357.2 & 2520.9 \\
\hline & & straight & & & $n$ & 3 & 27 & 12 & 22 & 1 & 4 & 27 & 8 & 15 & 1 & 5 & 26 & 1 & 11 & 1 & 1 & 22 & 1 & 9 & 5 & 2 & 11 & 0 & 3 & 1 \\
\hline & & & $t$ & 10 & mean & 178.5 & 285.8 & 213.9 & 324.6 & 155.7 & 245.8 & 340. & 183.3 & 260.8 & 248.1 & 257.6 & 394. & 215.1 & 345.0 & 180.4 & 220.2 & 328.8 & 200.4 & 244.9 & 237.9 & 410.7 & 323.1 & & 333.7 & 795.2 \\
\hline & & & & & $n$ & 4 & 25 & 10 & 15 & 3 & 4 & 25 & 6 & 15 & 1 & 1 & 25 & 2 & 15 & 3 & 0 & 20 & 0 & 4 & 0 & 1 & 25 & 0 & 2 & 3 \\
\hline & & & $\mathrm{n}$ & 4 & mean & 247.9 & 330. & 201.6 & 343.0 & 254.3 & 212.1 & 410.5 & 216.7 & 343.9 & 223.6 & \begin{tabular}{|l}
125.3 \\
\end{tabular} & 357.1 & 229.0 & 362.8 & 206.6 & & 377.2 & & 306.0 & & 227.9 & 475.2 & & 343.2 & 2155.2 \\
\hline & & & & & $n$ & 1 & 28 & 18 & 21 & 1 & 6 & 26 & 10 & 21 & 0 & 1 & 2 & 3 & 19 & 5 & 0 & 20 & 0 & 6 & 0 & 1 & 27 & 0 & 5 & \\
\hline & & & ir & & mean & 160.2 & 306.2 & 225.3 & 293.0 & 250.7 & 230.0 & 352.4 & 210.5 & 292.8 & & 185.2 & 314.4 & 211.1 & 285.7 & 230.4 & & 394.4 & & 306.2 & & 205.6 & 549.8 & & 177.1 & 1240.3 \\
\hline & & & & 1 & $n$ & 2 & 24 & 11 & 7 & 0 & 1 & 25 & 14 & 7 & 2 & 1 & 25 & 11 & 7 & 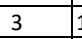 & 1 & 24 & 2 & 0 & 0 & 1 & 22 & 0 & 1 & 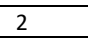 \\
\hline & & & no & 1 & mean & 206.5 & 375.8 & 230.4 & 302.7 & & 212.9 & 347. & 253.3 & 195.6 & 350.1 & 313.0 & 360.7 & 624.5 & 190.6 & 34.4 & 145.2 & 453.1 & 349.7 & & & \begin{tabular}{|l}
105.1 \\
\end{tabular} & 697.5 & & 199.5 & 5160.2 \\
\hline & & le & jirrel & & $n$ & 2 & 22 & 13 & 4 & 2 & 1 & 22 & 7 & 4 & 1 & 1 & 22 & 9 & 2 & 0 & 0 & 21 & 2 & 0 & 0 & 2 & 17 & 0 & 0 & 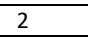 \\
\hline & & & IIrrelevant & & mean & 243.1 & 447.9 & 320.4 & 354.3 & 240.5 & 360.6 & 353.7 & 285.3 & 243.7 & 260.4 & 150.4 & 457.4 & 373.6 & 192.9 & & & 433.4 & 350.6 & & & 130.3 & 599.7 & & & 2297.6 \\
\hline & & & & & - & 1 & 22 & 8 & 8 & 2 & 1 & 24 & 8 & 4 & 4 & 2 & 2 & 4 & 10 & & 0 & 17 & 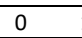 & 1 & 0 & 0 & 25 & 0 & 0 & \\
\hline & & & $n$ & 2 & mean & 318.5 & 417 & 196.1 & 430.3 & 324.4 & 240.4 & 417 & 199.2 & 264.7 & 198.2 & 251.9 & 382.5 & 254.1 & 261.3 & \begin{tabular}{|c|}
216.9 \\
\end{tabular} & & 387.8 & & 415.7 & & & 539.9 & & & 350.8 \\
\hline & & ri & & & 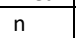 & 3 & 23 & 10 & 13 & 0 & 2 & 2 & 9 & 12 & 0 & 0 & 2 & - & 14 & 5 & 0 & 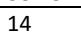 & 1 & 1 & 1 & 2 & 22 & 1 & 0 & \\
\hline & & & ir & 7 & mean & \begin{tabular}{|l|}
167.3 \\
\end{tabular} & 350.5 & 327.1 & 598.4 & & 163.2 & 644.6 & 283.4 & 274.0 & & & 375.4 & 424.8 & 467.3 & 239.5 & & 321.6 & 163.7 & 363.2 & 140.1 & 486.0 & 536.1 & 315.7 & & 160.2 \\
\hline & & & & 3 & 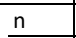 & 1 & 24 & 13 & 3 & 1 & 1 & 23 & 18 & 3 & 1 & 0 & 2 & 1 & 4 & 1 & 0 & 2 & 3 & 1 & 0 & 1 & 22 & 0 & & 1 \\
\hline & & & & 3 & mean & 388.0 & 357.4 & 265.2 & 432.6 & 496.2 & 21077.3 & 3381.2 & 276.9 & 185.6 & 816.6 & & 33 & 396.2 & 214.0 & \begin{tabular}{|l|}
120.3 \\
\end{tabular} & & 449.2 & 200.4 & 165.6 & & 220.4 & 591.8 & & 471.0 & 163.1 \\
\hline & & & & & $n$ & 0 & 22 & 9 & 9 & 0 & 0 & 2 & 11 & 1 & 0 & 1 & 2 & 6 & 1 & 2 & 0 & & -2 & 1 & 0 & 2 & 20 & 0 & 1 & 0 \\
\hline & & & & 8 & mean & & 364.2 & 341.4 & 364.7 & & & 387.9 & 313.2 & 931.5 & & 233.0 & 432.0 & 310.2 & 225.0 & 157.8 & & 495.4 & 324.6 & 315.6 & & 366.0 & 669.1 & & 239.7 & \\
\hline & & & relovan & & $n$ & 1 & 24 & 6 & 8 & 0 & 0 & & 7 & 2 & 1 & 1 & 2 & 8 & 3 & 3 & 0 & & 2 & 0 & 1 & 1 & 12 & 0 & 0 & 0 \\
\hline & & & & $2 \epsilon$ & mean & $\mid 661.8$ & 370.5 & 346.5 & 235.2 & & & 6 & 238.0 & 210.5 & 286.0 & 344.1 & 541.6 & 152.3 & 1209.1 & 221.8 & & 441.4 & 304.4 & & 245.4 & 304.2 & 702.6 & & & \\
\hline & & & & & $n$ & 0 & 22 & 4 & 5 & 0 & 3 & & 3 & 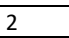 & 0 & 12 & -5 & 5 & 5 & 0 & 1 & 18 & 1 & 2 & 0 & t & 8 & 0 & & \\
\hline & & & no & 5 & mean & & 668.7 & 191.4 & 377.7 & & 202.8 & 629.5 & 140.2 & 140.3 & & 418.5 & 376.4 & 168.8 & 254.7 & & 162.2 & 661.6 & 132.1 & 170.2 & & 536.1 & 425.9 & & 430.7 & 7200.9 \\
\hline & & & & & $n$ & 1 & 20 & 4 & 9 & 0 & 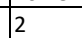 & 21 & 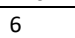 & 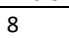 & 0 & 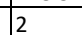 & -5 & 0 & ( & & 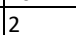 & 16 & r & 3 & 0 & to & 9 & 0 & 0 & \\
\hline & & & Irr & 10 & mean & 293.1 & 612.4 & 268.6 & 390.4 & & 217.5 & 543.6 & 214.1 & 288.0 & & 229.7 & 440.4 & & 284.6 & 125.1 & 291.9 & 430.1 & 180.2 & 159.9 & & 301.7 & 568.2 & & & 210.6 \\
\hline & & & & & $\mathrm{n}$ & , & 25 & - & $1-$ & 1 & & 26 & 8 & 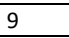 & 3 & & & 5 & -2 & & 0 & 13 & 2 & 2 & 0 & 0 & 26 & 0 & & \\
\hline & & & $n$ & 4 & $\overline{\text { mean }}$ & 236.3 & 432.6 & 199.2 & 300.8 & 270.5 & 455.9 & 427.9 & 266.2 & 386.8 & 226.8 & \begin{tabular}{|l|l|}
3220.4 \\
\end{tabular} & 430.5 & 392.7 & 256.7 & 390.3 & & 310.8 & & 325.8 & & & 578.3 & & 650.6 & 5217.3 \\
\hline & & & & & $\mathrm{N}$ & T & 21 & 8 & 16 & 1 & 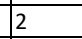 & 21 & 7 & 13 & 2 & 2 & 24 & 2 & 18 & 0 & 0 & 19 & 1 & 2 & 0 & 0 & 23 & 1 & 1 & 2 \\
\hline
\end{tabular}


TABLE 7: MEAN FIXATION DURATIONS FOR DIFFERENT GAZE LOCATIONS WHEN GIVING PRIORITY WITH YIELD SIGN. RELEVANT ONC. STANDS FOR RELEVANT ONCOMING TRAFFIC. N - SUBSAMPLE.

\begin{tabular}{|c|c|c|c|c|c|c|c|c|c|c|c|c|c|c|c|c|c|c|c|c|c|c|c|c|c|c|c|c|c|c|}
\hline \multirow[b]{2}{*}{ group } & \multirow[b]{2}{*}{ junction } & \multirow[b]{2}{*}{$\begin{array}{l}\text { driving } \\
\text { manoeuvre }\end{array}$} & \multirow[b]{2}{*}{ traffic } & \multirow{2}{*}{\multicolumn{2}{|c|}{$\begin{array}{l}\text { scenario } \\
\text { no. }\end{array}$}} & \multicolumn{5}{|c|}{$\begin{array}{l}\text { Fixation durations in segment } 1 \\
(75 \mathrm{~m} \text { to } 50 \mathrm{~m})\end{array}$} & \multicolumn{5}{|c|}{$\begin{array}{l}\text { Fixation durations in segment } 2 \\
(50 \mathrm{~m} \text { to } 25 \mathrm{~m})\end{array}$} & \multicolumn{5}{|c|}{$\begin{array}{l}\text { Fixation durations in segment } 3 \\
(25 \mathrm{~m} \text { to } 0 \mathrm{~m})\end{array}$} & \multicolumn{5}{|c|}{\begin{tabular}{|l}
$\begin{array}{l}\text { Fixation durations in segment } 4 \\
\text { (crossing) }\end{array}$ \\
\end{tabular}} & \multicolumn{5}{|c|}{$\begin{array}{l}\begin{array}{l}\text { Fixation durations in segment } 5 \\
\text { (exit) }\end{array} \\
\text {. }\end{array}$} \\
\hline & & & & & & down & straight & left & right & other & down & straight & left & right & other & down & straight & left & right & other & down & straigh & left & right & other & down & straigh & t left & right & other \\
\hline \multirow{32}{*}{ control } & & & & & $n$ & 1 & 28 & 19 & 9 & 3 & 1 & 28 & 23 & 20 & 4 & 0 & 27 & 28 & 22 & 8 & 0 & 27 & 7 & 0 & 0 & 3 & 23 & 0 & 1 & 2 \\
\hline & & & no & 11 & $\overline{\text { mean }}$ & 172.7 & 324.3 & 281.9 & 257.6 & 321.0 & 223.0 & 268.8 & 227.4 & 260.6 & 230.4 & & 342.5 & 258.4 & 238.3 & 3233.4 & & 434.0 & 342.7 & & & 175.7 & 556.1 & & 262.2 & 2303.2 \\
\hline & & & & & $n$ & 1 & 27 & 16 & 7 & 1 & 3 & 27 & 19 & 20 & 3 & 1 & 24 & 25 & 20 & 10 & 0 & 27 & 7 & 1 & 2 & 3 & 24 & 0 & 0 & 3 \\
\hline & & lef & irrele & 16 & mean & 230.0 & 482.7 & 234.5 & 323.2 & 298.9 & \begin{tabular}{|l|}
161.1 \\
\end{tabular} & 304.3 & 262.6 & 291.9 & 175.4 & 270.7 & 316.0 & 194.1 & 267.3 & 3294.4 & & 453.2 & 336.6 & 1057.0 & 134.0 & 292.3 & 434.7 & & & 316.6 \\
\hline & & & & & $n$ & 1 & 28 & 20 & 2 & 0 & 1 & 28 & 22 & 11 & 4 & 1 & 29 & 29 & 27 & 12 & 0 & 28 & 9 & 0 & 0 & 1 & 25 & 0 & 0 & 3 \\
\hline & & & evant & 21 & mean & 120.2 & 407.1 & 238.2 & 182.8 & & 290.5 & 335.4 & 278.7 & 270.9 & 194.0 & 227.5 & 301.3 & 207.3 & 241.8 & 3281.9 & & 384.3 & 357.5 & & & 213.8 & 401.2 & & & 173.6 \\
\hline & & & & & $n$ & 2 & 28 & 24 & 13 & 5 & 2 & 29 & 23 & 16 & 5 & 1 & 29 & 25 & 15 & 7 & 0 & 24 & 1 & 3 & 0 & 1 & 28 & 0 & 5 & 4 \\
\hline & & & & 12 & mean & 219.8 & 303.6 & 274.4 & 484.2 & 196.5 & $\begin{array}{l}513.6 \\
\end{array}$ & 297.0 & 241.7 & 247.5 & 217.3 & 220.3 & 292.1 & 413.5 & 348.3 & 3223.2 & & 381.9 & 336.7 & 397.5 & & 140.3 & 439.0 & & 338.5 & 5245.5 \\
\hline & & & & & $n$ & 0 & 26 & 18 & 10 & 3 & 1 & 27 & 23 & 16 & 6 & 0 & 27 & 26 & 15 & 9 & 0 & 17 & 0 & 5 & 0 & 2 & 27 & 2 & 4 & 3 \\
\hline & & & irrelevant & 17 & mean & & 394.5 & 252.7 & 332.8 & 423.2 & 435.9 & 281.0 & 259.0 & 286.5 & 375.5 & & 340.0 & 432.8 & 291.5 & 327.1 & & 364.3 & & 299.1 & & 253.2 & 529.9 & 257 & 3309.9 & 9199.9 \\
\hline & & & bant & קר & $\mathrm{n}$ & 2 & 27 & 18 & 12 & 1 & 3 & 28 & 24 & 12 & 5 & 0 & 28 & 28 & 17 & 19 & 0 & 20 & 0 & 6 & 1 & 1 & 27 & 0 & 6 & 7 \\
\hline & & & evant & 22 & mean & 231.7 & 461.8 & 294.6 & 287.0 & 160.4 & 220.6 & 338.5 & 266.3 & 322.5 & 202.8 & & 294.5 & 147.8 & 271.5 & 243.2 & & 365.0 & & 292.5 & 150.3 & 340.6 & 394.5 & & 228.2 & 2227.5 \\
\hline & & & & & $n$ & 2 & 28 & 10 & 11 & 1 & 1 & 27 & 19 & 21 & 5 & 2 & 29 & 28 & 17 & 4 & 0 & 29 & 8 & 0 & 1 & 1 & 21 & 0 & 1 & 3 \\
\hline & & & & 13 & mean & 246.7 & 369.2 & 310.6 & 274.9 & 317.6 & 185.4 & 296.0 & 218.7 & 240.7 & 193.9 & 130.3 & 384.2 & 370.2 & 235.9 & 158.7 & & 404.6 & 302.1 & & 141.0 & 283.0 & 453.0 & & 165.3 & 3278.2 \\
\hline & & & & & $n$ & 6 & 28 & 6 & 9 & 0 & 4 & 27 & 18 & 17 & 1 & 1 & 28 & 25 & 18 & 6 & 0 & 27 & 9 & 0 & 0 & 4 & 23 & 0 & 0 & 2 \\
\hline & & & irre & & mean & 225.8 & 427.8 & 193.7 & 309.7 & & 303.8 & 305.3 & 227.9 & 220.4 & 158.6 & 147.8 & 303.5 & 267.1 & 257.9 & 282.5 & & 445.9 & 356.6 & & & 283.7 & 422.4 & & & 557.4 \\
\hline & & left & & & $n$ & 2 & 28 & 16 & 8 & 0 & 3 & 28 & 26 & 9 & 2 & 1 & 29 & 29 & 23 & 13 & 1 & 29 & 7 & 1 & 1 & 2 & 21 & 0 & 0 & \\
\hline & & & $r E$ & 23 & mean & 260.6 & 536.1 & 332.3 & 232.0 & & \begin{tabular}{|l}
198.8 \\
\end{tabular} & 354.8 & 281.1 & 221.0 & 143.0 & 320.6 & 306.9 & 147.4 & 290.1 & 217.9 & \begin{tabular}{|l|}
137.8 \\
\end{tabular} & 449.5 & 318.9 & 223.3 & 208.0 & 152.2 & 504.4 & & & 182.9 \\
\hline & & & $\bar{r}$ & & $\mathrm{n}$ & 4 & 29 & 15 & 9 & 0 & 2 & 28 & 24 & 12 & 1 & 4 & 29 & 28 & 23 & 17 & 0 & 28 & 10 & 2 & 2 & 1 & 18 & 0 & 0 & \\
\hline & & & & 27 & mean & 234.9 & 443.6 & 275.7 & 200.5 & & 383.5 & 346.9 & 271.9 & 188.9 & 110.3 & 134.6 & 411.5 & 32.4 & 240.6 & 5222.5 & & 375.7 & 338.7 & 291.6 & 153.9 & 130.3 & 496.7 & & & 06.4 \\
\hline & & & & & - & 1 & 25 & 15 & 15 & 6 & 1 & 26 & 19 & 18 & 3 & 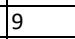 & 25 & 17 & 19 & 4 & $j^{\circ}$ & 23 & 2 & 8 & 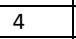 & 7 & 13 & 2 & 3 & 7 \\
\hline & & & no & 15 & mean & 298.1 & 390.8 & 253.7 & 263.5 & 370.5 & 201.6 & 316.5 & 261.0 & 223.8 & 386.3 & 192.0 & 359.2 & 473.1 & 238.5 & 242.9 & 158.1 & 408.1 & 351.3 & 282.9 & 293.1 & 286.3 & 437.6 & 175.3 & 3246.4 & 4400.8 \\
\hline & & & & & $n$ & 4 & 30 & 13 & 14 & 2 & 2 & 26 & 24 & 20 & 4 & 5 & 2 & 25 & 27 & 7 & -2 & 27 & & 10 & 7 & 7 & 14 & 0 & 4 & 5 \\
\hline & & straight & irrelevant & 20 & mean & 316.9 & \begin{tabular}{|l}
472.8 \\
\end{tabular} & 329.7 & 243.8 & 206.7 & 215.9 & 3. & 224.3 & 261.7 & 215.5 & 259.8 & 9.2 & 423.1 & 235.2 & 219.4 & 335.1 & 327.8 & 205.3 & 284.4 & 229.5 & 414.2 & 390.1 & & 386.8 & 8236.7 \\
\hline & & & & & $n$ & 2 & 27 & 15 & 16 & 0 & 0 & 26 & 23 & 14 & 2 & 0 & & 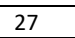 & 25 & 12 & 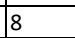 & 27 & & 9 & 5 & 6 & 17 & 0 & & 2 \\
\hline & & & viant & 25 & mean & 229.7 & 403.7 & 258.5 & 305.0 & & & 317.7 & 247.6 & 236.6 & 205.4 & & 296.1 & 230.3 & 242.2 & 2198.3 & 240.2 & 323.9 & 330.4 & 188.6 & 213.1 & 206.7 & 419.6 & & 438.1 & 1191.6 \\
\hline & & & & & (n) & 2 & 23 & 14 & 18 & 7 & 1 & 24 & 18 & 19 & 3 & 0 & 2 & 19 & 13 & 10 & 0 & 16 & 0 & 6 & 0 & 3 & 24 & 0 & 3 & 3 \\
\hline & & & & 14 & mean & \begin{tabular}{|l}
161.6 \\
\end{tabular} & 314.1 & 235.2 & 380.4 & 448.9 & 235.4 & 337.7 & 250.2 & 319.7 & 264.0 & & 336.1 & 291.0 & 350.1 & 239.1 & & 334.0 & & 535.0 & & 202.4 & 433.5 & & 359.8 & 8335.5 \\
\hline & & right & & & - & 1 & 29 & 16 & 17 & 1 & 2 & 29 & 26 & 14 & 5 & 1 & 2 & 20 & 18 & 12 & 0 & 22 & c & 3 & 0 & 0 & 30 & 0 & 2 & 4 \\
\hline & & right & & 19 & mean & 167.2 & 390.1 & 263.2 & 322.1 & 355.8 & 264.2 & 379.3 & 278.6 & 294.1 & 157.2 & 114.6 & 315.8 & 461.9 & 332.5 & 243.5 & & 431.0 & & 296.2 & & & 429.0 & & 212.9 & 9294.3 \\
\hline & & & & 21 & $n$ & 3 & 26 & 15 & 13 & 0 & 1 & 26 & 20 & 11 & 0 & $T_{1}$ & 2 & 26 & 18 & 12 & 0 & 20 & c & 6 & 0 & c & 26 & 0 & & $\tau_{2}$ \\
\hline & & & & 24 & mean & 239.5 & 421.1 & 216.1 & 283.3 & & 262.9 & 331.7 & 215.5 & 303.3 & & 636.4 & 308.3 & 157.8 & 264.6 & 207.2 & & 352.4 & & 242.9 & & & 402.9 & & 389.5 & 5204.2 \\
\hline & & & & & . & 2 & 21 & 15 & 7 & 2 & 0 & 22 & 16 & 12 & 0 & 0 & 2 & 21 & 14 & 5 & 0 & 22 & 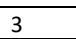 & 0 & 0 & 1 & 21 & 0 & 0 & , \\
\hline & & & & 11 & mean & 295.4 & 359.3 & 315.9 & 238.7 & 258.6 & & 342.2 & 249.8 & 273.3 & & & 346.4 & 337.8 & 234.8 & 3166.5 & & 480.0 & 300.5 & & & 383.4 & 678.3 & & & 160.7 \\
\hline & & & & & $\mathrm{n}$ & 1 & 24 & 8 & 3 & 1 & $f^{+}$ & 23 & 16 & 11 & 0 & 1 & 26 & 22 & 20 & 7 & 0 & 26 & 3 & 2 & $\overline{0}$ & 2 & 21 & 0 & 0 & \\
\hline & & le & $i$ & 16 & mean & 130.3 & 518.8 & 228.7 & 266.0 & 227.6 & \begin{tabular}{|l}
658.7 \\
\end{tabular} & 435.4 & 278.0 & 210.5 & & 125.3 & 362.8 & 258.8 & 240.2 & 233.6 & & 441.3 & 360.1 & 147.8 & & 364.6 & 606.7 & & & 332.8 \\
\hline & & & & & $n$ & 2 & 22 & 12 & 1 & 1 & 3 & 23 & 13 & 6 & 1 & 10 & 2 & 23 & 21 & 8 & 10 & 20 & 4 & 0 & 0 & 0 & 20 & 0 & 0 & 0 \\
\hline & & & vant & 21 & mean & \begin{tabular}{|l}
135.0 \\
\end{tabular} & 392.9 & 310.5 & 164.9 & 231.8 & \begin{tabular}{|l|l}
217.1 \\
\end{tabular} & 448.1 & 286.4 & 191.3 & 420.8 & & 340.8 & 165.8 & 228.5 & 260.6 & & 425.5 & 410.2 & & & & 529.8 & & & \\
\hline & & & & & $n$ & 1 & 22 & 12 & 4 & 3 & 3 & 21 & 16 & 9 & 2 & 0 & 2 & 13 & 7 & 2 & 0 & 16 & 0 & 2 & 0 & 1 & 22 & 0 & 1 & \\
\hline & & & & 12 & $\overline{\text { mean }}$ & 500.0 & 486.7 & 300.6 & 230.7 & 260.4 & 200.0 & 298.9 & 261.7 & 220.7 & 185.6 & & 387.6 & 491.4 & 261.9 & 255.6 & & 392.2 & & 410.6 & & 434.3 & 549.2 & & 7 & 718 \\
\hline & & & & & $n$ & 1 & 25 & 14 & 8 & 3 & 2 & 25 & 18 & 9 & 0 & 0 & 26 & 24 & 11 & 8 & 0 & 18 & 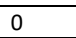 & 0 & 0 & 0 & 25 & 0 & 1 & 2 \\
\hline & & rig & ir & 17 & mean & \begin{tabular}{|l|l} 
& \\
\end{tabular} & 416.1 & 277.0 & 338.4 & 226.4 & \begin{tabular}{|l} 
\\
\end{tabular} & 360.9 & 278.6 & 352.5 & & & 310.0 & 406.6 & 282.7 & 7318.0 & & 334.9 & & & & & 534.1 & & 395.7 & 7193.1 \\
\hline & & & & & $n$ & 0 & 21 & 10 & 4 & 1 & 0 & 21 & 16 & 4 & 1 & ]$^{1}$ & 21 & 22 & 10 & 3 & 1 & 14 & 1 & 1 & 0 & C & 20 & 0 & 2 & 3 \\
\hline & & & & 22 & $\overline{\text { mean }}$ & & 567.0 & 278.7 & 357.4 & 455.9 & & 319.5 & 326.0 & 248.5 & 461.0 & 180.4 & 290.5 & 176.6 & 279.3 & 198.1 & 16 & 403.7 & 145.3 & 455.9 & & & 371.6 & & 248.0 & 0297.3 \\
\hline
\end{tabular}


ECSEL JU

\begin{tabular}{|l|l|l|l|l} 
Fixation durations in segment 1 & Fixation durations in segment 2 & Fixation durations in segment 3 & Fixation durations in segment 4 & Fixation durations in segment 5
\end{tabular} \begin{tabular}{l|l}
$(75 \mathrm{~m}$ to $50 \mathrm{~m})$ & $(50 \mathrm{~m}$ to $25 \mathrm{~m})$ \\
\hline
\end{tabular} (exit)

\begin{tabular}{|c|c|c|c|c|c|c|c|c|c|c|c|c|c|c|c|c|c|c|c|c|c|c|c|c|c|c|c|c|c|c|}
\hline \multirow{3}{*}{ group } & \multirow[b]{2}{*}{ junction } & \multirow{2}{*}{$\begin{array}{l}\text { driving } \\
\text { manoeuvre }\end{array}$} & \multirow[b]{2}{*}{ traffic } & \multirow{2}{*}{\multicolumn{2}{|c|}{$\begin{array}{l}\text { scenario } \\
\text { no. }\end{array}$}} & & & & & \\
\hline & & & & & & \multirow{3}{*}{\begin{tabular}{|l|} 
down \\
1 \\
388.3
\end{tabular}} & \multicolumn{2}{|c|}{ straight left } & \multirow{2}{*}{$\begin{array}{l}\text { right } \\
6 \\
\end{array}$} & \multirow{2}{*}{$\begin{array}{l}\text { other } \\
0\end{array}$} & \multicolumn{3}{|c|}{ down straight left } & \multirow{2}{*}{$\begin{array}{l}\text { right } \\
10\end{array}$} & \multirow{2}{*}{$\begin{array}{l}\text { other } \\
2 \\
\end{array}$} & \multicolumn{3}{|c|}{ down straight left } & right & other & down & straight & left & right & other & down & straigh & t left & right & other \\
\hline & \multirow{20}{*}{$\begin{array}{l}\text { X- } \\
\text { intersection } \\
\text { (four way) }\end{array}$} & \multirow{8}{*}{ left } & \multirow{2}{*}{ no } & \multirow{2}{*}{13} & \multirow{2}{*}{\begin{tabular}{l|}
$\mathrm{n}$ \\
mean
\end{tabular}} & & 23 & 9 & & & 2 & 22 & 14 & & & 0 & 23 & 15 & 12 & 8 & 0 & 21 & 2 & 0 & 0 & 1 & 16 & 0 & 0 & 1 \\
\hline & & & & & & & 461.6 & 263.4 & 308.0 & & 352.4 & 365.8 & 244.8 & 255.7 & 458.3 & & 386.9 & 221.7 & 268.3 & 3265.3 & & 493.6 & 387.7 & & & \begin{tabular}{|l|l|}
488.5 \\
\end{tabular} & 546.9 & & & 175.2 \\
\hline & & & & & $\mathrm{n}$ & 1 & 23 & 8 & 4 & 1 & 3 & 21 & 18 & 11 & 2 & 0 & 23 & 18 & 16 & 6 & 0 & 23 & 3 & 0 & 1 & 1 & 19 & 0 & 1 & 1 \\
\hline & & & Irrelevant & & mean & 125.3 & 389.6 & 287.8 & 186.0 & 235.6 & 214.0 & 293.5 & 250.2 & 225.7 & 326.0 & & 336.9 & 372.7 & 246.6 & 6258.5 & & 460.5 & 606.3 & & $\begin{array}{l}418.0 \\
\end{array}$ & 571.0 & 644.7 & & 139.9 & 299.6 \\
\hline & & & & & $\mathrm{n}$ & 1 & 24 & 11 & 4 & \begin{tabular}{l|l}
0 \\
\end{tabular} & 0 & 26 & 20 & 7 & 1 & 0 & 26 & 25 & 20 & 6 & 0 & 25 & 4 & 0 & 2 & 1 & 22 & 0 & 0 & 0 \\
\hline & & & relevant & 23 & mean & 162.8 & 529.8 & 283.1 & 237.0 & & & 373.5 & 280.6 & 205.0 & 210.3 & & 319.6 & 179.1 & 254.0 & 0354.6 & & 399.2 & 294.2 & & 295.7 & 328.0 & 699.2 & & & \\
\hline & & & relevant & & $\mathrm{n}$ & 1 & 22 & 11 & 2 & 1 & 2 & 21 & 19 & 7 & 0 & 1 & 23 & 23 & 14 & 8 & 0 & 22 & 3 & 0 & 0 & 0 & 15 & 0 & 0 & 1 \\
\hline & & & onc. & 27 & mean & 110.2 & 485.7 & 261.5 & 220.5 & 295.3 & 209.3 & 339.8 & 282.6 & 309.8 & & 165.3 & 413.1 & 322.4 & 194.7 & 7248.5 & & 442.5 & 247.1 & & & & 680.0 & & & 170.2 \\
\hline & & & & & $n$ & 1 & 21 & 12 & 6 & 0 & 1 & 21 & 16 & 12 & 1 & 2 & 22 & 11 & 15 & 1 & 4 & 21 & 1 & 7 & 0 & 1 & 8 & 0 & 0 & 2 \\
\hline & & & no & 15 & mean & 175.5 & 400.3 & 255.6 & 267.9 & & 273.0 & 412.3 & 248.5 & 288.7 & 217.8 & 180.7 & 486.3 & 441.8 & 3297.5 & 5168.6 & 238.5 & 628.8 & 190.4 & 4295.9 & & 334.2 & 507.3 & & & 269.6 \\
\hline & & & & & $\mathrm{n}$ & 1 & 25 & 11 & 5 & 1 & 0 & 25 & 18 & 12 & 2 & 2 & 25 & 19 & 20 & 6 & 1 & 25 & 0 & 7 & 3 & 2 & 9 & 0 & 0 & 0 \\
\hline & & straight & irrelevant & 20 & mean & 143.6 & 453.6 & 295.0 & 391.0 & 165.3 & & 409.6 & 249.6 & 268.1 & 142.8 & 131.9 & 499.8 & 397.5 & 287.9 & 9248.8 & 341.9 & $\begin{array}{l}681.8 \\
\end{array}$ & & 321.6 & 187.9 & 125.2 & 359.8 & & & \\
\hline & & & & & 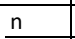 & 2 & 24 & 10 & 5 & 1 & 1 & 25 & 19 & 9 & 2 & 0 & 26 & 24 & 25 & 4 & 1 & 24 & 2 & 10 & 1 & 1 & 8 & 0 & 1 & 2 \\
\hline & & & relevant & 25 & mean & 108.3 & 497.4 & 254.7 & 367.7 & 170.6 & \begin{tabular}{|l|}
177.6 \\
\end{tabular} & 475.8 & 286.8 & 226.5 & 5175.2 & & 382.3 & 218.2 & 266.2 & 2203.8 & 290.5 & 467.9 & 247.9 & 9317.9 & 130.1 & 348.0 & 442.2 & & 459.5 & $\longdiv { 1 3 2 . 7 }$ \\
\hline & & & & & $\mathrm{n}$ & 0 & 21 & 9 & 10 & 1 & 0 & 22 & 12 & 8 & 1 & 0 & 21 & 9 & 12 & 3 & 0 & 12 & 0 & 0 & 0 & 0 & 21 & 0 & 0 & 0 \\
\hline & & & no & 14 & mean & & 422.0 & 252.2 & 286.2 & 363.1 & & 467.8 & 279.6 & 265.8 & $\begin{array}{l}303.4 \\
\end{array}$ & & 448.4 & 425.8 & 3315.7 & 7276.4 & & 403.3 & & & & & 632.1 & & & \\
\hline & & & & & $n$ & 0 & 26 & 11 & 8 & 2 & 0 & 26 & 15 & 8 & 1 & 1 & 25 & 23 & 8 & 10 & 0 & 17 & 0 & 2 & 2 & 1 & 25 & 1 & 1 & 3 \\
\hline & & right & Irrelevant & 19 & mean & & 443.1 & 287.1 & 376.3 & 268.1 & & 390.2 & 248.3 & 289.1 & 1220.3 & 115.3 & 325.6 & 357.1 & 1352.8 & 8321.6 & & 462.4 & & 316.9 & 198.0 & \begin{tabular}{|l|l|}
199.6 \\
\end{tabular} & 477.8 & 318.4 & \begin{tabular}{|l}
851.8 \\
\end{tabular} & 3207.8 \\
\hline & & & & 24 & $\mathrm{n}$ & 0 & 20 & 9 & 5 & 1 & 2 & 22 & 18 & 4 & 2 & 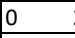 & 22 & 21 & 9 & 5 & 0 & 12 & 0 & 2 & 1 & 1 & 22 & 0 & 0 & 1 \\
\hline & & & $r$ & 24 & mean & & 523.1 & 236.3 & 509.9 & 165.5 & 303.2 & 344.1 & 279.8 & 176.5 & 5345.6 & & 294.7 & 228.3 & 3288.7 & 7282.6 & & 389.0 & & 460.8 & 240.4 & 149.9 & 441.8 & & & 272.8 \\
\hline
\end{tabular}




\subsection{Secondary task engagement}

To check the effectiveness of the secondary task performance of counting back numbers in steps of 2 , two measures are suitable:

1. the amount of numbers being counted back in a certain amount of time

2. and the amount of errors being made

To make the scenarios comparable, the amount of numbers being counted back and the number of errors were standardized by the time being used. Figure 29 shows the task performance in numbers being counted back per second for all 27 scenarios and Figure 30 shows the task performance of errors being made per second, again for all 27 scenarios. As seen before, black bars stand for left turns, grey bars for right turns, and blue bars for going straight. Filled bars present scenarios having none surrounding traffic, striped bars show scenarios with irrelevant traffic, dotted bars show scenarios with relevant traffic causing the driver to stop, and chess patterned bars show the two additional scenarios of having extra relevant oncoming traffic.

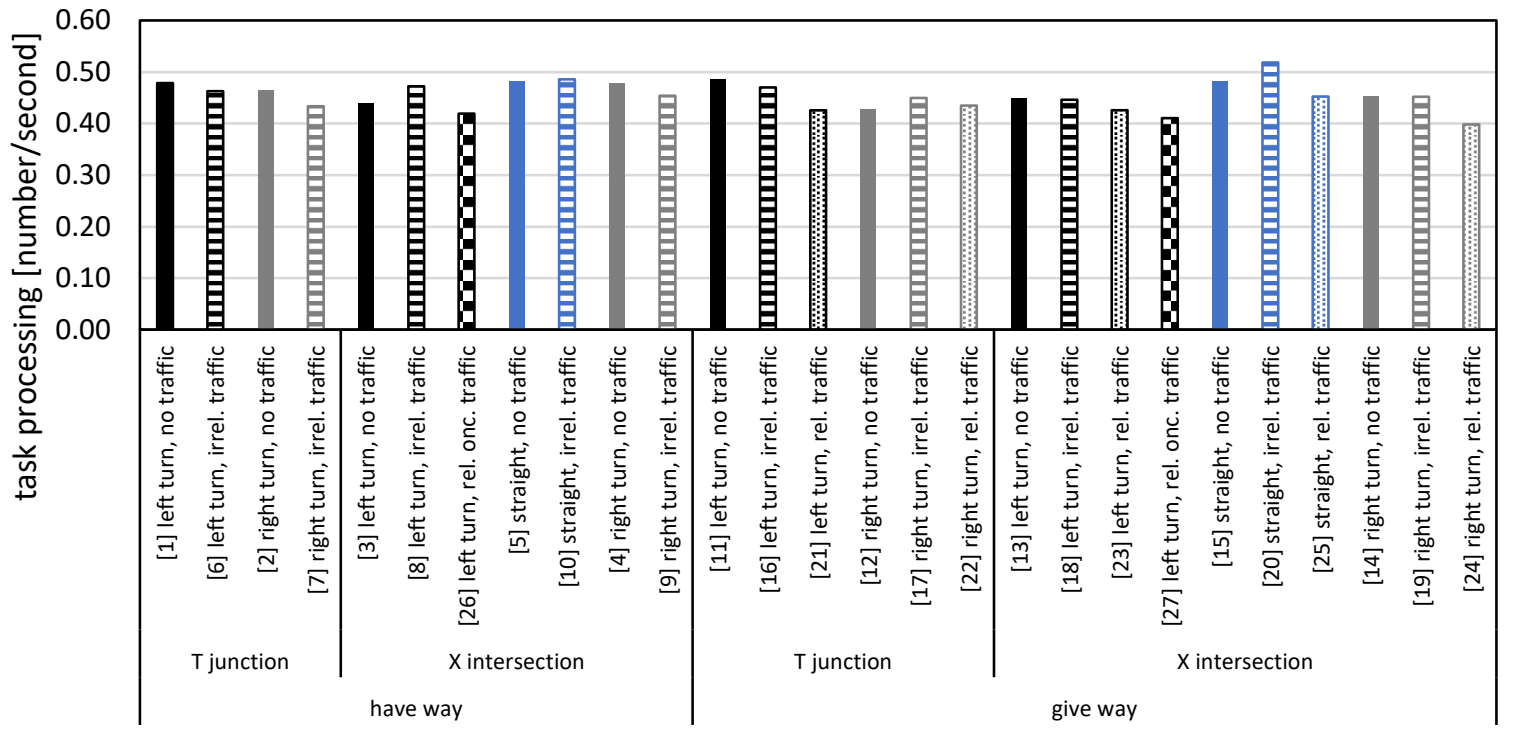

FIGURE 29: TASK PROCESSING OF SECONDARY TASK IN NUMBER PER SECOND FOR ALL 27 INTERSECTION SCENARIOS 


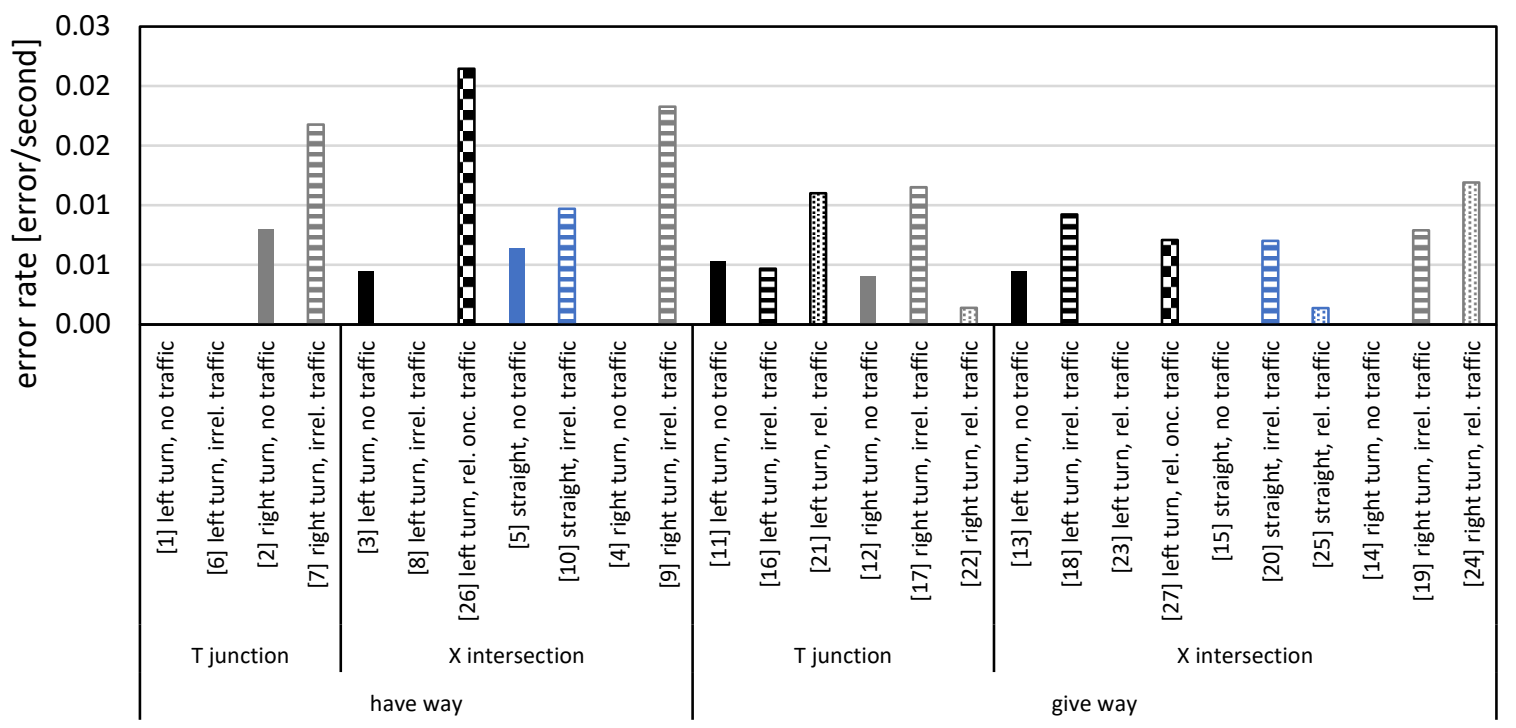

FIGURE 30: ERROR RATE OF SECONDARY TASK IN ERRORS PER SECOND FOR ALL 27 INTERSECTION SCENARIOS

The speed of counting back the numbers is relatively stable throughout the scenarios. There are some scenarios with descriptively faster task processing (e.g. going straight at X-intersections) and others with shorter task processing (e.g. the two additional scenarios with relevant oncoming traffic), but the differences are very small. It seems more that there was a routine in counting back the numbers over all scenarios.

More interesting are the results concerning the errors. In general, there were only a few participants of the study making errors while counting back in steps of 2. From all scenarios being driven with a secondary task, $90 \%$ of them were without mistakes in the secondary task. Nevertheless, it is noticeable that scenario 26 has the highest amount of errors per second. In this scenario, the driver stood at a signalized $\mathrm{X}$-intersection with green traffic light and waited for the oncoming traffic. This scenario was probably too mentally overloading, so the driver made mistakes. However, the secondary task evoked only a few errors. Future studies analysing the mental workload of different intersections by comparing the error rate in secondary tasks should therefore be more difficult for the drivers.

All in all, the secondary task performance was quite good for all subjects. This in turn shows that the manipulation of driver distraction was successful in the sense that the task performance of the scenarios was largely the same. 


\section{Discussion and conclusion}

This study provided detailed information about driving characteristics and gaze behaviour when approaching, crossing, and leaving urban intersections that vary regarding intersection type, priority regulations, planned driving manoeuvres, and surrounding traffic.

The analysis of the driving characteristics showed the course of speed and acceleration when approaching and crossing intersections. Interestingly, the speeds of drivers being distracted by a secondary cognitive verbal task (counting back numbers in steps of 2) were higher when approaching the intersection and the deceleration was only later in approaching segments as strong as in the control group. This shows the possible influence of the secondary task engagement, both when drivers have the right of way and when they have to give it. For the development of driver behaviour models, the aspect of driver distraction should therefore definitely be considered. With regard to the visual attention, the results indicated the influence of secondary task engagement on gaze distribution when approaching intersection with having the right of way by increasing the amount of fixations towards the road centre. This is in line with previous research regarding the influence of cognitive load on eye movements (Engström et al., 2005). For intersections in which the driver had to give priority, the fixation distributions regarding the gaze locations were only differently shortly before entering the intersection (for $\mathrm{T}$-junctions and $\mathrm{X}$-intersections) and when crossing the intersection (for $\mathrm{X}$ intersections). It is possible that the influence of the cognitive secondary task is reduced in more demanding intersection scenarios like yielding.

The planned driving manoeuvre affected the fixation distribution when approaching intersections while having the right of way. The drivers looked more in the direction of the turn at T-junctions while having a green traffic light. This is comparable to Plavšić (2010), who found that drivers look at the lane more closely to their own when turning. However, when the driver had to give the right of way, the results of the present study show that fixations patterns regarding the gaze locations were inconsistent for turning right, turning left, and going straight. This differentiation between having and giving right of way is in line with research of Robbins et al. (2019). They found different gaze behaviour (fixation durations) when turning right in low demanding driving situations (traffic light controlled traffic environment), but not for medium demanding driving situations (driver had to yield). Therefore, this study proofed that the gaze behaviour is highly dependent on the current priority regulation.

Finally, it must be critically argued, that eye movements and gazes do not represent one-to-one the cognitive focus of the driver, as concepts like change blindness and looking but failing to see (Galpin et al., 2009) proof the limits of attentional focus. However, implementing the distribution of gazes in traffic participant models is a first step to model the visual attention of drivers for further evaluation of driver assistance functions and the interactions of the driver with his or her driving environment. The model would further benefit from a comparison with real world eye movement data, because previous research showed some inconsistencies between real world and simulated driving for mean fixation durations of left turns and when going straight (Robbins et al., 2019).

The simulated driving environment had one major disadvantage: the displayed viewing area of the monitors together only gave 135 degrees. When entering an intersection, a larger viewing angle would have been advantageous. The participants verbally mentioned this incision and also in the INVENT project of Vollrath et al. (2004), the visibility of the intersection had proofed to be a major influencing 
factor on driving behaviour at intersections. It should be noted that the use case of the results of this study applies therefore mainly to all intersections where the field of view is very limited.

A further aspect that must be considered is the way of segmenting the approach, the crossing, and the exiting of an intersection. Different methodologies have been used in previous research. Werneke and Vollrath (2012) defined the range for analysing their data regarding attention allocation at intersections, starting from 20 m before the intersection until after the right-hand bend. In the study by Robbins et al. (2019), landmarks were used to define the evaluation range of the intersection. Plavšić (2010) on the other hand divided the segments when crossing the intersection into phases that are either separated in time ( $3 \mathrm{~s}$ before the entrance of the intersection, $2 \mathrm{~s}$ after the exit of the intersection) or based on geometric features (intersection start and end, as well as lane widths). Dependently on the methodology being used, the results of gaze data and driving data will change. However, in order to compare the variety of intersection types being analysed in this study, a geometrical segmentation was necessary.

All in all, this study made a huge attempt to systematize the influence of different intersection scenarios regarding driving and gaze behaviour. The Chair of Automobile Engineering of the Technische Universität Dresden profits from the data about real human drivers for the development of driver behaviour models within the stochastic traffic simulation. The development of reliable and valid traffic simulations is in turn highly important for the testing of concepts of highly automated driving functions in traffic. 


\section{References}

Crundall, D. and Underwood, G. (2011), "Visual Attention While Driving. Measures of Eye Movements Used in Driving Research", in Porter, B.E. (Ed.), Handbook of Traffic Psychology, 1st ed., Elsevier/Academic Press, Amsterdam, pp. 137-148.

de Waard, D. (1996), "The measurement of drivers' mental workload", Dissertation, Traffic Research Center, Groningen University, Groningen, 1996.

Engström, J., Johansson, E. and Östlund, J. (2005), "Effects of visual and cognitive load in real and simulated motorway driving", Transportation Research Part F: Traffic Psychology and Behaviour, Vol. 8 No. 2, pp. 97-120.

Fastenmeier, W. (Ed.) (1995), Autofahrer und Verkehrssituation: Neue Wege zur Bewertung von Sicherheit und Zuverlässigkeit moderner Straßenverkehrssysteme, Mensch - Fahrzeug - Umwelt, Bd. 33, Verl. TÜV Rheinland, Köln.

Fastenmeier, W. and Gstalter, H. (2007), "Driving task analysis as a tool in traffic safety research and practice", Safety Science, Vol. 45 No. 9, pp. 952-979.

Galpin, A., Underwood, G. and Crundall, D. (2009), "Change blindness in driving scenes", Transportation Research Part F: Traffic Psychology and Behaviour, Vol. 12 No. 2, pp. 179-185.

Hancock, P.A., Wulf, G., Thom, D. and Fassnacht, P. (1990), "Driver workload during differing driving maneuvers", Accident Analysis \& Prevention, Vol. 22 No. 3, pp. 281-290.

Jahn, G., Oehme, A., Krems, J.F. and Gelau, C. (2005), "Peripheral detection as a workload measure in driving: Effects of traffic complexity and route guidance system use in a driving study", Transportation Research Part F: Traffic Psychology and Behaviour, Vol. 8 No. 3, pp. 255-275.

Labett, S. and Langham, M. (2006), What do drivers do at junctions?, Road Safety Congress 2006.

Lansdown, T.C. (2019), "The temptation to text when driving - Many young drivers just can't resist", Transportation Research Part F: Traffic Psychology and Behaviour, Vol. 65, pp. 79-88.

Loo, M. (2009), "Motion Sickness", in Loo, M. (Ed.), Integrative medicine for children, Saunders/Elsevier, St. Louis, Mo, pp. 393-397.

Mourant, R.R. and Rockwell, T.H. (1970), "Mapping eye-movement patterns to the visual scene in driving: an exploratory study", Human factors, Vol. 12 No. 1, pp. 81-87.

Mourant, R.R. and Rockwell, T.H. (1972), "Strategies of visual search by novice and experimental drivers", Human factors, Vol. 14 No. 4, pp. 325-335.

Paxion, J., Galy, E. and Berthelon, C. (2014), "Mental workload and driving", Frontiers in psychology, Vol. 5, p. 1344.

Plavšić, M. (2010), "Analysis and Modeling of Driver Behavior for Assistance Systems at Road Intersections", Dissertation, Lehrstuhl für Ergonomie, Technische Universität München, 2010.

Robbins, C.J., Allen, H.A. and Chapman, P.R. (2019), "Comparing drivers' visual attention at Junctions in Real and Simulated Environments", Applied ergonomics, Vol. 80, pp. 89-101.

Rumar, K. (1990), "The basic driver error: late detection", Ergonomics, Vol. 33 No. 10-11, pp. 12811290.

Scholey, A.B., Harper, S. and Kennedy, D.O. (2001), "Cognitive demand and blood glucose", Physiology \& Behavior, Vol. 73 No. 4, pp. 585-592.

Shinar, D. (2008), "Looks are (almost) everything: where drivers look to get information", Human factors, Vol. 50 No. 3, pp. 380-384.

Shinohara, Y. and Nishizaki, Y. (2017), "Effect of Driving Situation and Driving Experience on Eye Movements", Information Engineering Express, Vol. 3 No. 3, pp. 31-40. 
Summala, H., Pasanen, E., Räsänen, M. and Sievänen, J. (1996), "Bicycle accidents and drivers' visual search at left and right turns", Accident Analysis \& Prevention, Vol. 28 No. 2, pp. 147-153.

Verwey, W.B. (1993), "How can we prevent overload of the driver?", in Parkes, A.M. and Franzen, S. (Eds.), Driving future vehicles, Taylor \& Francis, London, pp. 220-229.

Verwey, W.B. (2000), "On-line driver workload estimation. Effects of road situation and age on secondary task measures", Ergonomics, Vol. 43 No. 2, pp. 187-209.

Vollrath, M., Briest, S., SchießI, C., Drewes, J. and Becker, U. (2006), Ableitung von Anforderungen an Fahrerassistenzsysteme aus Sicht der Verkehrssicherheit, Berichte der Bundesanstalt für Straßenwesen, Reihe F. Fahrzeugtechnik, available at: https://bast.opus.hbz-nrw.de/opus45bast/frontdoor/deliver/index/docld/237/file/F60.pdf.

Vollrath, M., Brünger-Koch, M., Schießl, C. and Waibel, F. (2004), INVENT Kreuzungsverhalten. Endbericht: Normalverhalten, Beanspruchung und kritische Situtationen bei Kreuzungsfahrten, Braunschweig.

Werneke, J. and Vollrath, M. (2012), "What does the driver look at? The influence of intersection characteristics on attention allocation and driving behavior", Accident; analysis and prevention, Vol. 45, pp. 610-619.

Wickens, C.D., Goh, J., Helleberg, J., Horrey, W.J. and Talleur, D.A. (2003), "Attentional models of multitask pilot performance using advanced display technology", Human factors, Vol. 45 No. 3, pp. 360-380. 


\section{List of figures}

Figure 1. The most relevant factors influencing workload and task demand at intersections from Plavšić (2010)

Figure 2. Static driving simulator (left) and eye tracking system SMI HED4 (right)

Figure 3. Schematic representation of intersection scenarios for the right of way "having priority with green traffic light"

Figure 4. Schematic representation of intersection scenarios for the right of way "giving right of way with yield sign"

Figure 5. A selection of intersection scenarios from the driver's perspective (left - scenario 24 , middle

- scenario 5, right - scenario 16)

Figure 6. T-junction from the driver's perspective (left), X-intersection from a bird's eye view (right)14

Figure 7. Gaze locations for data processing

Figure 8: Segmentation of intersection for data analysis

Figure 9. Segment durations for scenarios of control group when having the right of way. Brackets present the scenario number. Left shows scenarios with T-junction and right shows scenarios with $\mathrm{X}$ intersection.

Figure 10. Segment durations for scenarios of task group when having the right of way. Brackets present the scenario number. Left shows scenarios with T-junction and right shows scenarios with Xintersection.

Figure 11. Mean segment speed for scenarios of control group when having the right of way. Brackets present the scenario number. Left shows scenarios with T-junction and right shows scenarios with Xintersection.

Figure 12. Mean segment speed for scenarios of task group when having the right of way. Brackets present the scenario number. Left shows scenarios with T-junction and right shows scenarios with Xintersection.

Figure 13. Mean segment acceleration for scenarios of control group when having the right of way. Left shows scenarios with T-junction and right shows scenarios with X-intersection. [ ] is the scenario number.

Figure 14. Mean segment acceleration for scenarios of task group when having the right of way. Left shows scenarios with T-junction and right shows scenarios with X-intersection. [ ] is the scenario number.

Figure 15. Segment durations for scenarios of control group when giving the right of way. Brackets present the scenario number. Left shows scenarios with T-junction and right shows scenarios with Xintersection.

Figure 16. Segment durations for scenarios of task group when giving the right of way. Brackets present the scenario number. Left shows scenarios with T-junction and right shows scenarios with $\mathrm{X}$ intersection.

Figure 17. Mean segment speed for scenarios of control group when giving the right of way. Brackets present the scenario number. Left shows scenarios with T-junction and right shows scenarios with Xintersection.

Figure 18. Mean segment speed for scenarios of task group when giving the right of way. Brackets present the scenario number. Left shows scenarios with T-junction and right shows scenarios with Xintersection. 
Figure 19. Mean segment acceleration for scenarios of control group when giving the right of way. Brackets present the scenario number. Left shows scenarios with T-junction and right shows scenarios with X-intersection. 24

Figure 20. Mean segment acceleration for scenarios of task group when having the right of way. Brackets present the scenario number. Left shows scenarios with T-junction and right shows scenarios with X-intersection. 25

Figure 21: Proportions of fixations in the specific segment regarding the gaze locations 'straight', 'left', and 'right' for T-junctions of control group when having the right of way. Brackets present the scenario number. 26

Figure 22: Proportions of fixations in the specific segment regarding the gaze locations 'straight', 'left', and 'right' for T-junctions of task group when having the right of way. Brackets present the scenario number.

Figure 23: Proportions of fixations in the specific segment regarding the gaze locations 'straight', 'left', and 'right' for X-intersections of control group when having the right of way. Brackets present the scenario number.

Figure 24: Proportions of fixations in the specific segment regarding the gaze locations 'straight', 'left', and 'right' for X-intersections of task group when having the right of way. Brackets present the scenario number. 28

Figure 25: Proportions of fixations in the specific segment regarding the gaze locations 'straight', 'left', and 'right' for T-junctions of control group when giving the right of way. Brackets present the scenario number. 29

Figure 26: Proportions of fixations in the specific segment regarding the gaze locations 'straight', 'left', and 'right' for T-junctions of task group when giving the right of way. Brackets present the scenario number.

Figure 27: Proportions of fixations in the specific segment regarding the gaze locations 'straight', 'left', and 'right' for X-intersections of control group when giving the right of way. Brackets present the scenario number.

Figure 28: Proportions of fixations in the specific segment regarding the gaze locations 'straight', 'left', and 'right' for X-intersections of task group when giving the right of way. Brackets present the scenario number.

Figure 29: Task processing of secondary task in number per second for all 27 intersection scenarios 40 Figure 30: Error rate of secondary task in errors per second for all 27 intersection scenarios...... 41 


\section{List of tables}

Table 1: Contributions

Table 2: Driving characteristics for every segment for scenarios with priority for the driver (1-10, 26). Relevant onc. stands for relevant oncoming traffic. Segment $1-75 \mathrm{~m}$ to $50 \mathrm{~m}$ before intersection. segment $2-50 \mathrm{~m}$ to $25 \mathrm{~m}$ before intersection. segment $3-25 \mathrm{~m}$ to 0 before intersection. segment 4 - crossing the intersection. $\mathrm{n}$ - subsample. 33

Table 3: Driving characteristics for every segment for scenarios where drivers gave priority $(11-25,27)$. Relevant onc. stands for relevant oncoming traffic. Segment $1-75 \mathrm{~m}$ to $50 \mathrm{~m}$ before intersection. segment $2-50 m$ to $25 m$ before intersection. segment $3-25 m$ to 0 before intersection. segment 4 - crossing the intersection. $\mathrm{n}$ - subsample.

Table 4: Mean fixation proportions for gaze locations when having priority with green traffic light. Relevant onc. stands for relevant oncoming traffic. $n$ - subsample

Table 5: Mean fixation proportions for gaze locations when giving priority with yield sign. Relevant onc. stands for relevant oncoming traffic. $\mathrm{n}$ - subsample.

Table 6: Mean Fixation durations for different gaze locations when having priority with green traffic light. Relevant onc. stands for relevant oncoming traffic. $n$ - subsample.

Table 7: Mean Fixation durations for different gaze locations when giving priority with yield sign. Relevant onc. stands for relevant oncoming traffic. $n$ - subsample 
- Last page of the document is intended to be blank! -

- Okay! - 